SER EDUCADA: THE PERSISTENCE AND RESISTANCE STRATEGIES OF FIRST-GENERATION LATINAS

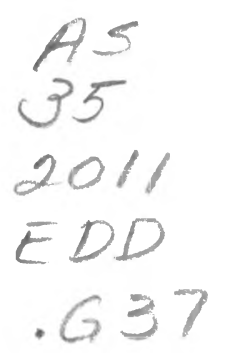

A dissertation submitted to the faculty of

San Francisco State University

In partial fulfillment of

The Requirements for

The Degree

Doctor of Education

In

Educational Leadership

by

María Angélica García

San Francisco, California

May 2011 
Copyright by

María Angélica García

2011 


\section{CERTIFICATION OF APPROVAL}

I certify that I have read SER EDUCADA: The Persistence and Resistance Strategies of First-generation Latinas by Maria Angelica Garcia, and that in my opinion this work meets the criteria for approving a dissertation submitted in partial fulfillment of the requirements for the degree: Doctor of Education in Educational Leadership at San Francisco State University.
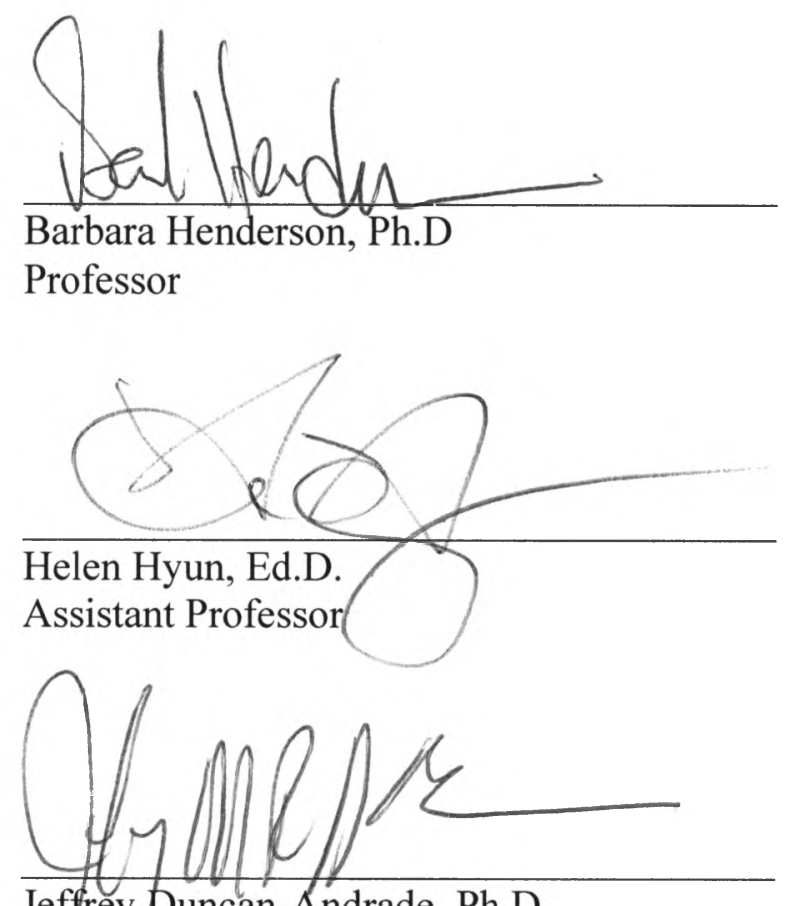

Jeffrey Duncan-Andrade, Ph.D.

Associate Professor 


\title{
SER EDUCADA: THE PERSISTENCE AND RESISTANCE STRATEGIES OF FIRST-GENERATION LATINAS
}

\author{
María Angélica García \\ San Francisco State University \\ 2011
}

First-generation college students of color are one of the most frequently targeted groups for access and retention programs in higher education. However, literature on the persistence and resistance strategies of this student population remain predominantly limited to empirical research. The dissertation was undertaken as a mixed methods study focused on a case study of one private, four-year predominantly white institution. The importance of this study is that while access to higher education has increased for marginalized groups, the persistence and graduation rates of first-generation students of color are alarmingly low in comparison to white students. Significantly, the study introduces a new conceptual framework to the literature, Ser Educada [to be educated], which uncovers the educational experiences of first-generation Latinas as they successfully navigate and persist in higher education. The quantitative data demonstrate how these trends play out at the site of study, especially among first-generation Latinas. Through qualitative data, gathered through focus groups, the women add their testimonios to the literature. Data were analyzed through the lenses of LatCrit, Critical Race Feminism, and borderlands. The study finds that the mujeres negotiate their identity by creating opportunities for transformational resistance through their familia, as they define their educación, in owning their feminidad, and in finding hermandad. The findings of this study have great potential to contribute to policy in higher education at the institutional level, in terms of admissions practices, advising practices, reforms to teaching practices, increased hiring of Latina/o faculty and staff, and the support of student diversity groups.

I certify that the Abstract is a correct representation of the content of this dissertation.

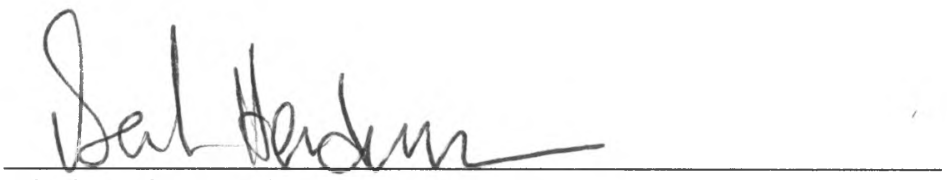

Chair, Dissertation Committee

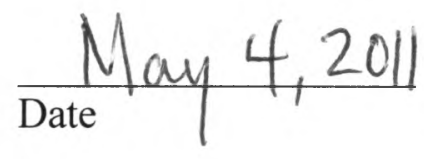




\section{ACKNOWLEDGEMENTS}

I had no idea what I was getting myself into when I started this process. What I know now is that I could not have completed this dissertation without the love and support of many individuals. I am humbled by the young mujeres who participated in this study and am a better educator and researcher because of them. Their words have inspired me to continue to be a scholar practitioner.

To my advisor, Barbara Henderson, I thank for the countless hours that she spent reading my work, challenging my thoughts, and encouraging me to stay strong in the process. To my committee members, Helen and Jeff, I thank for their feedback, encouragement, and for being an instrumental part of my process of coming to understand myself as a scholar.

Para mi mamá, Angelina, gracias por todos los esfuerzos que hizo para darme la oportunidad de continuar mi educación cuando menos teníamos dinero.

To my loving and supporting wife, Maria, I cannot thank her enough for all that she has done. For three years, she reminded me that I am worthy to do this work. Maria, thank you for giving birth to our daughter, Chiara Esmeralda, in the middle of this process. And thank you for choosing to share your life with me and supporting me as I continue to work for educational justice. 


\section{TABLE OF CONTENTS}

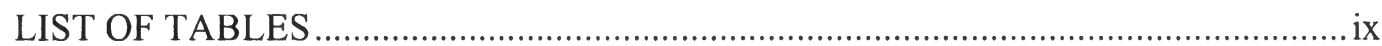

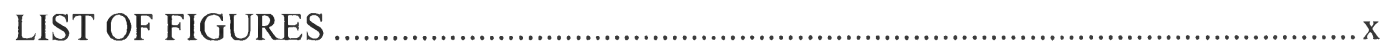

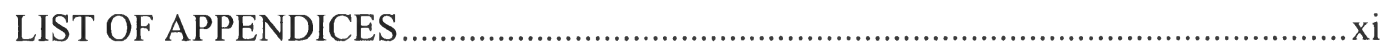

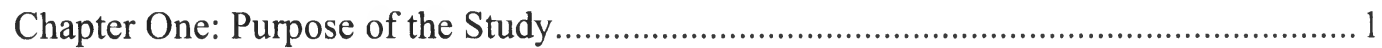

Introduction and Problem Statement .................................................................. 3

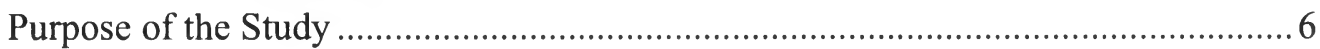

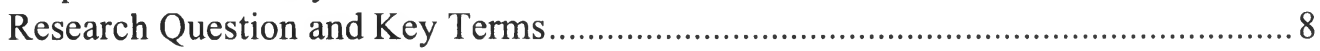

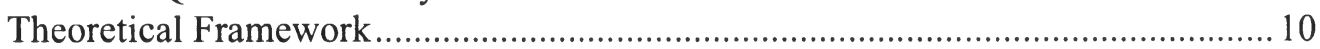

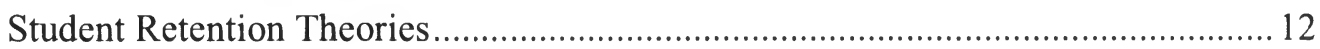

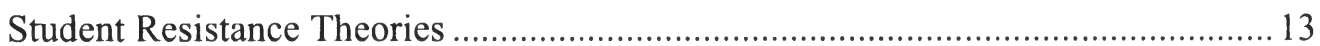

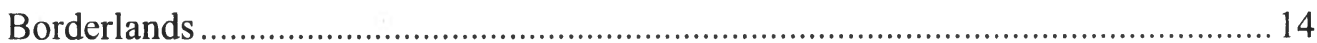

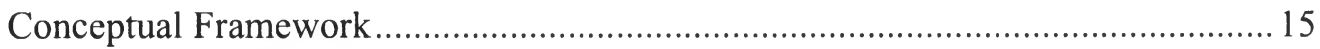

Statement of Delimitations and Scope of Study .................................................. 16

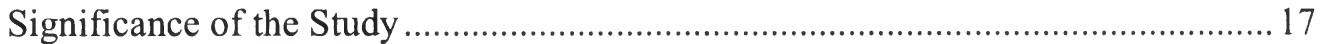

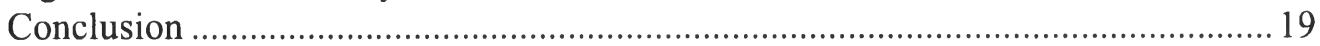

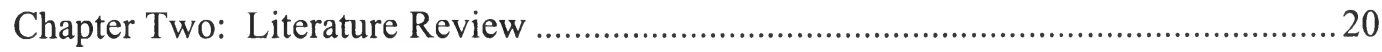

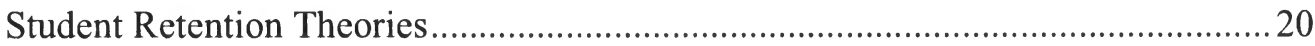

Student Retention Theories- Inclusion of Students of Color ...................................25

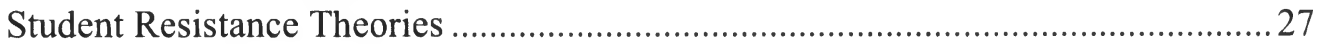

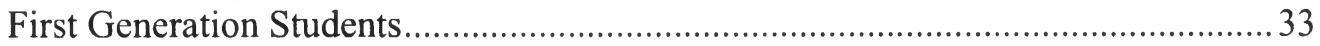

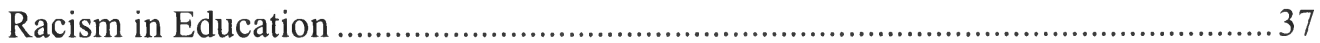

Critical Race Theory and LatCrit Theory ............................................................ 40

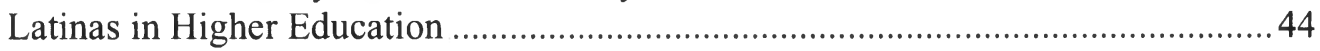

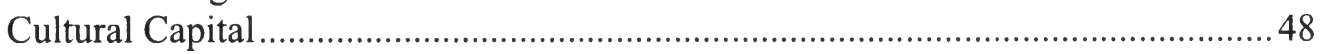

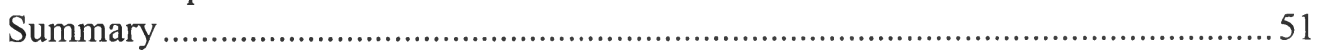

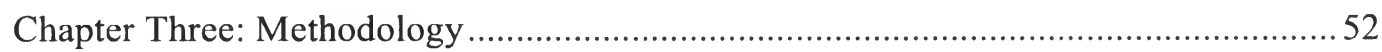

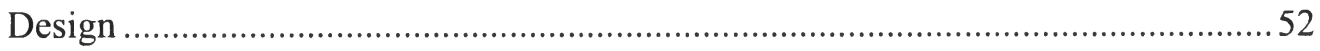

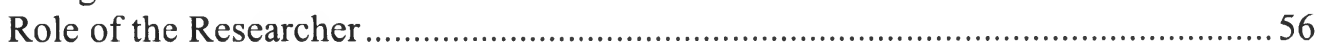

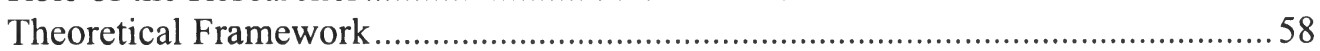

Research Questions and Sub-Questions, or Initial Objectives.............................. 59

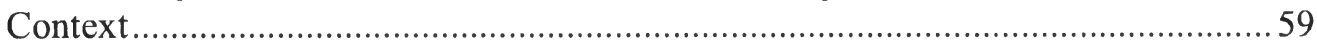

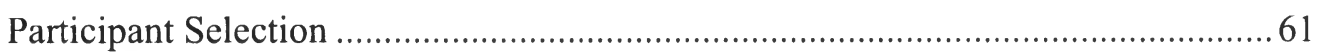

Ethics and Protection of Human Subjects .......................................................... 63 


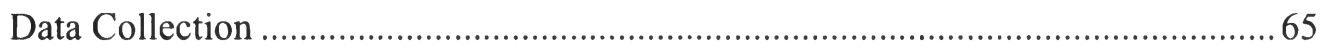

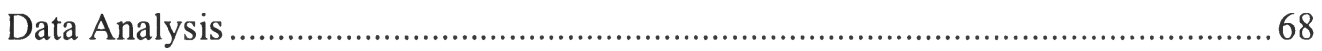

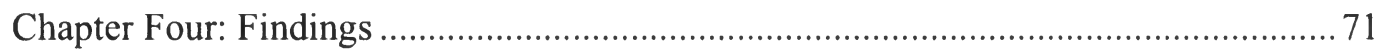

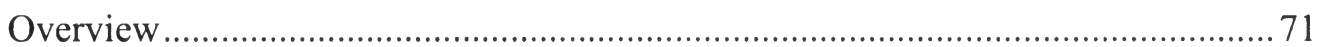

Section 1 - Campus Climate: "I like it here and I hate it here." ............................... 72

Section 2 - RHC Longitudinal Data 2000 - 2010: Who's Graduating?................... 77

Section 3 - Quantitative to Qualitative Data: Transformational Resistance Survey 82

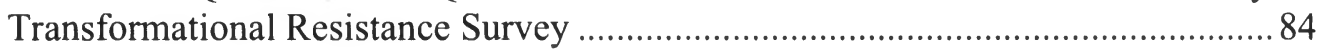

Chapter Five: Las Mujeres' Testimonios......................................................................... 98

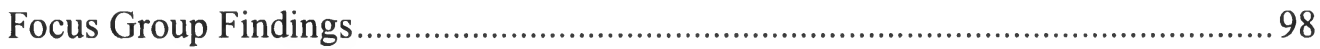

Introducing the Concept Ser Educada........................................................... 102

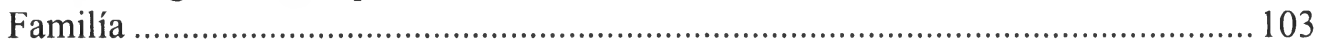

Familía Role Models - Pride and Pressure …................................................. 107

Living in the Borderlands - Mestiza Consciousness .................................... 110

Familía - Mestizaje as Resistance ................................................................. 111

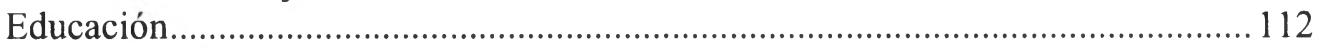

Educación - Race and Gender Matter ........................................................ 114

Finding Their Way - Educación in Seminar.................................................... 117

Educación - Resistance as Capital ............................................................... 119

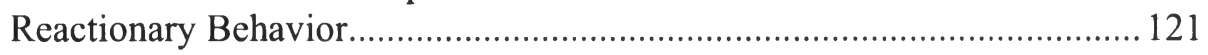

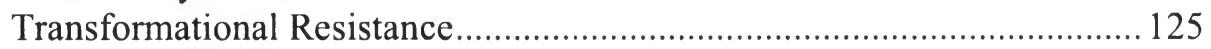

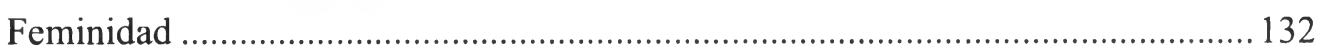

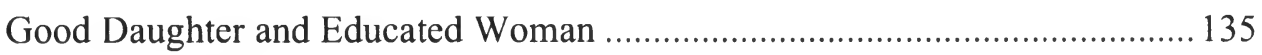

Feminidad: Queer Latinas ......................................................................... 137

Transformational Resistance Through Feminidad........................................ 139

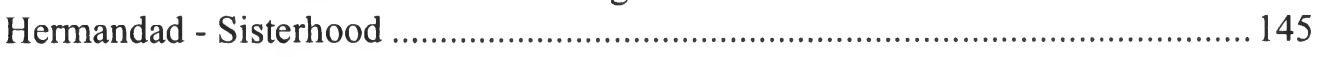

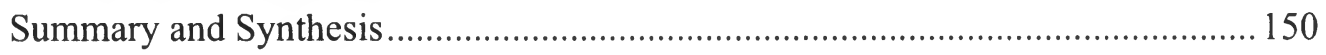

Chapter Six: Discussion and Conclusions ……….................................................. 153

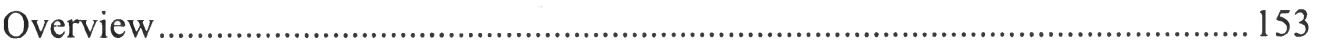

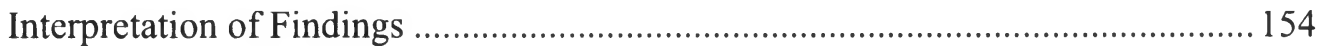

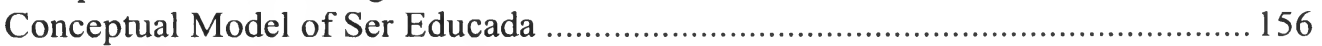

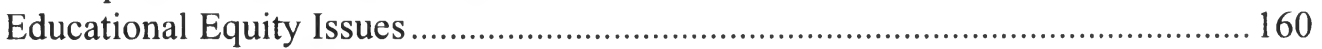

Implications for Theory, Policies, and Research ................................................ 161

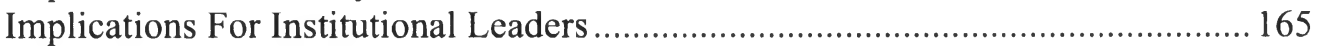

Bi-lingual and Bi-cultural Presence in Campus Leadership ............................ 165

Know Academic Success and Retention Rates of Marginalized Students ....... 167

Curriculum \& Research on Feminidad Mestiza............................................... 168

Pedagogy That Integrates Students' Lived Experiences.................................. 170 
First Year Experience Courses..................................................................... 171

RHC Seminar (Great Books) Program .......................................................... 172

Advising That Addresses the Intersectionalities of Students............................ 174

Mentoring Programs that Promote Hermandad .............................................. 176

Collaboration of Academic and Student Affairs............................................. 177

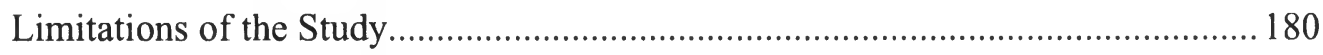

Recommendations for Disseminating Ser Educada ............................................ 181

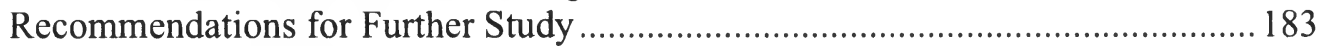

Reflections on the Research Process.................................................................. 184

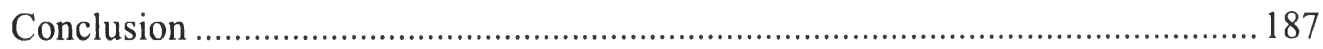

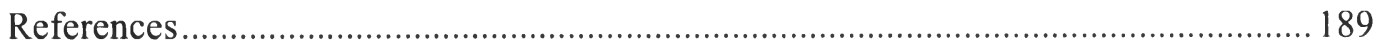

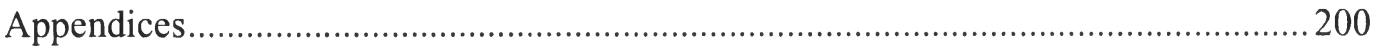




\section{LIST OF TABLES}

1. Table 1. Campus climate survey: comparison of Latino/a and white students ........ 75

2. Table 2. Enrollment of first-generation Latinas at RHC ....................................... 83

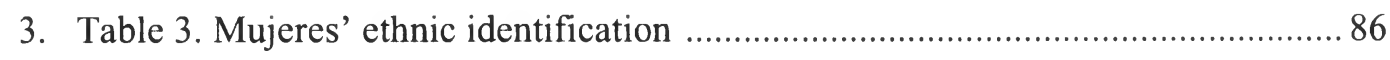

4. Table 4. Transformational Resistance Survey ....................................................... 96

5. Table 5. Focal mujeres' descriptors ................................................................. 100 


\section{LIST OF FIGURES}

Figure Page

1. Figure 1. Theoretical framework towards Ser Educada ........................................ 10

2. Figure 2. Initial conceptual framework of Ser Educada ........................................ 15

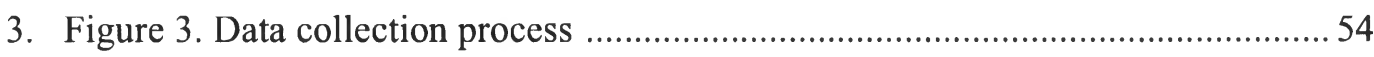

4. Figure 4. Transformational resistance quadrants ................................................ 121

5. Figure 5. Conceptual framework of Ser Educada .............................................. 157 


\section{LIST OF APPENDICES}

Appendix

Page

1. Appendix A. Mujeres recruitment letter ............................................................. 201

2. Appendix B. Demographics \& Transformational Resistance Survey ................... 202

3. Appendix C. Focus group participants' demographic data ................................... 205

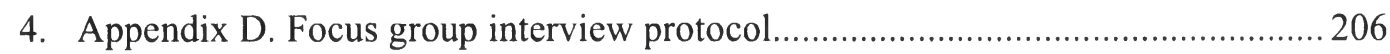


Chapter One: Purpose of the Study

Borders are set up to define the places that are safe and unsafe, to distinguish us from them. A border is a dividing line, a narrow strip along a steep edge. A borderland is a vague and undetermined place created by the emotional residue of an unnatural boundary. It is in constant state of transition.

Gloria Anzaldúa (1987, p.25)

I identify as Latina, a daughter from a mostly single mother household, and the product of years of lived experiences in my education, love, career, and mi cultura.

Only now am I able to truly see that I have lived and continue to live in the borderlands, trying to make sense of things as I negotiate the varied spaces in which I live.

I've always known there is something different about me. I've always been aware that depending on how I acted, people would either see me as one of them or not. More often than not I was considered not one of them, until I became more educated, or schooled as some might call it. What I do know is that the privilege of being an educated Latina does not come without some responsibilities. As I have worked in education, I have wondered why the students of color always seem to be the ones that do not persist from year to year, do not graduate, and if they do graduate, often do so apenas [just barely]. As I started to work with first-generation college students, I began to learn of their experiences as young people entering a world that is familiar, yet unfamiliar. I began to see more Latinas enrolling in college, but not graduating at the 
same rates as white women. And while some scholars and researchers are focusing on the experiences of young men and how to get them to college in stronger numbers, I am focused on how it is that there are larger numbers of women, of Latinas enrolling in higher education, yet not graduating at the same rates as white women. I know we are a strong people as Latinas and women, but what it is about the experience of acquiring a college education that makes some Latinas persist while others do not?

As an educator, I am focused on the retention and graduation rates of marginalized students as issues of educational equity. And I found myself becoming infuriated with the lack of attention to students of color in the literature for retention theories and programming. Furthermore, there is a gap in the literature of scholars problematizing retention theories for marginalized students from the perspectives of Critical Race Theory, Latino Critical Race Theory, or Critical Race Feminism. It is by intentionally looking at the intersection of race and gender that I seek to challenge current retention theory, while also illustrating how first-generation Latinas persisting and graduating from higher education is a form of Transformational Resistance. So to be as transparent as possible, informing my lens is the desire to critically analyze how retention theories can include the voices of Latinas by telling their stories of strength and resistance to the normative cultures of higher education. 
Introduction and Problem Statement

Higher education has increasingly become a vehicle for upward social mobility, especially for those who come from historically marginalized communities, such as first-generation, low-income, and minority college students. Students whose parents did not go to college are one of the most frequently targeted groups, along with low-income students and minorities, for access programs into higher education (Swail, Cabrera, Lee, \& Pew Hispanic Center, 2004). While access to higher education has increased for marginalized groups, the persistence and graduation rates of first-generation, lowincome, and students of color are alarmingly low in comparison to white students. Across all institution types (four-year, two-year, public, and private), low-income, firstgeneration students (predominantly students of color) are nearly four times (26 to 7 percent, respectively) more likely to leave higher education after the first year than students who had neither of these risk factors (Engle \& Tinto, 2006). Additionally, some of the protective factors that enable low-income, first-generation students to persist in higher education beyond the critical first year include, family support, engagement in the college/university, financial aid, and taking appropriate courses towards degree (ASHE - ERIC Higher Education Report, 2003).

According to the National Center for Education Statistics, white students earned $72 \%$ of all bachelor's degrees awarded, while black students earned $10 \%$, Hispanic students earned 8\%, and Asian/Pacific Islander students earned 7\%, and American 
Indian/Alaska Native students earned 1\% of all bachelor's degrees awarded, (2008). More specifically, in 2007-08, Latino degree attainment lagged behind other racial/ethnic groups (NCES, 2010). The gap between Latinos and white students in degree attainment among 18-27 year olds is $27 \%$ and presents the largest gap between a minority group and white students across the nation (NCES, 2010). Among college going students in California, Latinos represent the least numbers of students in higher education even though they represent the largest numbers of college going students in the population (NCES, 2010)

California reports that $37.6 \%$ of its population identifies as 'Hispanic or Latino,' a $27.8 \%$ increase since the 2010 census (US Census Bureau, 2010). Within the state, $77 \%$ of white students enroll in college and $76 \%$ earn a certificate or degree, while only $13 \%$ of Latinos enroll in college and $11 \%$ of them earn a certificate or degree (CDE, 2010). The California Report (2007) includes the racial opportunity gap within California that is characterized by consistent patterns of unequal opportunities experienced by students from traditionally underserved groups - African American, Latino, American Indian, and poor students (p.5). The number of students enrolling in higher education is projected to increase by 10 percent, between fall 2007 and fall 2017 (NCES, 2008). California reported an increase (9.8\%) in degrees for Latinos between 2005-2008; however, there is still a $12.6 \%$ equity gap between the $34.8 \%$ of Latinos earning a college degree versus $47.4 \%$ of white students (NCES, 2010). 
Women, as a whole have closed the gap in enrollment, persistence, and graduation from postsecondary education (NCES, 2011). By 2003, women had outpaced men in their college career in terms of enrollment and degree attainment since $51 \%$ of women compared to $41 \%$ of men had graduated. However, when disaggregated by race/ethnicity, 'Hispanic or Latino' women graduate at a rate of $17 \%$ lower than white women (NCES, 2011). Therefore, while women as a whole have gained presence in the culture of higher education, women of color can still be considered a marginalized group. The statistical realities of the gap in educational achievement, namely earning a baccalaureate degree, combined with my lived experiences as an educator and woman of color brought me to this point of wanting to learn about the experiences of first-generation Latinas in higher education. Attempting to provide support structures for low-income and first-generation students to successfully navigate higher education often challenges educators and practitioners to more fully understand the context and experiences of this student population.

In California, it is especially important to critically analyze the experiences, opportunities, and realization of Latino students' educational goals (Shulock \& Moore, 2007). According to the UCLA Chicano Studies Policy Brief (2006), Latino students are less likely to earn a college degree than their White and Asian counterparts. Using NCES 2000 data, out of 100 Latino elementary students, 46 graduate from high school, 26 enroll in college, 8 earn a baccalaureate degree, 2 earn a professional degree, and 
only 0.2 go on to earn a doctoral degree (p. 2). Chicano/a students often perceive that their college classmates and professors believe that they somehow do not "deserve" to be at the university; and that they believe to experience higher levels of stress in navigating the culture of higher education (Yosso \& Solórzano, 2006). Bernal's (1998) study of Chicana students in higher education underscores how historically, traditional mainstream educational scholarship has not addressed the intersection of gender, race, class, and sexuality. This area of research and scholarship specific to the experiences of women of color in higher education is critical to explore to inform our educational and institutional practices for marginalized groups of students.

The culture of higher education remains one that holds the values of the middleto-upper middle class culture, such as individuality, social capital, and academic discourse, along with the norms that are considered male, white, and heterosexual. Most colleges and universities are considered to be predominantly white institutions (PWIs) because of the historical and institutional racism upon which they were built. Even when an institution of higher education undergoes a demographic shift in the number of minority students it enrolls, the culture of higher education is predominantly white.

\section{Purpose of the Study}

The primary purpose of this study was to highlight the educational experiences of first-generation Latinas as they successfully navigate and persist in higher education, 
and to add their testimonios to the literature, analyzed through the lenses of LatCrit, $\mathrm{CRF}$, and borderlands. These biographical narratives (testimonios) provided a rich account to the lived experiences of first-generation Latinas persisting at a PWI. This study focuses on the role of hearing the voices of these young women as they share the role that their identities as a woman, a person of color, and a first-generation college student play in their educational experiences. It also emphasizes the constant state of transition that these young women must endure in their academic persistence and success, which is characterized by the construct of borderlands (Anzaldúa, 1987). It was in hearing the stories of their experiences that I was able to develop a conceptual framework that critically analyzes how traditional retention theories can be enhanced by infusing an intentional race and gendered lens. This conceptual framework suggests that first-generation Latinas who seek their education as a form of transformative resistance become part of the constant state of transition known as Ser Educada [to be educated].

Most of what we know about first-generation students of color comes from empirical data that focuses on national, longitudinal data (Chen \& Carroll, 2005; Choy, 2001; Pike \& Kuh, 2006; Schwartz \& Washington, 2007; Swail, 2004; and Tinto, 20062007). Therefore, this study used a mixed methods study design to combine both quantitative and qualitative data to gain insight about the educational experiences of first-generation Latinas as they persist at a private, four-year predominantly white 
institution. Using a mixed methods case study design, quantitative data come from institutional data sets as well as from a survey I developed to gather demographic data on the population. Out of 253 eligible women in this accessible population, 149 (59\%) responded to the online survey and $49(20 \%)$ indicated an interest in participating in a focus group. The qualitative data come from four different focus groups, which included 24 women, and provide insight into the educational experiences of firstgeneration Latinas as they persist at a PWI.

Adding to the literature of first-generation college students, this study looked critically at the experiences of this student population through a lens that is centered on race/ethnicity and gender. The narratives of the young women reveal how the concept Ser Educada is described by the daily navigation of Familia, Educación, Feminidad, and Hermandad that first-generation Latinas must engage in daily if they are to persist in a predominantly white institution (PWI).

\section{Research Question and Key Terms}

The research questions for this study is, "How do first-generation Latina college students persist in the normative, pre-dominantly white culture at a private four-year college?" "What resistance strategies, if any, do they use to persist academically?" I proposed to explore how Latina, first-generation college students persist in higher education because of their resilience to fully assimilate to the dominant culture. I also proposed to explore how not all strategies to succeed and persist in higher education 
may not be currently considered as transformative resistance (Solórzano \& Delgado Bernal, 2001). However, the findings reveal that many Latinas enact varying forms of resistance as they persist and eventually graduate from higher education. Additionally, the findings will provide a nuanced insight into the experiences of first-generation Latinas and contribute to the literature on retention of students in higher education. For purposes of this study, the following are key terms that require definition: First-generation student: A college student whose parents did not earn a bachelor's degree at a four-year institution in the United States. Latina: A college student who self identifies as a female from Latin American descent.

Resistance: It describes the way in which marginalized people navigate the societal oppressions of poverty, racism, sexism, and heteronormativity, using their human agency - the confidence and skills to act on one's behalf (Solorzano, 1998).

Persistence: Describes the pattern of students who continue in higher education from semester to semester, in good academic standing ( 2.00 grade point average or higher).

Predominantly white institution: An institution of higher education that perpetuates a culture that is predominantly, white, middle-class, male, and 
heteorsexual. Even if institutions are diverse in terms of demographics, they can still be identified as PWIs.

\section{Theoretical Framework}

My theoretical framework consists of multiple constructs that come together to inform my conceptual framework. Figure 1 illustrates how my theoretical framework is like a funnel, which takes in student retention theories, resistance theories, and literature on borderlands identity. Using Critical Race Theory (CRT) as the primary tool from which to analyze the other constructs, the funnel is representative of how the other three constructs move throughout the funnel. The mouth of the funnel is representative of how Latino critical race theory (LatCrit) is the filter by which all of the other constructs travel through to inform my conceptual framework of Ser Educada.

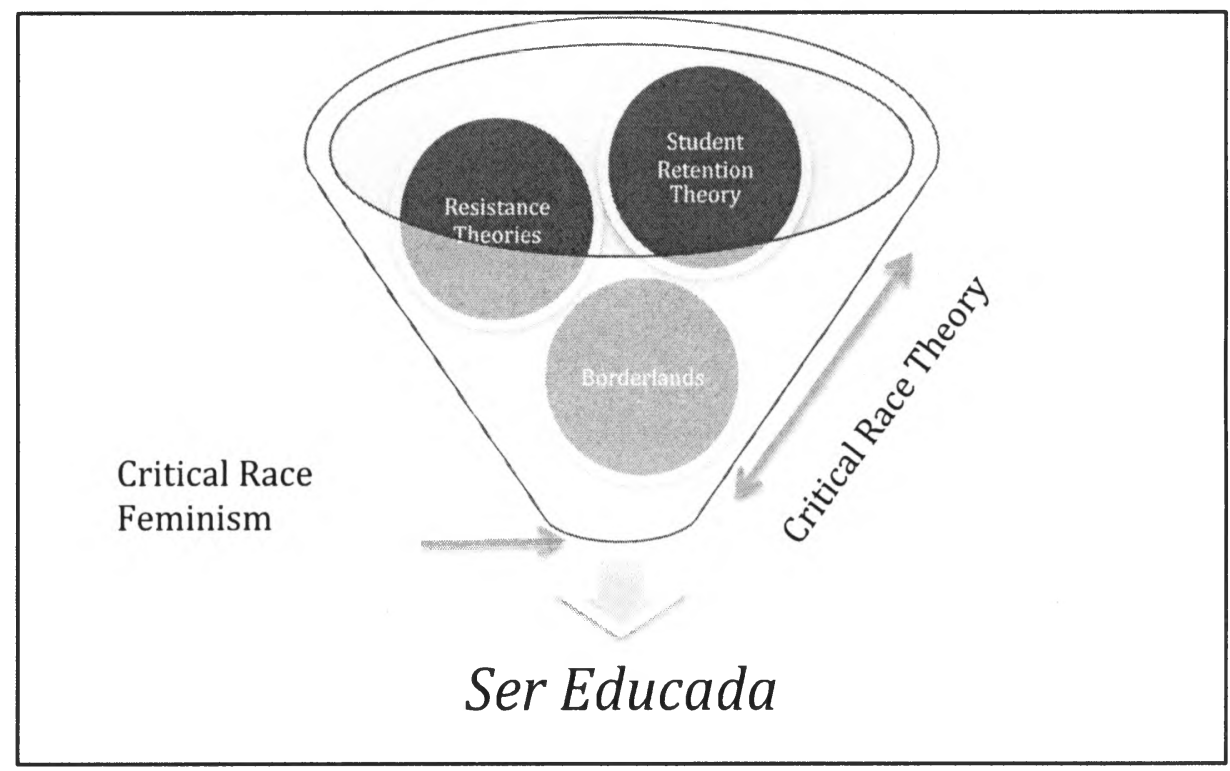


Figure 1. Theoretical Framework Towards Ser Educada

\section{Critical Race Theory/Latino Critical Race Theory}

Critical Race Theory (CRT) extends a broad literature base in sociology, history, ethnic studies, and women's studies, with its foundation stemming from legal scholarship - Critical Legal Studies, (Crenshaw et al, 1995,). CRT is a theoretical framework often used in education, which keeps race and racism at the center of oppression (Ladson-Billings, 1998). Ladson-Billings and Tate (1995) articulate, "despite the salience of race in U.S. society, as a topic of scholarly inquiry, it remains untheorized," (p.47). Therefore, they theorize race and "use it as an analytic tool for understanding school inequity," (p.48), an analytical tool used by CRT scholars. CRT provides the framework to analyze the microaggressions students of color face in higher education, covertly rampant as they are (Sue et al., 2009).

Latino Critical Race Theory (LatCrit) is often viewed as a more valid and reliable lens through which to analyze the intersections of Latinos' identities, specifically addressing the intersection of oppression of race, gender, class, language, and immigration status (Solórzano \& Bernal, 2001). According to Solórzano and Bernal, there are five tenets of CRT/LatCrit (2001): a) the centrality of race an racism and the intersectionality with other forms of subordination; b) the challenge to dominant ideology; c) the commitment to social justice; d) the centrality of experiential 
knowledge; and e) the interdisciplinary perspective to education. These five themes provide a foundational platform to analyze student resistance strategies to the normative, white culture of higher education.

Bernal (2002) highlights how LatCrit and Critical Race Feminism (CRF)

provide a lens through which to also look at the intersections of migration, immigration, and language in Latinas' identities. "It is a theory that has already developed a tradition of offering a strong gender analysis so that it can address the concerns of Latinas in light of both of our internal and external relationships in and with the worlds that have marginalized us," (Hernandez - Truyol, 1997, p. 885). Saenz et al., (2007) illustrate the experiences of first-generation college students who are first in their family to attend college. However, literature on student retention lacks an emphasis of the intersection of first-generation status, race, and gender.

\section{Student Retention Theories}

Research on the persistence and retention rates of marginalized students in higher education is quite extensive. Data on the length of time that a student remains in school is one of the most heavily studied areas in higher education (Bean \& Eaton, 2002; Cabrera, Nora, \& Cabrera, 1996; Tierney, 1999; Tinto, 1988). Much of the literature on retention and transition (Astin, 1970; Bean \& Eaton, 2002; Cabrera, Nora, \& Cabrera, 1999; Padilla, 1999; Schlossberg, 1981; \& Tinto, 1997) is rooted in Spady’s 
(1971) "Model of Undergraduate Dropout Process." This model was the first to describe the connections between variables such as family, grades, social integration, and overall satisfaction at the college and their impact on a student's decision to drop out or persist in college (Bean \& Eaton, 2002).

Tinto's (1988) Student Integration Model is often viewed as a deficit model, which asks the students to integrate and adapt to the school culture, often at the expense of their cultural norms and traditions. Within this model, first-generation, low-income, and students of color are further marginalized as lacking the academic, social, and cultural capital needed for success in higher education. And while his later work addressed some of the criticisms of neglecting race and ethnicity, it has still not directly addressed the role of race on student retention. Therefore, I found it necessary to look to the literature on student resistance to learn more about marginalized students navigate the racism that exists in a PWI.

\section{Student Resistance Theories}

Resistance theorists (Bernal, 1998; Fine et al., 2004; Fordham \& Ogbu, 1986; Giroux, 1983; Macleod, 1986; Solórzano \& Delgado Bernal, 2001; and Willis, 1977) analyze how marginalized people navigate with the societal oppressions of poverty, racism, sexism, and heteronormativity. At the core of resistance is an individual's human agency - the confidence and skills to act on one's behalf (Solorzano, 1998). 
Self-defeating resistance is the most commonly discussed type of resistance, which highlights how students' behaviors keep reinforcing the domination of their own communities (Akom, 2003, 2008; Fine, et al., 2004; Foley, 2005; Fordham \& Ogbu, 1986; and Ogbu, 1986, 2004)). With a CRT lens, transformational resistance (Solórzano \& Delgado Bernal, 2001) describes how students are both motivated by social justice and have a level of awareness to be able to critique the dominant and oppressive structures that impact their daily experiences. The first-generation Latinas in this study illustrate how they enact in transformational resistance as a means to persist in college.

\section{Borderlands}

Gloria Anzaldúa (1987) was a Chicana feminist who wrote about the Chicana identity as one that lives in the borderlands. "Alienated from her mother culture, 'alien' in the dominant culture, the woman of color does not feel safe within the inner life of her Self. Petrified, she can't respond, her face caught between los intersitios, the spaces between the different worlds she inhabits" (p.42). Anzaldúa's work has been studied by Chicana feminists (Anzaldúa, 1987; Benmayor, 2002; Darder, 1997; Delgado Bernal, 1998, 2001; Moraga, 1983; Perez, 1999; Rendón 1992; Sandoval, 1998) who believe that exploring the unique experiences of Chicanas/Latinas is critical for understanding how they navigate living in multiple worlds as women of color. 


\section{Conceptual Framework}

This study focuses on hearing the voices of these young women as they share the role that their identities as a woman, a person of color, and a first-generation college student play in their educational experiences. It also emphasizes the constant state of transition that these young women must endure in their academic persistence and success, which is characterized by the construct of borderlands (Anzaldúa, 1987). It was in hearing the stories of their experiences that I was able to develop a conceptual framework that critically analyzes how retention theories can be enhanced by infusing an intentional race and gendered lens. This conceptual framework suggests that firstgeneration Latinas who seek their education as a form of transformative resistance become part of the constant state of transition known as Ser Educada [to be educated].

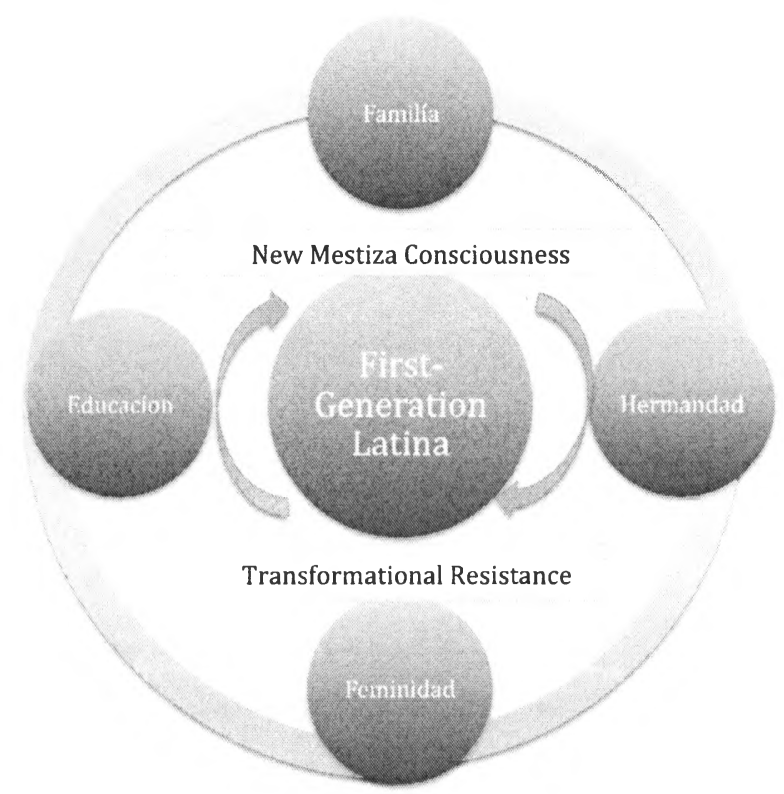

Figure 2. Initial Conceptual Framework of Ser Educada 
Figure 2 illustrates how the first-generation Latina is at the center of a constant state of energy that is necessary to successfully navigate and persist in higher education. It also illustrates how she is aware of her mestiza identity and enacts in transformational resistance as a strategy to persist in higher education. Further description and analysis of this new concept is provided through their stories found in Chapters 4 and 5 . The women in this study described what it means and what it costs to Ser Educada.

\section{Statement of Delimitations and Scope of Study}

This study was designed to develop a conceptual framework for the educational experiences and resistance strategies of first-generation Latinas at a predominantly white institution. More specifically, it was designed to gain insight into the nuances of experiences of first-generation Latinas and how they persist in higher education. While there is extensive literature on first-generation college students, it is primarily empirically based and does not directly analyze its intersection with Latinas. As one of three studies about first-generation Latinas, and the only one that using mixed methods, the results of this study are transferable and may have some generalizability. The mixed methods, sequential case study design enhances this study's transferability, especially with the high response rate of $59 \%(n=149)$ for this population. However, the generalizability may be limited by the fact that the research was conducted with women at one institution, which is also a private, non-profit four-year college. Although I did not know all of the respondents, my position on the campus as one of four prominent 
Latina professionals (faculty and staff) may have influenced the results, both positively and negatively. More descriptions on these limitations are discussed in chapter three. With the growing number of Latinas and first-generation college students in California, the design of this study was essential to add to the literature on student retention and resistance.

\section{Significance of the Study}

The primary significance of this research is that it deliberately looks at the intersectionality of first-generation status, race/ethnicity, and gender, told from the perspectives of the women themselves. Their narratives, or testimonios, contribute to the predominantly male, white, heterosexual literature of student retention, as well as contribute to the existing literature on LatCrit and Critical Race Feminism (CRF). Introducing a LatCrit and CRF perspective into the literature on student retention provides an opportunity to stretch the discussion beyond that of diversity and more towards one of equity. Within this approach, I was able to develop a conceptual framework that explains the educational experiences and resistance strategies that firstgeneration Latinas enact to persist in higher education.

By focusing on their strengths, I was provided with rich testimonios that describe the process of Ser Educada, becoming educated. And as a mixed methods study design, it addresses a gap by contributing quantitative data to the literature on 
borderlands, Chicana feminism, and transformational resistance, broadening the type of study that look at the intersectionalities of students' lives.

This research suggests that the educational experience of first-generation Latinas in higher education include the constant state of transition and navigation of four key areas: Familia, Educación, Feminidad, and Hermandad. The study's findings suggest that if institutions design, implement, and assess retention programs without considering these four areas they will only contribute to a lack of equity in higher education for first-generation Latinas. As a practitioner-scholar, I have considered how the findings of this study can inform how I work with first-generation women, and other marginalized students. As an administrator, I have considered how the findings of this study can inform our staff to become more intentional at providing advising sessions that address the intersectionality of students' identities, as well as provide opportunities for them to share their educational experiences in college. This study's significance is in gaining students' perspective to inform the educational practices and retention policies of our universities and colleges, especially for California's growing Latino/a student population. These are further discussed in Chapter 6 as part of the discussion and recommendations for improving practice. 


\section{Conclusion}

Employing a mixed methods case study design, my research seeks to learn from both institutional data on the persistence and graduation rates of first-generation Latina students, as well as learn from their educational experiences, to better understand how they navigate and persist in a predominantly white institution. The literature on firstgeneration students is primarily quantitative and the literature on Latinas is primarily qualitative. With a mixed methods study design, this study provides a more comprehensive description of the nuances of being a first-generation Latina in higher education. Chapter two presents a review of the theoretical, student retention, and student resistance literature that guided this investigation. Chapter three presents the methodology of this mixed methods study, including the transformational resistance survey I constructed. The findings are presented into the following two chapters. Chapter four provides a synthesis of the quantitative findings, including those data from the Transformational Survey I developed. Chapter five provides a rich synthesis of the results of focus groups, through the voices of four focals, which describe the key elements of the concept Ser Educada. And the final chapter includes a discussion of the significance of the results, implications of the findings, and recommendations for future research. 
Chapter Two: Literature Review

This literature review begins with a brief overview of retention and resistance theories in higher education. These theories provide the lens from which I will analyze and synthesize the literature. Within this review, I will examine how race and racism impact the experiences of students of color and their persistence in higher education. Following, I will examine how contemporary student resistance strategies begin to look at the multidimensionality of students. This will lead into the closing section, which reviews how first-generation, students of color experience higher education.

\section{Student Retention Theories}

Research on the persistence and retention rates of marginalized students in higher education is quite extensive. Data on the length of time that a student remains in school is one of the most heavily studied areas in higher education (Tinto, 1988). Much of the current literature on retention and transition (Astin, 1970; Tinto, 1988, 1998, 2009; Bean \& Eaton, 2002, Cabrera \& Padilla, 2004, Schlossberg, 1981, Padilla, 1999) are rooted in Spady's (1971) "Model of Undergraduate Dropout Process," which illustrates the connections between variables, such as family, grades, support, social integration, and overall satisfaction at the institution to an individual student's decision to drop out or persist in college. Building upon Spady's work, Astin's (1970) 
Involvement Model, and Van Gennep's (1960) “Rites of Passage: separation, transition, and incorporation," Tinto (1988) examined longitudinal data over a decade to develop his position on student departure as the successful completion of stages typical to transitioning into and through new phases of major life stages. He called for a more ethnographic approach to understanding the quality of a student's experience in college.

Tinto's (1988) Student Integration Model is comprised of three phases for student retention begins with "separation," which is identified by leaving all past connection behind. Researchers who challenge this phase (Cabrera et al, 1999; Padilla, 1991) critique how the lack of acknowledging past experiences and relationships with family and community can be an asset further stigmatizes students of color as overly lacking the skills necessary for successful navigation of higher education. The second phase, "transition," includes the new interactions and experiences a student has in college. Tinto posited that only with complete separation from past connections could a student fully transition. In the transition phase, students are learning to live and exist without their families and communities, often feeling isolated. They are also learning how to interact in their new environment.

Tinto (1988) believed that if the isolation is unbearable or the learning too slow, a student would depart prematurely from the institution. The final stage, "incorporation," calls for students to adapt to the new patterns of interaction within this new environment. Students, who now identify with the new group of being in college, 
respond to past connections from the perspective as a member of the new group. For first-generation and students of color, this can pose problematic interactions with family and community members, who may view them as being "different," "acting white," or believe they "are better than family." Tinto's model is often viewed as a deficit model, which asks the student to integrate and adapt to the school culture. Within this model first-generation, low-income, and students of color are further marginalized as lacking the academic, social and cultural capital needed for success in higher education. Students of color, in particular, are expected to assimilate in the culture of higher education, according to Tinto's model (Cerna, Pérez, \& Sáenz, 2009; Kim \& Sax, 2009, and London, 1992).

While Tinto (2006-2007) acknowledges that he did not disaggregate data based on variable such as race, gender, and socioeconomic status, it was only after he received much criticism from more contemporary researchers. Nonetheless, his model for student integration into the university, along with earlier models, have neglected to account for the variables that impact first-generation, students of color, and low-income students, such as, family college knowledge, finances, employment, and institutional barriers such as racism and sexism. Researchers that followed Tinto (1988), such as Bean and Eaton (2002), Padilla (1999), and Cabrera et al. (1999) include the variables neglected in Tinto's work, plus some additional circumstances which may affect why particular student populations do not persist at the same rate as the general student population. 
Braxton, Hirschy, and McClendon (2004) provide an analysis and expansion of Tinto's student departure model. They identify key factors that have a positive impact on an institution's retention rates: 1) Commitment of the institutions to students' welfare, 2) Communal potential, 3) Institutional integrity, 4) Proactive social adjustment, 5) Psychosocial engagement, and 6) Students' ability to pay. Based on these six key factors, Braxton et al. (2004) provide specific strategies for residential colleges, which include mandatory first-year on campus housing, structured opportunities for students to interact with faculty, such as first year seminars, and creating a space for diverse students that honors their cultures and traditions.

Within the retention literature for predominantly white institutions (PWI), Brier, Hirschy, and Braxton (2008) studied the effects of Vanderbilt's Strategic Retention Initiative, in which the Dean of Students makes phone calls to each first year student as a means to gather information on the experiences of 300 first year students. Fall calls are made during the fourth or fifth week in the fall semester, usually in the midst of the academic pressure points of midterms and final essay preparations. Follow-up phone calls and individual meetings are provided as students identify their needs. However, every first year student receives a follow-up phone call during the spring semester. Vanderbilt reports an increase in their retention of $10 \%$, over a period of ten years. The researchers report that the satisfaction surveys given to seniors indicated that there was a correlation between the Student Retention Initiative and its effect on retention of 
students throughout their time at the college. It's important to note that Vanderbilt is a highly selective institution that is predominantly white, but has a growing number of students of color. They were not able to report any significant changes in retention of students of color during the ten-year study.

The literature on retention of students of color becomes evident after the passage of the 1964 Civil Rights Act and the 1965 Higher Education Act (Oseguera, Locks, \& Vega, 2009). "This era witnessed growth in funding for students to attend college, demands of campuses to enroll a greater number of Latinas/os, and demands for culturally specific programs on college campuses" (Oseguera et al, 2009, p.26). Berger and Lyon (2005) provide a historical review on the issues of retention in higher education as they analyze the characteristics of the college experience that impact student success. By the 1970s, retention theories were established based on the persistence data, which were based on predominantly male, white, and middle-class cultural norms (Berger \& Lyon, 2005). The 1980s became known as the period of "Managing Enrollments," in which administrators created intentional programs for recruitment and retention of students, especially students of color and first-generation students (Braxton, 2000; Siedman, 2005a). This led to what Berger and Lyon (2005) call the period of "Broadening Horizons," which called for national attention to prioritize and research the educational experiences and outcomes for students of color. And the final time period that Berger and Lyon (2005) describe is known as the 
"Current and Future Trends," in which initiatives and programming regarding retention issues is virtually in every institution of higher education. With so much emphasis on the research of retention, especially for students of color, it would be logical to infer that the retention rates have improved over the last decade. However, the retention of marginalized student groups by racial, ethnic, and first-generation status continues to fall below that of white, male students. "One major limitation in the evolution of retention studies is the continued attention to traditional college students" (Oseguera et al, 2009), p.27). Therefore, the following section in this literature review focuses on those retention studies that are framed around the experiences of students of color.

\section{Student Retention Theories- Inclusion of Students of Color}

Padilla (1999) uses qualitative data analysis in his model of student retention, the "Black Box" theory, which aims to provide an asset-based theoretical approach. Padilla focused his research on successful students, especially Chicano students. Padilla's (1999) model illustrates four categories of barriers: discontinuity, lack of nurturing, lack of presence, and resources. He also assumes that students bring with them Heuristic knowledge, that is experiential knowledge, and Theoretical knowledge, knowledge learned in books, as they enter college. This asset based approach to student integration and retention is based on the assumptions that barriers do exist, must be negotiated, are not homogeneous, and are uniquely diverse for each student. Padilla 
concludes that students who were able to increase their areas of knowledge and negotiate the four categories of barriers, were more likely to persist and graduate.

The "Institutional Components of Student Persistence," is a model by Swail, Redd, and Perna (2003) that views the institution as the individual that must make accommodations to ensure the retention and success of minority students. Their framework names the following five areas as critical focal areas to the retention of minority students: 1) financial aid, 2) recruitment and admissions, 3) academic services, 4) curriculum and instruction, and 5) student services. They provide an in-depth analysis within each of these areas that puts the students at the center of each, challenging institutions to rethink its delivery methods for information and services. The underlying theme is that if institutions are to retain students of color, they need to know where their students come from, admit them based on their strengths, and provide them with a curriculum that is diverse and culturally relevant.

Overall, the retention literature is focused on the experiences of predominantly white, male students and has only recently started to focus on marginalized student populations. The literature often puts the student as the one who succeeds or fails at remaining in college. Institutions miss opportunities to learn from minority students who are persisting in higher education. Studies on campus climate often cite that students who perceive bias on the basis of their race, class, gender, or sexual orientation may experience and conscious or unconscious resistance to the campus, which may lead 
to impacting retention (Hurtado \& Carter, 1997; Nora \& Cabrera, 1996). From a strengths-based perspective, the following section reviews the literature on how students of color engage with resistance in education.

\section{Student Resistance Theories}

Resistance theorists, both traditional and contemporary (Bernal, 1998; Brayboy, 2005; Cammarota, 2004, 2006; Willis, 1977; Giroux, 1983; Fordham \& Ogbu, 1986; Macleod, 1986; Solorzano \& Delgado Bernal, 2001; and Fine et al., 2004), analyze how marginalized people navigate with the societal oppressions of poverty, racism, sexism, and heteronormativity, using their human agency - the confidence and skills to act on one's behalf (Solorzano \& Solórzano, 1995). While resistance theories might help us understand the experiences of students of color in higher education, they do not significantly emphasize the importance of striving towards and working for social justice.

Self-defeating resistance is the most commonly cited type of resistance theory, which highlights how students' behaviors keep reinforcing the domination of their own communities (Fine, 1991; Foley 1990, MacLeod, 1987; and Fordham \& Ogbu, 1986). Furthermore, there are a small number of studies that address the subtle resistance strategies of women (Delgado Bernal, 1997, Fuller, 1980; and Ward, 1996), who are 
motivated by issues of social justice, to challenge the patriarchal system that dominates higher education.

Delgado Bernal's (2001) qualitative study of 50 women providing their "counter-stories" to their educational experiences in the normative, white, patriarchal values of higher education underscores the diversity of experiences, even within this student population. Analysis of these "counter-stories" indicates that students develop key tools and strategies to navigate their daily existence in a culture that overtly and subtly silences them. She found that the application of their previous family/community knowledge, including, bilingualism, biculturalism, and community solidarity "interrupts the transmission of official college knowledge and even helps students navigate their way around educational obstacles" (Delgado Bernal, 2001, p.113 $-114)$.

Solórzano and Delgado Bernal (2001) expand on Delgado Bernal's (1997) study of Chicana resistance defined resistance in four categories: 1) reactionary behavior resistance, 2) self-defeating resistance, 3) conformist resistance, and 4) transformative resistance. These are based on Giroux's (1983a, 1983b) notion that resistance as the following intersecting dimensions: "(a) Students must have a critique of social oppression, and (b) students must be motivated by an interest in social justice," (Solórzano \& Delgado Bernal, 2001, p.316-317). Of Solórzano \& Delgado Bernal's (2001) four categories of resistance, reactionary behavior is the only one that does 
include a critique on social oppression and does not stem from an interest in social justice. An example would be a college student who challenges a professor "just because," without any thought or reflection about the oppressions that actually silence marginalized groups. It could also be a student who is disruptive in class or at a school gathering and has no critical reflection of why s/he might be disruptive in the first place.

Self-defeating resistance is the one traditionally discussed in resistance theory research (Fordham \& Ogbu, 1986 and Fine et al., 2004). Students enacting selfdefeating resistance might include the student who is critical of the heteronormative, white, patriarchal structure of higher education, but engages in behavior, which leads to dropping out of school. Fine et al. (2004) describe how students become aware of "their place" in the structure, often leaving them disempowered to believe that their lives could be any different than its current oppressive state.

The concept of "acting white," when students of color acculturate and assimilate to the values of norms of white culture in order to be successful in college, is an example of self-defeating resistance (Akom, 2003, 2008). Fordham and Obgu's (1986) study on how oppositional culture contributed to Black students' school performance has been critiqued by resistance theorists for its focus on blaming the students for their lack of educational achievement. The contemporary perspective of Fordham and Ogbu's (1986) study is that black students think white people are smart, like school, and thereby own school. Therefore, in opposition to this "whiteness," black students do not 
engage in behaviors that will lead to "acting white." This view is an example of selfdefeating resistance because in the study, black students are basing their collective identity as not "being white"; therefore, they do not seek to be successful in educational settings. This oversimplification leads to the students being seen as problematic instead of the systems they must navigate. There is virtually no discussion on the experiences that led to the black students' beliefs of feeling like they could never truly be equal to white students.

Solórzano and Delgado Bernal's (2001) third form of oppositional behavior is conformist resistance. Students who exhibit conformist resistance are motivated to increase the quality of their individual lives and that quality of life for their entire community. Yet, they do not critique the social oppressions or racist structures that act as a barrier to enhancing their quality of life. Conformist resisters have internalized the values and ideology of color-blind processes and meritocracy. They believe that in order to be successful, they must be as different as possible as the communities that they come from. The conformist resister is the student who believes that it is her individual hard work and determination that has allowed her "to beat the odds," (Wang and Catañeda-Sound, 2008). These students discuss feeling proud about their academic success and getting ahead, especially when other "minorities like them are not." They emulate the meritocratic analogy of pulling oneself up by her bootstraps because she blames others' lack of desire to pull up their boots rather than questioning the structural 
inequalities that exists when there are no boots. This student may succeed beyond even her white counterparts in terms of academic and social successes, but her conformist resistance is based on further embedding the dominant, normative, white culture in education.

Transformational resistance (Solórzano \& Delgado Bernal, 2001) describes how students are both motivated by social justice and have a level of awareness to critique the dominant and oppressive structures that impact their daily experiences. "With a deeper level of understanding and social justice orientation, transformational resistance offers the greatest possibly for social change” (Solórzano \& Delgado Bernal, 2001, p. 319). Delgado Bernal, Alemán, \& Garavito’s (2009) study of first-year Latina graduates and the their social and academic experiences at a predominantly white institution reveals how students who integrate their theoretical knowledge with their educational experiences of providing mentoring for a community elementary classroom, provides them with the "physical, social, and discursive borderlands occupied by Latina/o students help to construct their hybrid identities" (Delgado et al., 2009, p. 565). Students in this study exemplify transitional resistance because they are challenging the dominant paradigm that to be educated means to abandon your ethnic, social, or community identity. As mentors to elementary school students, they modeled what a Latina in higher education looks like. This experience, coupled with bringing them on campus for college visit days, provided the elementary students a cultural representation 
of themselves in higher education.

Cammarota's (2004) study on the educational goals of Latinos shows how the intersection of race and gender in the social construction of Latina/o youth fosters different responses and resistances. "Resistance for many Latinas in the study, for example, centered on graduating and being the first in the family to receive a high school diploma, a credential that would mark a status change for them among men and women in the home, community, and society at large" p. 54). Akom's (2003) study of high school women in the Nation of Islam adds to the literature on reexamining resistance as oppositional behavior. His study provided insight into the strength that ethnic and religious identification held for the young women in his study.

The literature on student resistance ranges from oppositional behavior that is viewed as defiant and negative to resistance behavior that is transformational. There is an underlying theme that those students who do not find community in the institution of higher education will enact in oppositional behaviors. While resistance theories might help us understand the experiences of students of color in higher education, they do not significantly emphasize the importance of striving towards and working for social justice. Delgado Bernal (1997) and Akom (2003) are the only scholars that have researched this aspect, specifically from a perspective of women of color. Throughout the remainder of this literature review, an examination of the experiences of marginalized student populations such as first-generation students, students of color, 
and women of color will provide additional insight into current theories on retention and persistence.

\section{First Generation Students}

First generation students are often described as being disadvantage for postsecondary access and success, even after controlling for educational expectations, academic preparation, support from parents and schools, and family income (Choy, 2001; Naumann \& Bandalos, 2003; Pascarella et al., 2004). Students of color are often more likely to be first-generation than white students, and more likely to be from lowerincome families (Choy, 2001). Comparative studies (Bui, 2002; Reihl, 1994) indicate that first-generation college students often encounter more challenges than do their peers, making them more vulnerable to lower academic performance as they adjust to college.

Choy's (2001) meta-analysis of three longitudinal studies, National Education Longitudinal Study (1988 - 1992, 2000); Beginning Post Secondary Students Longitudinal Study $(1989,1992,1998)$; and Baccalaureate \& Beyond Longitudinal Study $(1992,1994,1997)$ provides the field of higher education with empirical data that supports that enrollment in postsecondary education is strongly related to parents' educational level. First generation college students tend to come from postsecondary schools with lower academic rigor (including lack of AP and IB courses) and seem less 
academically prepared than non-first generation students. Even with the goal of achieving a bachelor's degree, $58 \%$ of first-generation students are less likely than their counterparts $(17 \%)$ to remain on a persistent track to a college degree (Choy, 2001).

First-generation college students of color engage less frequently with faculty and staff than white students (Chen \& Carroll, 2005; Kim, 2005). They are also described as having less cultural and social capital, erecting barriers for effective communication with faculty (Collier \& Morgan, 2008), leading to misunderstandings and misconceptions of their academic capabilities (Choy, Horn, Nunez, \& Xianglei, 2000). For example, a first-generation student, who is also a student of color, may not hold as a value that his/her questions are valid and worth a professor's time. This same student might not possess the social capital to communicate with a faculty member after class, via email, or by phone. This lack of capital may attribute to the lower engagement levels with the university that first-generation students exhibit. This deficit view of first generation students of color does not acknowledge the cultural capital that is described by Yosso (2005) as that of cultural community wealth, which is discussed later in this literature review.

Using a stratified random sample of 4,501 undergraduate students from fouryear institutions who completed the College Student Experiences Questionnaire (CSEQ by Pike \& Kuh, 1998) between 1998-2001, Lundberg, Schreiner, Hovaguimian, and Miller (2007) conducted a national longitudinal study. They categorized their 
participants into seven distinct racial/ethnic groups ( $\mathrm{n}=643$ per group) and identified that first-generation status had a positive effect on student learning, but a negative effect on involvement. Given that involvement in college is a predictor for persistence and graduation (Pascarella, Pierson, Wolniak, \& Terenzini, 2004), this negative effect on involvement could later impact student learning as well. Lundberg et al., (2007) discuss how the limited involvement for first-generation college students "pays off" better than it does for their continuing generation counterparts. While limited involvement might be good for their academic progress, it might overlook how they can be marginalized from fully feeling as full members of the community. They did not include socioeconomic status as one of the variables, limiting the study's findings, especially given the high number of first-generation students that are also low-income students.

Bui's (2002) study of first-generation college students a four-year university examined the reasons and background characteristics for this population to pursue a college degree. Bui's study included first-generation college students $(n=64)$, non-first generation college students whose parents had some college but no degree $(n=75)$, and non-first generation college students ( $n=68)$. Her study found the following: 1$)$ that the chances of first-generation college students earning a college degree were greater when students started at a four-year institution over a two-year college; 2) first-generation students felt less prepared and worried more about financial aid; 3) first-generation students knew less about the social norms and values of the environment; and 4) first- 
generation students tend to be students of color with low socioeconomic status, and are more like to speak a language other than English at home.

The literature reveals that first-generation college students are at a disadvantage for postsecondary access and success, even after controlling for variables such as academic preparation, family income, and parental support (Choy, 2001). Students of color are more likely than white students to be first-generation and encounter more challenges than do their peers. They are seen as having less cultural and social capital, which impacts how they less frequently engage with faculty and staff than do white and continuing generation students (Chen \& Carroll, 2005; Kim \& Sax, 2009).

Furthermore, first-generation college students are more likely to have to work over 20 hours a week and identify with being an employee over being a college student as a result (Choy, 2001, García, 2009). They are also more likely to persist and graduate from college if they begin at 4-year institutions versus a 2-year community college.

Although the literature provides some insight into the educational experiences of first-generation students of color, it does so as a peripheral approach. As I reviewed my research question regarding the persistence and resistance strategies of first-generation Latinas, I knew that I would need to look at the experiences of students of color in higher education, and especially Latinos. The following section holds the perspective that race is central to understanding the experience of first-generation Latinas. 


\section{Racism in Education}

Educational and social disparities within communities of color, especially blacks and Latino/as, have always been conceptualized from a deficit perspective. Since the early 1900's, theories that gaps in the successes and achievements of particular minorities were due to inherited, biological differences have dominated society's views about people of color (Aronowitz \& Giroux, 1991; Astin \& Oseguera, 2004; Foley, 1997). Bonilla-Silva (2001) states that "the cultural explanation of black's predicament by neoconservative analysts such as George Gilder, Nathan Glazer, Lawrence Mead, Charles Murray, Shelby Steele, and Thomas Sowell [.... [a]cknowledge that blacks and, to a lesser extent, other minority groups are behind whites but blame them for their situation," (p. 4). These analysts hold not only that black culture is flawed, but also, that the policies and politics of the 1960s are the cause of their lack of personal responsibility and welfare mentality (Bonilla-Silva, 2001).

Charles Murray's (1984) book, Losing Ground, perpetuates that minorities are lazy and that spending tax dollars on policies such as affirmative action and reforming segregated schools is discriminatory to whites. Additionally, Herrnstein' and Murray's (1994) book, The Bell Curve, is one the most controversial and criticized books for perpetuating racism in the United States. Herrnstein and Murray suggested, "the status of blacks and Latinos is primarily due to their lower cognitive ability," (Bonilla-Silva, 2001, p. 5). This belief fueled by society's views on policy issues, such as eliminating 
affirmative action, because students of color and other minority groups inherently are not as intelligent as whites. From a biological to a cultural deficiency perspective, there is a tendency to view the issues of people of color as something that is inherently wrong with them, rather than acknowledging a "lack of sophisticated understanding of how racism operates in the contemporary United States," (Bonilla-Silva, 2001, p.9).

Challenging the status quo would require that we "study the practices, institutions, and ideologies that help sustain white privilege," (Bonilla-Silva, 2001, p.12). There is a tendency for society to believe that even though racial stratification inequality is not eradicated, the experiences of people of color is far better today than during the times of slavery and Jim Crow periods. This form of historical amnesia perpetuates institutional racism, maintains the status quo, and contributes to the inequalities in education today.

One of the more contemporary perspectives around issues of race and racism among conservatives and liberals is the "pesoptimist" position on racial matters, that is that racial matters are neither great nor terrible" (Bonilla-Silva, 2001, p. 8). The academy is notorious for reinforcing a sense of meritocracy, wherein every person has an opportunity to prove herself based on a demonstration of knowledge and skills. However, this is further perpetuates the belief that those folks of color who engage in "acting white," that is, modeling and upholding the status quo in terms of dress, speech, and behavior, reinforce that maintaining a raceless existence is beneficial for all (Leonardo \& Hunter, 2007). Lacking from this perspective is the critical analysis of 
how communities of color become essentialized, such as, people of color who remain in urban, poor communities act within "authentic cultural practice," while members from the same community who persist in higher education "act white" (Leonardo \& Hunter, 2007).

This false binary reinforces that students of color who enter higher education must choose between their "authentic cultural practice," which can include speaking a language other than English, and becoming an educated person. Valenzuela (1999) describes this condition as "subtractive schooling," which is another way of saying that education for young people of color, namely Latinos, not only fails to add to their school experience, but actually slowly unravels their cultural way of being.

Valenzuela's (1999) three-year ethnographic study of Mexican immigrant and U.S. born Mexican students at an urban high school in Houston, Texas, revealed findings that support schooling as a subtractive process, which "diverts youth of important social and cultural resources, leaving them progressively vulnerable to academic failure" (p.3). She clearly captures how Latino, namely culturally Mexican families, view educación in conceptually broader terms than is understand in the English language, as it refers to "the family's role of inculcating in their children a sense of moral, social, and personal responsibility and serves as the foundation for all other learning," (2001, p. 23). Education is, therefore, viewed as an act of liberation and community uplifting. 
One of Valenzuela's key findings is that educators view students who resist or challenge their education as "inherently antischool or oppositional," rather than seeing that "they oppose a schooling process that disrespects them; they oppose not education, but schooling," (p. 5). Subtractive schooling does not honor the capital that students possess from their lived experiences in their communities. Therefore, it is necessary to better understand the role that racism plays in the educational experiences of students of color, which calls for and intentional and critical analysis of the centrality of race of education.

\section{Critical Race Theory and LatCrit Theory}

Critical Race Theory (CRT) extends a broad literature base in sociology, history, ethnic studies, and women's studies, with its foundation stemming from legal scholarship - Critical Legal Studies, (Crenshaw et al, 1995). CRT is a theoretical framework often used in education, which keeps race and racism at the center of oppression (Ladson-Billings, 1998). Ladson-Billings \& Tate (1995) articulate, “despite the salience of race in U.S. society, as a topic of scholarly inquiry, it remains untheorized," (p.47). Therefore, they theorize race and "use it as an analytic tool for understanding school inequity," (p.48), an analytical tool used by CRT scholars.

CRT researchers interested in K-12 (Ladson-Billings, 1998; Ladson-Billings and Tate, 1995; Parker; Solórzano, 1997; and Solórzano and Delgado Bernal, 2001), as well 
as those interested in higher education (Delgado Bernal \& Villalpando, 2002; Solórzano \& Villalpando, 1998; Solórzano \& Delgado Bernal, 2001; Teranishi, Allen, \& Solórzano, 2000; Villalpando, 2003; Yosso, 2002) critically analyze the racialized barriers that are instutionalized in education. Chapter one described the five tenets of CRT, which, provide a foundational platform to analyze student resistance strategies to the normative, white culture of higher education.

CRT and Latino Critical Race Theory (LatCrit) "help expose the ways in which so-called race-neutral institutional policies and practices perpetuate racial or ethnic subordination" (Villalpando, 2004, p.42). LatCrit holds the heterogeneity of Latinos as central to the examination of racialized marginalization. Valdes (1996) describes how other dimensions of Latinos' identity, such as language, immigration status, gender, sexuality, and class further complicate the educational experiences of Latino students. Lat Crit is often viewed as a more valid and reliable lens through which to analyze the intersections of Latinos' identities, specifically addressing their intersection with oppression of race, gender, and class (Solórzano \& Bernal, 2001). Villalpando (2004) describes how for Latinos, "each of these dimensions of their identity can potentially elicit multiple forms of subordination, and each dimension can also be subjected to different forms of oppression." (p.43). And while overt forms of racism are not as common in educational settings (Cabrera et al., 2004; Chang, Astin, \& Kim, 2004; Fischer, 2007; Sue et al., 2009), the racial microaggressions students of color endure 
challenge educators to critically analyze the centrality race in students' educational experiences.

Racial microaggressions refer to the daily, insidious forms of oppression that people of color experience. A psychiatrist and professor at Harvard, Chester Pierce (1974) coined the term "offensive mechanisms" to define the comments and actions that black people experienced on a daily basis. Yosso et al. (2009) further describe how "racial microaggressions cause stress to their victims, who must decipher the insult and then decide whether or how to respond" (p. 661). These subtle and insidious remarks and actions, lead to the emotional and mental stress that eventually cause "racial battle fatigue" (Smith, 2004). Racial battle fatigue results in students of color becoming exhausted from having to confront racial microaggressions that they become desensitized to respond. Villalpando (2001) provides a theoretical perspective which illustrates how Latino/a students, and students of color in general, surround themselves with other students of color as a form of protection against racial microaggressions.

However, when students of color stick together, or are seen as a clique, they are seen as perpetuating exclusion and racial balkinazation. Racial balkinazation is perceived as the tendency for students of color to self-segregate from the predominantly white student population and into their respective enclaves (Altbach \& Lomotey, 1991; Astin \& Oseguera, 2004; Duster, 1991, 1993, 1995; Foley, 1997, 2005; and Villalpando, 2001). Popular culture of the late 1980's fueled anecdotal beliefs that when 
students of color affiliate with their own ethnic/racial group in college, they will learn behaviors that have a negative influence on their values even after college (Bloom, 1987; Duster, 1995; Schlesinger, 1993). As Villalpando (2001) critiques, “Indeed, a deeper analysis of the racial balkanazation myth reveals how it is undergirded by a racist, white supremacist ideology (hooks, 1995), that is influenced by cultural deprivation and deficit theories of students of color (p.620).

LatCrit's focus to contest the dominant ideology challenges the traditional practices of "objectivity, meritocracy, color blindness, race neutrality, and equal opportunity" (Villalpando, 2004, p.44). Because of institutional racism, race neutral practices, especially in admissions practices, further perpetuates an equity gap in graduation rates of Latinos. Therefore, LatCrit's emphasis on social justice practice moves beyond the simple perception of providing a holistic experience. Rather, it provides an opportunity for institutional leaders and practitioners to explicitly design curricular and support programs to address the unique needs of marginalized groups of students. Within the CRT and LatCrit framework, the experiential knowledge of students of color, provides the basis on which to better "understand how their identities as Latinos can actually nourish and empower their personal and academic success in college" (Villalpando, 2004, p.46).

The theoretical frameworks of CRT and LatCrit provide the lens by which to analyze the institutionalized forms of oppression that keep marginalized students from 
succeeding in higher education. In "Mapping the Margins," Kimberlé Crenshaw (1995) analyzes the different ways in which gender, race/ethnicity, class, and sexuality intersect in shaping the lives of women of color. "The fact that women of color are situated within at least two subordinated groups that frequently pursue conflicting political agendas...is a dimension of intersectional disempowerment which men of color and white women seldom confront" (Crenshaw, 1995, p.360). Crenshaw critiqued how women of color suffer discrimination that keeps her at the margins, a violent act against the equitable inclusion of women in society $(1989,1993)$. In an effort to continue to drill back to better understanding the educational experiences and resistance strategies of first-generation Latinas, I then looked at literature that focused specifically on Latinas in higher education.

\section{Latinas in Higher Education}

Researchers in the area of Latinas and their educational experiences have more recently been discussed over the last decade (Benmayor, 2002; Darder, 1997; Gándara, 1982, 1995; Holguín, 2005; Kim, 2009; Pérez, 1999, Réndon, 1992; Saunders \& Serna, 2004; and Silvestrini, 1997). The experiences of Latinas in higher education include the constant binaries restricted to their existence as students. For example, Benmayor's (2002) study of Mexicanas' immigration status and their education revealed that to be identified as simply Latina does not capture the complexities of being a recent Mexican 
immigrant. Réndon (1992) records the oral histories of Chicanas who have been successful in college, often at the expense of their relationships with family and community. This psychic preservation of marginalized groups, via storytelling [testimonios], is "a kind of medicine to heal the wounds of pain caused by racial oppression," (Ladson-Billings \& Tate, 1995, p.57). Storytelling as a form of healing the wounds of oppression has become a staple in the critical literature of women of color (Hill, 2009). Its significance is in gaining students' perspective to inform the educational practices and retention policies of our universities and colleges, especially for California's growing Latino student population.

Bernal (2002) highlights how LatCrit provides a lens through which to also look at the intersections of migration, immigration, and language in Latinos' identities. "It is a theory that has already developed a tradition of offering a strong gender analysis so that it can address the concerns of Latinas in light of both of our internal and external relationships in and with the worlds that have marginalized us" (Hernandez - Truyol, 1997, p. 885).

Among the Latino college-going population, Chicano students represent the second largest ethnic/racial group enrolled in higher education in California (US Department of Education, 2010a). However, it was not until the early 2000s that the educational paths of Latinas, namely Chicanas was considered a priority in education research. Gándara (1982), Seguar (1993), and Vásquez, (1982) have all researched the 
institutional barriers to education that this population of women face. Cuádraz (1996) and Rendón (1992) have studied the marginalization of Chicanas in higher education. And Delgado Bernal (2001) provides an in-depth analysis of the integration of home culture and the academy in her study of 30 Chicana college students. As I revisit my research question about the educational experiences of first-generation Latinas in California, I intentionally explored the literature on Chicanas in higher education. Gloria Anzaldúa and Cherríe Moraga (1983) deliberately used Chicana when describing their lived experiences as Mexican-American women. Chicana feminists are adamant in expressing how the lived experiences of Chicanas vary greatly from that of White women, and even other women of color (Vera \& de los Santos, 2005). Pesquera and Segura (1996) describe being Chicana has having to live in the "tripleness of oppression," in which race/ethnicity, intersects with gender and class.

Elenes, Gonzalez, Delgado Bernal, and Villenas (2001) provide a synthesis on the Chicana/Mexicana feminist pedagogies that influence Chicanas in higher education. "Our theoretical understanding of pedagogies embraces Chicana and Mexicana and Latina ways of knowing that extend beyond the public realm and formal schooling as articulated by conventional, critical, and white feminist interpretations of pedagogy" (p.595). They build on the work of Anzaldúa's (1987) concept of mestiza consciousness, which names the daily process in which Chicanas engage in multiple cultures at multiple points in time. Delgado Bernal (2001) further defines the concept of 
mestiza consciousness "as the way a student balances, negotiates, and draws from her biculturalism, bilingualism, commitment to communities, and spiritualities in relation to her education" (p.623). This mestiza identity is rooted in the femininity of a Chicana, which calls for adaptability and flexibility to "switch constantly between differed codes of conduct and languages" (Vera \& de los Santos, 2005, p.106). This constant crossing of cultures, of borders, is a key characteristic of the Chicana educational experience. González (2001) describes the braiding of personal, academic, and other narratives to define the concept of trenzas. She stated, "The conceptual grounding of trenzas elucidates a social process of la cultura mestiza" (p.645). Latina critical theorists (Anzaldúa, 1987; Delgado Bernal, 2001; González, 2001; Montoya, 1999) add to the literature of critical race feminism by challenging that the intersectionality of Latinas, of Chicanas be told from the cultural perspectives that honor their race/ethnicity, gender, language, sexual orientation, and spirituality. González (2001) combines the work of Montoya (1999), Delgado Bernal (2001), and Sandoval (1998) to define the methodology of trenza y mestizaje, "from forms of identities, theories, and practices....that strengthen the production of knowledge by and about people's own experiences, more specifically Chicana and Mexicana bicultural lives and voices" (p.645).

The literature about Latinas, namely Chicanas in higher education includes a strengths-based, feminist pedagogy that values the traditional norms and values of the 
Latino culture. This cultural knowledge can be better understood as cultural capital and is further described in the next section of this literature review.

\section{Cultural Capital}

Bourdieu (1973) asserted that privileged groups in society possess and inherit an accumulation of knowledge, skills, and networks, which he calls social and cultural capital.

He explained that acquisition of cultural capital (i.e., education, language), social capital (i.e., social networks, connections), and economic capital (i.e., money and other material possessions) occurs through family socialization practices and/or formal schooling. Dominant groups within society maintain power and restrict social mobility by limiting access to these forms of capital.

(Bartolomé, 2009, p. 339).

Bourdieu's critique of how hegemony perpetuates the status quo and the hierarchical structures that keep power in the hands of a privileged few has since been misunderstood as a "how-to-guidebook" to upward social mobility (Bartolomé, 2009). Within this deficit lens, there is no critique of the power that "whiteness" and privilege hold, thereby perpetuating that students of color (marginalized student groups) are robbed of their cultural and community wealth. The expectation is that if people of color emulate the norms of the privileged few, than they, too, can experience social mobility.

CRT, LatCrit, and Chicana feminist scholars honor students' cultural community wealth, and in doing so, challenge the "one size fits all" approach that is 
often used in our colleges and universities to work with marginalized student groups. Research supports the multiplicity of roles that Latinas hold in their families, especially those who are considered to be successful at fulfilling family obligations and who also navigate higher education successfully (Delgado Bernal, 2001; Delgado-Gaitan, 2001; and Hernandez, 1997).

There are responsibilities that Latinas usually have in their families, often rooted in gender roles of caretaking and "haciendo que hacer" (González, 2001). For many first-generation to college Latinas, it is to serve as a translator, co-parent, and even as a support system to the parents. These roles and responsibilities are often described as deficits for students and women of color. However, Delgado Bernal (2001) provides an analysis that the "communication, practices, and learning that occur in the home and community - pedagogies of the home - often serve as a cultural knowledge base that helps students survive and succeed within an educational system that often excludes and silences them" (p. 623). From the perspective that the home culture is one that is rich with wisdom and knowledge, the following section of cultural capital is explored.

Capturing the educational experiences of Latinas in higher education in a manner that honors their lived experiences and community cultural wealth is critical to challenging the status quo (Yosso, 2005). Yosso (2005) describes community cultural wealth using a CRT framework, in which she identifies 6 forms of capital that emerge from communities of color: 1) Aspirational Capital (hopes and dreams for a better 
future amidst challenges), 2) Linguistic Capital (intellectual and social skills acquired by communicating in multiple languages/language styles), 3) Familial Capital (community history, memory, and cultural intuition), 4) Social Capital (networks of people and community resources), 5) Navigational Capital (skills to maneuver through social institutions), and 6) Resistant Capital (skills and oppositional behaviors that challenge inequality) (Yosso \& Garcia, 2007). Bartolomé (2009) asserts, "by robbing students of their culture, language, history, and values, schools often deduce these students to the status of subhumans who need to be rescued from their "savage" selves. The end result of this cultural and linguistic eradication represents... a form of dehumanization" (p. 340).

Delgado Bernal (2001) operationalizes mestiza consciousness as one that builds from the cultural capital students posses from their upbringing in Latino/Chicano families. In her study of 30 Chicanas in higher education, she found that the young women saw their bilingualism and biculturalism as additional capital to navigate the institution of higher education. She also found that the Chicanas had a deep commitment to communities, such serving as a role model to younger siblings to holding leadership positions on campus. Delgado Bernal (2001) also found that the young women described a deep sense of spirituality that provided them with the encouragement and support to continue to work hard in school. She provides a rich analysis of how Chicanas live out the concept of mestiza consciousness as " - an 
identity that is fluid, resilient, and oppositional" (p.635). Gonzalez \& Moll (2002) describe the capital that Latino students bring from home to the academy as "funds of knowledge. " There is cultural wealth in students acknowledging and harnessing the capital that exists within their own communities.

\section{Summary}

Much of the existing data on first-generation students is quantitative, longitudinal, and uses secondary data sources. Many of the researchers conducted studies for the United Stated Department of Education and are more recent in the field of education, as first-generation status has only been identified since the 1970s. There is a gap in the literature of qualitative studies of first-generation college students, as well as a gap in the research of the impact of sex on their persistence and graduation rates. The review of the literature also exposes the lack of research on how the educational experiences of first-generation Latinas are impacted by race, ethnicity, and sex.

The literature also describes how Latinas, namely Chicanas, develop a mestiza consciousness to navigate the transition between the home culture and the school culture. While there is data on first-generation students and data on Latina students, there were only two studies that intentionally studied the intersection of first-generation Latinas. 


\section{Chapter Three: Methodology}

\section{Introduction}

A case study mixed methods design was used in this study to explore the following questions: What are the educational experiences and resiliency strategies of first-generation college Latinas at a predominantly white institution? What experiences influence Latinas' ability to be able to persist in a predominantly white institution (PWI)? And how do first-generation Latinas in college negotiate the challenges that come with resisting the normative culture of higher education? This chapter begins with a description of the study design and the steps taken for the quantitative and qualitative data collection. Demographic data about the site of the research study sets the context for the study. The role of researcher is then described, as well as the participant selection criteria and process. The chapter concludes with a description of the qualitative and quantitative collection and the procedures for data analysis.

\section{Design}

This study used a case study design, which is "an empirical inquiry that -a) investigates a contemporary phenomenon within its real-life context, especially when b) the boundaries between phenomenon and context are not clearly evident (Yin, 2009, p.14). Essentially, a case study research method aims to understand a real-life 
phenomenon in-depth. He also states that because real-life context and phenomenon are always distinguishable, the case study inquiry:

- Copes with the technically distinctive situation in which there will be many more variables of interest than data points, and as one result

- Relies on multiple sources of evidence, with data needing to converge in a triangulating fashion, and as another result

- Benefits from prior development of theoretical propositions to guide data collection and analysis (p.18).

Therefore, the case study research method called for and allowed for a detailed examination of multiple data sources about one setting or one population to address the proposed research question (Bogden \& Biklen, 2007). Using a case study provided the funnel to better understand the educational experiences of first-generation Latinas at the predominantly white, four-year institution, Rolling Hills College. Bogden and Biklen (2007) describe the case study design as best represented by a funnel, in which the start is wide and the more the researcher learns about the population s/he wishes to study, the narrower the data becomes. However, given the complexity of understanding this experience, a case study design was insufficient to answer the nuances of the women's experiences in my study. Therefore, I used a mixed methods sequential design, in which the quantitative data collection preceded the qualitative data collection. A mixed methods sequential design (Creswell \& Plano Clark, 2010) provides the lens from which to analyze both quantitative and qualitative data to capture a more holistic set of 
explanations for the research questions regarding the experiences of first-generation Latinas at predominantly white institutions (PWIs).

The use of the mixed methods sequential design as a case study provided the opportunity to begin with the quantitative analysis of the campus climate experiences of minority students and their persistence and graduation rates, followed by data collected from the Transformational Resistance Survey, all of which informed how I developed the interview protocol for the focus groups (Creswell, Plano Clark, et al., 2003). Figure 3.0 illustrates the roles of the qualitative and quantitative data in this sequential case study design.

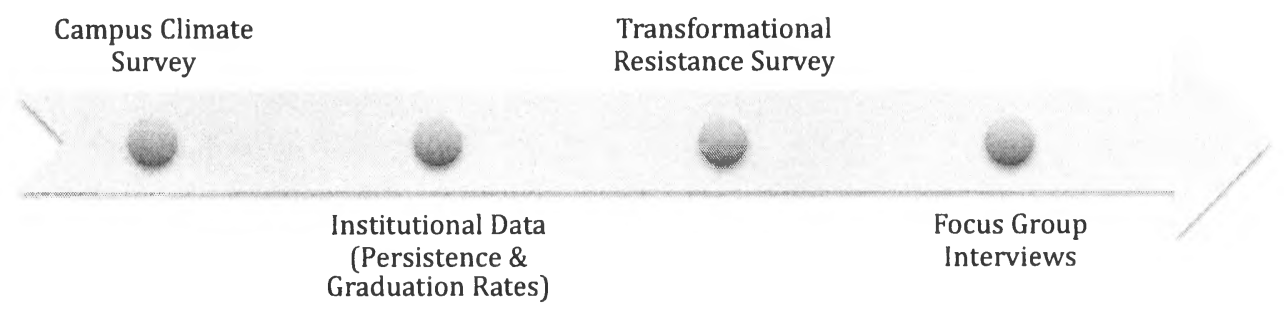

Figure 3.0 Data Collection Process

Quantitative data on the persistence and gradation rates of minority students (students of color, women, first-generation) coupled with the Campus Climate Survey data led to the development of the Transformational Resistance (TR) survey. The TR survey was developed as part of the demographic data collection tool to determine if a 
baseline could be established for Transformational Resistance within the population of first-generation Latinas at RHC. It also served as a means to identify participants for the focus groups. In this study, the qualitative data are dominant while the quantitative data provide the statistical trends as a platform from which to dive into the experiences of first-education Latinas at a PWI.

Because this study seeks to understand the experiences of first-generation Latinas and whether or not their persistence can be understood as Transformational Resistance (Solorzano \& Delgado Bernal, 2001), a mixed methods sequential design is most appropriate. Within this study design, qualitative data tell the "story" of the Latinas' experiences, while the quantitative data show the larger picture of persistence and graduation rates for this student population. Within Critical Race Theory (CRT), counterstorytelling is a method of recounting the experiences and perspectives of racially and socially marginalized people (Yosso, 2006). "Counterstories reflect on the lived experience of People of Color to raise critical consciousness about social and racial injustice," (Mason \& Goulden, 2002, p.24). Counterstorytelling challenges the majoritarian story that often omits the lived experiences of marginalized groups of people. CRT scholars categorize three types of counterstories: autobiographical, biographical, and composite (Mason \& Goulden, 2002). For this dissertation, I use biographical counterstories of four focal women, which highlight the themed 
experiences found in the focus groups and the TR survey that was administered to tell the story of the educational experiences of first-generation Latinas at RHC.

This sequential research design informs the scope of the study by incorporating the quantitative data (Campus Climate Survey, persistence and graduation rates, TR survey) with the qualitative data collected from the focus groups and TR survey. The respondents to the TR survey comprised of more than half of the Latinas enrolled at RHC. While the qualitative data provides the platform to better understand the nuanced experiences of this student population in one Northern California PWI, the quantitative data allows for the findings to be generalized outside the particular context of one institution. Therefore, this sequential case study design seeks to provide findings that can be generalized for first-generation Latinas, especially those at other 4-year PWIs.

\section{Role of the Researcher}

The researcher should always anticipate how she would negotiate her role within a given study. I am fully aware of my bias in researching this topic because I have similar lived experiences as a first-generation Latina who attended a PWI for my undergraduate studies. My relationship with the participants varied, depending on the level of interaction participants have had with the Academic Advising Center prior to data collection. I did not personally know most of the participants who completed the online survey and I only personally knew about half of the young women who participated in the focus groups. 
This research is personal to me because I want to learn more about why firstgeneration Latinas, especially in California, are not persisting and graduating from higher education. It is personal to me because I have worked with countless numbers of students, primarily Latinas, who seem to struggle and inevitably leave the institution. In this dissertation, I am the researcher, yet my lived experiences both as a first-generation Latina and as someone who works with students filters the lens by which I see this work. This study has forced me to acknowledge that my daily, lived experiences as a Latina are important, meaningful, and very telling of the different paths we all walk to accomplish our goals.

Because of my closeness to the study setting and participants, I incorporated additional strategies to the study design for truthfulness of the findings. I had three critical colleagues, none of which identify as a first-generation Latina, from my doctoral program read my data memos throughout the five-month data collection period. Their comments and questions continually served as a checking mechanism to diffuse any of my own personal biases. Additionally, they read through detailed parts of the transcripts to confirm that the main findings that I describe in chapters four and five were in fact the major findings. My advisor also played a critical role in reading my data memos, transcripts summaries, and posing me with questions to limit my bias. These often took place during our weekly meetings during the data analysis and writing of the dissertation. 


\section{Theoretical Framework}

Latino Critical Race Theory (LatCrit) and Critical Race Feminism (CRF) are the anchors of my theoretical framework because of the intra- and inter-group focus of LatCrit and the emphasis of women of color as a conscious one, which honors the intersectionality of first-generation Latinas. LatCrit theory calls for the following four goals: 1) the production of knowledge 2) the advancement of social transformation 3) the expansion and connection of anti-subordination struggles and 4) the cultivation of community and coalition, both within and beyond the confines of legal academia in the United States (Hernandez-Truyol, 1997). It calls for us to contexualize the local and global categories to ground both theory and praxis. This is where my role as an educator, a researcher, and a fellow Latina at Rolling Hills College (RHC) intersects within this study.

Critical Race Feminism (CRF), as described in chapter two, is used to describe an emphasis on women of color as a conscious one, indicating its link to Critical Legal Studies, Critical Race Theory, and feminist jurisprudence (Wing, 1999). CRF lends itself to a storytelling methodology, which aims to demarginalize the roles people of color have played in traditional history and discourse (Crenshaw, 1988). A mixed methods sequential design complements my theoretical framework from a LatCrit and CRF perspective because a single data set is insufficient to answer the research questions about persistence and graduation rates and the educational experiences of 
first-generation Latinas. Therefore, a combination of quantitative data on the persistence and graduation rates of students, specifically first-generation Latinas, at RHC were used, followed by the qualitative data collected from the online survey and transcripts from the focus groups.

Research Questions and Sub-Questions, or Initial Objectives

The research question for this study is: How do Latina, first-generation college students persist in the normative, predominantly white culture at a private, four-year college? Sub-questions include: What are the educational and lived experiences of firstgeneration Latinas? What resistance strategies, if any, do they use to persist? I set out to explore how Latina, first-generation college students persist in higher education because of their resilience against conforming to the dominant culture. I also propose to explore how their persistence and resistance strategies come directly from their experiences as women of color.

\section{Context}

Rolling Hills College (RHC) is a private, liberal arts, faith-based institution located in the greater bay area and is the setting for this study during the 2010-2011 academic year. It was selected because of its growing Latino and first-generation student population, as well as its growing population of women. It sits among a wellestablished set of public and private institutions of higher education and has a total enrollment of undergraduate and graduate students of approximately 4,000 . RHC is one 
of the oldest colleges in the west coast with over 150 years of establishment. It was originally a college for primarily the poor and working class men of Irish and Italian heritage descent; and it was not until 1970 when it admitted the first group of women and became co-educational. Currently, RHC is comprised of $39 \%$ men and $61 \%$ women, and $43 \%$ students of color. Given its growing number of women, firstgeneration, and Latino students, RHC is an ideal site for the study of first-generation Latinas in higher education. Seventy-two percent of students receive some-type of need-based grant averaging $\$ 20,676$, with an additional $\$ 7,278$ in loans to cover the cost of tuition, fees, and room board $(\$ 47,780)$. The average federal loan indebtedness of graduating seniors is $\$ 20,679$, with an additional $\$ 17,000$ for possible private loans, totaling an average of $\$ 37,759$.

There are 192 full-time faculty of whom $73.4 \%$ are white, $3 \%$ are Latino. The largest representation of faculty of color is Asian (13.5\%) though the Asian student population represents only $4 \%$ of the student population. Women make up $48 \%$ of the full-time faculty and data on the number of women in the part-time faculty is not available. Of the 271 part-time faculty, $68.6 \%$ are white and $5 \%$ are Latino. Among the staff, $71 \%$ are white, $11 \%$ are Latino, and $6 \%$ each for Asian and Black.

It is a college that is rooted in educating the poor and working class and has shown commitment over the years in providing first-generation to college students an opportunity to earn a baccalaureate degree. My access as a researcher to the participants 
was made possible because of the institution's support of research that informs the field on issues that impact Latino students in higher education and my role as a staff member. The researcher-participant working relationship was carefully established once the focus group participants were identified.

\section{Participant Selection}

Participants for this study were selected based on two criteria: first-generation to college status and self-identification as a Latina upon admission to the college. There were 253 eligible participants in the sample population enrolled for the 2010-2011 academic year. I sent all eligible participants an email invitation (see Appendix A) with the online survey and dates for future focus group sessions. Women who completed the online Transformational Resistance survey (see Appendix B) were considered respondents. They were then invited to consider being part of a focus group to meet after completion of the online survey. Of 141 respondents ( $56 \%$ response rate), fortynine women indicated they would be interested in participating in a focus group. Of those 49 women, 24 were randomly selected to take part in one of 4 focus groups and are considered participants and make-up the sample for this study based on times of availability. The 24 mujeres who comprised the 4 focus groups ranged in year in school, across academic departments, and were part of a group of 49 women who expressed interest in participating in a focus group (see Appendix C). 
All 24 women participated in one of four focus groups and represented $17 \%$ of the total respondent population $(n=141)$ and $9 \%$ of the total population $(n=253)$ of firstgeneration Latinas at RHC. Although a majority of Hispanic students begin their college career in community colleges (Santiago \& Brown, 2004), this was not the case for these participants. Each of these young women started their college experience at RHC and expect to graduate within 4 years. The majority of the participants identified as either Latina or Hispanic, with few exceptions specifying their ethnicity. Almost all of the participants indicated that they spoke Spanish first at home and consider themselves bi-lingual. Three of the participants spoke English first at home and considered themselves to understand Spanish, but not able to speak it fluently. Most of the participants came from predominantly Latino neighborhoods, with several students indicating that their families had moved to a "better neighborhood" in recent years. All of the participants' families live in California, mostly from the bay area and the central valley.

I selected a focal woman from each interview based on how I heard her articulate the experiences of the general group and after reviewing the transcripts. I selected them to each identify a different year in school, as well as from different majors. Each of these four young women provided a pseudonym to identify their "voice" in this study. This is a form of honoring the truth and the lived experiences of the participants, as part of the counterstorytelling methodology. Three of the young 
women chose to use a variation of their given name, and one student chose to use her mother's name. This young woman indicated that she wanted her mother to have her name on a college paper, a dissertation, so that even if she had not gone to college, her name could be forever printed in the world of higher education.

Ạs previously mentioned, all of the participants self-identified as Latina upon admission. However, when given other options for identification, some of the women chose to identify as Chicana, Hispanic, or Other. All of the respondents $(n=8)$ that indicated 'Other' indicated that they were bi- or multi-racial, Mexican, Salvadoreña, or Peruvana and wanted to honor their whole identity. Therefore, the majority of the women $(n=134)$ in this study are, in fact, of Mexican descent.

\section{Ethics and Protection of Human Subjects}

The protection of participants' rights and privacy is of the utmost importance to me as an educator and researcher of color. "A growing number of education scholars of color are raising critical questions about the way that research is being conducted in communities of color" (Ladson-Billings \& Tate, 1995, p.58). As a woman of color I value the experiential knowledge and stories of the young women in this study, but also understand... [something about right to or value of confidentiality]. The focus groups were conducted in the Academic Advising Center office, a setting familiar to all students, especially to students of color. Our Academic Advising Coordinators each have an area of emphasis to reach out to particular student ethnic groups (Latinos, 
African-American, and Asian Pacific Islanders) to provide support and promote academic success within each of these groups.

The research data was kept in a secure locked cabinet in my office, and I was the only person to have access to the data. Electronic transcripts, notes, and data were password protected and all identifying information was immediately removed. At the conclusion of the study, the data, audiotapes, and notes will be stored for one year following the completion of the study then destroyed.

There is a risk of loss of privacy, however, no names or identities were used in the final publication of this dissertation research. Also, because the focus groups include discussion of personal opinions, extra measure was taken to protect each participant's privacy. Each of the focus groups began with asking the participants to agree to the importance of keeping information discussed in the focus group confidential. The researcher then asked each participant to verbally agree to keep everything discussed in the room confidential, and reminded them at the end of the group not to discuss the material outside the group. Participants were affirmed that there is a risk of discomfort or anxiety due to the nature of the questions asked; however, they could answer only those questions they chose to answer. The informed consent form contained the contact information for the college counseling center for additional support, should participants require it. 


\section{Data Collection}

Using a mixed methods study design, quantitative institutional data on the tenyear persistence and graduation of RHC students (2000-2010) and the Campus Climate Survey data for the years 2004, 2006, 2008, and 2010 were collected for this study. These data were disaggregated to provide a more complete picture on the academic profile of first-generation and Latina students. Data from the Campus Climate Survey were collected to provide a more comprehensive picture of how the experiences of minority students, namely students of color and women, differ from the experiences of the majority students. An additional survey, the Transformational Resistance survey, was created to collect demographic data on first-generation Latinas at RHC, determine if a baseline could be established for operationalizing Transformational Resistance, (Solorzano \& Delgado Bernal, 2001), as well as identify possible focus group participants for the qualitative data collection. The data collected from the open-ended questions on the online survey and the focus group interviews provide the qualitative data to answer the research question(s).

The institutional data on the persistence and graduation rates and the Campus Climate Survey data were provided by the Director of Institutional Research at RHC, with written approval from the Provost. Although the data from these sources is reported in aggregated forms to the college community, the raw data was provided to me to conduct disaggregated data analysis for this research. I constructed the online 
survey (see Appendix B), using Survey Monkey, to collect demographic data on the participants' family background and their educational aspirations, followed by a 7-point Likert scale to operationalize Transformational Resistance for first-generation Latinas.

Data collection with the participants began with the distribution of the online survey to 253 first-generation Latinas enrolled at RHC in fall 2010. The online survey was available for a 10-day period, based on the data from the Office of Institutional Research, which outlined that respondents at RHC were more likely to respond to a survey with the first 10 days of it being available. Once the survey was open, I sent a reminder email to all those who had not responded after the third day, followed by additional emails at days 7 and 9. Once the online survey was closed, 24 of the 49 respondents who indicated that they would be willing to participate in a focus group were randomly selected and placed into one of four focus groups, based on their indicated time of availability.

Each focus group consisted of no more than 6 participants and lasted for about 90 minutes. The protocol for the focus groups (see Appendix D) began with an acknowledgement that participants were in a room of Latinas on a college campus and asked to recall the last time this had happened to them. The interview moved from recalling their first weekend in college, to their relationships with family back home, to their experiences as women of color in college. Within these discussions they provided insight as to how they resist or do not resist conforming to the normative culture of 
higher education. At the conclusion of each focus group, I requested their permission to check in with them individually or as a group, as needed, to ensure data accuracy. All of the participants agreed to be contacted to this request. One of the three groups asked if we could meet as a large group again, as opposed to contacting them individually. I met with this group at a later time to discuss the emerging themes, after I had selected the focals from each of the groups. I met with each of the four focals for member-checking purposes and recorded their pseudonyms at this time. All focus groups and individual interviews for member-checking were audio recorded, transcribed, and coded for emerging themes.

Because of an emerging theme of hermandad, or sisterhood among Latinas, I attended three Hermanas Unidas (HaU) meetings to see, in a larger setting, what the young women were referring to when they described hermandad. These meetings each took place on a Wednesday evening and were open to the public. I was always among, at least, 3-5 other faculty/staff members present at the meetings. Using field notes as the data collection tool, I kept a record of the agendas, discussion points, and overall interaction among $\mathrm{HaU}$ members.

Although the findings of this study may not be generalizable to all institutions of higher education, they are helpful in developing a deeper understanding of the educational and lived experiences of first-generation Latinas, especially at a PWI. They are, however, generalizable to other private, four-year institutions because of the mixed 
methods design. The validity of the findings is supported by the triangulation of quantitative and qualitative data, which included member checking and exchanging data memos with critical colleagues who were familiar with this study. The findings are transferable in that they provide emerging themes that are helpful in developing theories to understand and further explore how first-generation Latinas' experiences can influence the level of transformational resistance they enact. As there is limited research on the operationalization of transformational resistance in the field, this work could be foundational for future research on first-generation Latinos in higher education.

\section{Data Analysis}

Data analysis included using descriptive statistics with Excel and SPSS for the quantitative data, as well as writing data memos to share with my critical colleagues and advisor. Analysis also included reviewing field journal entries, transcripts, and transcripts for the qualitatative data. As part of the sequential design, I reviewed quantitative data prior to collecting and reviewing qualitative data. Once both data were collected and analyzed, I referred to the findings continuously as I wrote chapters four and five.

The Campus Climate Survey (CCS) data is institutional data that provides information on the campus climate and was disaggregated by race, gender, SES, and campus positionality (student, staff, or faculty). These data could not be directly disaggregated for the study's participants because the CCS data is only categorized for 
race, gender, SES and whether a respondent was a student, staff, or faculty. Institutional data on persistence and graduation rates were disaggregated by race, gender, and SES to see the trends among first-generation students, Latino students, and women, as compared to the general student population. Data on first-generation students is the most limited, as RHC only started coding first-generation status beginning in 2004 . Quantitative data included the categorical data of race, ethnicity, gender, educational aspirations, family educational background, and SES, which were collected in the online survey I developed. Once the respondents were identified, data on their most recent GPA and probation history were also analyzed.

Analysis of the quantitative data included using SPSS for running the descriptive statistics to see what the data was telling me about the persistence and graduation rates of students at RHC. The quantitative data set contains 8,749 entries $(\mathrm{n}=8749)$, of which 5427 are female and 3304 are male (14 reported neither female nor male). When looking for ethnicity, the dataset contained 4127 (47.2\%) white students, $1533(17.5 \%)$ Latino students, and the remaining students were made up of a large variety of ethnicities. For purposes of this dissertation, I disaggregated the persistence and graduation rates of Latino students as compared to white students, with a special emphasis on first-generation Latinas.

I looked at the frequencies and cross-tabulations in the data, as well as conducting means tests, including one-sample t-tests, independent - samples t-tests, and 
paired-sample t-tests. Many of the tests that I conducted were statistically significant at the $\mathrm{p}<.000$ and $\mathrm{p}<.001$ levels; however, my analysis of the data included determining how meaningful these findings were. Thus, I used Cohen's (1992) classification of meaningful data when comparing means and determining statistical significance. For distribution of means, Cohen (1992) suggests that we use the difference in effect size in units of standard deviation. Therefore, statistically significant data are reported as having a small (.020), medium (0.50, or large (0.80) effect size (Cohen, 1992). As stated earlier, much of the tests conducted for this study yielded statistically significant results, although at the small and medium effect sizes as classified by Cohen (1969).

Qualitative data were recorded, transcribed, and coded for emerging themes. Part of the coding process included writing data memos, which were then read by critical colleagues and my advisor to provide feedback and check for biases. Once data memos were read by critical colleagues and returned with feedback and questions, I coded the transcriptions, which resulted in 12 topics. I reviewed the topics and conducted another line-by-line read to condense the data into the four themes, which are further discussed in chapter four. These four themes: Familía, Educación, Feminidad, and Hermandad, are critical characteristics for first-generation Latinas' persistence in higher education. The four themes are foundational to a new theoretical framework, which I have termed Ser Educada. 


\section{Chapter Four: Findings \\ Overview}

Anzaldúa (1987) described how Latinas, namely Chicanas, have the daily struggle of crossing multiple borders, both literally and figuratively. The findings of this study capture the experiences of first-generation Latinas at a predominantly white institution, experiences that span across the realms of their families, their identities as women of color, and their newly developing academic identities. Because this study used a mixed methods design, their stories provide rich descriptions that will challenge educational leaders to re-think how programs and services provided in the name of student success, especially when there is so much emphasis on retention and graduation rates.

The findings of this study are organized into three sections: Section1 - Campus Climate Survey Data provides quantitative data and a closer look at the climate which students of color and women experience at RHC at three points in time, spring 2006, 2008, and 2010. Section 2 - RHC Longitudinal Data provides the retention and graduation rates for the general student population from the years $2000-2010$, as well as a more in-depth analysis of the graduation rates for first-generation Latinas who were enrolled at RHC between fall 2004 -spring 2010. Section 3 - Las Mujeres describes the 
lived and educational experiences of 141 first-generation Latinas at RHC, told from the perspective of 4 focal mujeres. Overall, the data reveal there are different experiences between the students of color and white students, between men and women, and between first-generation and non-first-generation college students. More specifically, the findings reveal the educational experiences and resistance strategies used by firstgeneration Latinas to persist at a four-year institution of higher education.

Section 1 - Campus Climate: "I like it here and I hate it here."

The campus climate survey (CCS) data, as described in Chapter 3, are from spring 2006, spring 2008, and spring 2010 and provide a snapshot at three different points in time of how students, faculty, and staff experience the campus climate. With three years of CCS data for faculty, staff, and student respondents, there is significant longitudinal data collected in these surveys. For purposes of this study, the data on the student respondents will be provided, with an emphasis on the spring 2010 data. The student response rate has slightly increased over the three collection years, 11\% (2006), $11 \%(2008)$, and $13 \%(2010)$. The respondents are generally representative of the overall populations. Despite the low response rates from students over the years, "the numeric outcomes to the survey are not skewed or bimodal, though written student comments suggest polarization on the issues of diversity and inclusiveness," (CSS Summary, 2010). It is not surprising that there is polarization on the issues of diversity because it involves are parties to reflect on how their experiences are impacted by those 
who identify as different than they. The following section provides more analysis on the experiences between Latino and White students, highlighting how their experiences at Rolling Hills College are drastically different in terms of issues of diversity.

Students of color, more specifically Latino students, have seen or heard insensitive or disparaging comments directed towards people of color more often than do white students, $56 \%$ compared to $32 \%$ respectively. Latino students also reported a higher percentage of respondents having seen or heard insensitive or disparaging comments directed towards women, when compared to white students, $50 \%$ compared to $32 \%$ respectively. When asked if they have "frequently" or "occasionally" been harassed, pressured, or discriminated against on campus because of their ethnic group, $20 \%$ of Latino respondents indicated this, compared to $7 \%$ of white students. When asked the same type of question for harassment, pressure, or discrimination based on gender, $16 \%$ of white students reported that they had, compared to $15 \%$ of Latino students. The data show that students of color and women experience what is now known as racial microaggressions (Pierce, 1969). These subtle and insidious remarks and actions lead to the emotional and mental stress that eventually causes "racial battle fatigue" (Smith, 2004). Racial battle fatigue results in students of color becoming exhausted by having to confront racial microaggressions that they become desensitized. However, the qualitative data in this study reveal how first-generation Latinas at RHC 
refuse to become victimized by the racial microaggressions in their pursuit of academic success.

When asked to report if, "It is important to me to have friends who are part of the same ethnic group as my own," Latino students were more likely to indicate that they agree or strongly agree as compared to white students, $39 \%$ and $12 \%$ respectively. Both Latino students (66\%) and white students (59\%) agree that "people here tend to stick with their own clique." Most people, especially students of color do not see same race/ethnicity associations as problematic, unless it involves groups other than whites, which then is often called racial balkanization (Villalpando, 2003). Later in this chapter, the mujeres in this study reveal how coming together as women of color, and specifically as Latinas is a form of support, encouragement, and resistance that helps them persist in at this predominantly white institution.

When asked to report if "In order to fit in at RHC, I often feel the need to change some of my personal characteristics, Latino students (34\%) were more likely to indicate that they agree or strongly agree as compared to white students (12\%). Along the same line of questioning, $39 \%$ of Latinos indicated that they feel awkward in situations at RHC in which they were the only one of their ethnic or racial group present, as compared to $11 \%$ of white students. At a predominantly white institution, these findings are not surprising, as it is likely that whites would rarely find themselves in the minority, unless they sought out such settings. Such feelings of cultural 
awkwardness are further compounded by findings that $34 \%$ of Latino/as feel they are expected to represent all members of their ethnic group in classroom discussions, compared to only $10 \%$ of white students. Table 4.0 summarizes the comparisons between how Latino/as responded to statements on the Campus Climate Survey in comparison to whites.

Table 1.0 Campus Climate Survey: Comparison of Latinola and White Students

\begin{tabular}{lcc}
\hline Question/Statement & $\begin{array}{l}\text { Latino } \\
\text { Students }\end{array}$ & $\begin{array}{l}\text { White } \\
\text { Students }\end{array}$ \\
\hline $\begin{array}{l}\text { Have seen or heard insensitive or disparaging } \\
\text { comments directed towards people of color }\end{array}$ & $56 \%$ & $32 \%$ \\
$\begin{array}{l}\text { Have seen or heard insensitive or disparaging } \\
\text { comments directed towards women }\end{array}$ & $50 \%$ & $32 \%$ \\
$\begin{array}{l}\text { Have frequently or occasionally been harassed, } \\
\text { pressured, or discriminated against on campus } \\
\text { because of their ethnic group }\end{array}$ & $20 \%$ & $7 \%$ \\
$\begin{array}{l}\text { Have frequently or occasionally been harassed, } \\
\text { pressured, or discriminated against on campus } \\
\text { because of their gender }\end{array}$ & $15 \%$ & $16 \%$ \\
$\begin{array}{l}\text { It is important to me to have friends who are part of } \\
\text { the same ethnic group as my own }\end{array}$ & $39 \%$ & $12 \%$ \\
$\begin{array}{l}\text { In order to fit in at RHC, I often feel the need to } \\
\text { change some of my personal characteristics }\end{array}$ & $34 \%$ & $12 \%$ \\
$\begin{array}{l}\text { I feel awkward in situations at RHC, in which I'm } \\
\text { the only person of my ethnic background present }\end{array}$ & $38 \%$ & $11 \%$ \\
\hline
\end{tabular}

Data available to me have not been analyzed to demonstrate intersectionalities of race and gender, and instead disaggregate only by single categories. Therefore, when 
the data are disaggregated by gender, women are more likely to indicate that they have seen or heard insensitive or disparaging comments directed towards women (44\%) and towards people of color ( $44 \%)$ than do the men (35\% and $31 \%$ respectively). Women also reported slightly higher levels of incidents of direct harassment, pressure, or discrimination based on gender and ethnicity.

Yosso et al. (2009) described a positive campus racial climate as featuring: overall inclusion of students, faculty, and staff; a curriculum that is representative of a diverse population; programs to support the recruitment, retention, and graduation rates of students of color; and an institutional mission that reinforces its commitment to diversity and pluralism. Generally, the campus climate data show that students of color have a paradoxical experience at RHC. Although they describe their experiences at RHC as including a hostile environment of racial microaggressions (Pierce, 1969; Villalpando, 2003; Yosso et al, 2009), they also like the college for its small size and for their level of access to faculty and staff (RHC Institutional Research). Further, although the demographic data described in Chapter 3 show that women make up the majority of the student population, there is still a sense of male dominance in the culture of the college, as demonstrated by the fact that the majority of administrative and faculty appointed leaders are male. This is also demonstrated by the bylaws of Rolling Hills College, which state that only a member of the male religious order that founded the school can hold the office of President. 
Audre Lorde (1984) describes how women are "called upon to stretch across the gap of male ignorance and to educate men as to our existence and our needs" (p.113). Lorde explains that these expectations help institutions to maintain the status quo. She writes, "This is an old and primary tool of all oppressors to keep the oppressed occupied with the master's concerns" (p.113). Chicana feminists (Anzaldúa, 1987; Delgado Bernal, 1998, 2001; Perez, 1999; Rodrigúez 1994; Sandoval, 1998) believe that exploring the unique experiences of Chicanas/Latinas is critical for understanding how Chicanas/Latinas navigate living in multiple worlds as women of color. It is with this lens that I continued to review quantitative data to learn more about the academic persistence and progress of first-generation Latinas.

Section 2 - RHC Longitudinal Data 2000 - 2010: Who's Graduating?

Unlike the Campus Climate Survey data, the longitudinal data could be disaggregated by multiple variables. As described in chapter two, the categories that I included in my data analysis included gender, first-generation status, race, and ethnicity. Within and across these categories, I looked at GPA, probation rates, retention rates, and terms to graduation.

Drawing on longitudinal data for RHC it is evident that RHC has an average four-year graduation rate of $46.2 \%$ for the general student population. The six-year graduation rate for the general student population increases to $63.7 \%$, indicating an 
almost $20 \%$ increase. When disaggregating by gender, female students have a four-year graduation rate of $46.5 \%$, while male students have a four-year graduation rate of $45.8 \%$. The six-year graduation rate shows a small increase in the gap between female and male students at $65 \%$ and $61.4 \%$ respectively.

Latino/a students have a four-year graduation rate of $45 \%$, while white students have a four-year graduation rate of $51 \%$. Given a longer time horizon, $57 \%$ of Latino/as do graduate from RHC within 5 years, but take an average of two more terms to complete (14 terms), as compared to white students (12 terms). This difference is equivalent to nearly an additional year at RHC for time to degree, which, as well as slowing students down, also adds to their debt load, and tends to indicate weaker academic records with more instances of withdrawals and incompletes appearing on these transcripts. At the six-year graduation rate the gap between Latino/a and White students becomes wider at $60 \%$ and $71 \%$ respectively. The data show how Latino/a students graduate at lower rates than white students overall.

Students on academic probation are those students who have not earned an institutional gpa of 2.0 or have not earned the gpa as specified for particular majors, such as business administration, honors track programs, or specialized programs within a given major. Overall the data report that $18 \%$ of the general student population has ever been on academic probation. Female students (16\%) were less likely than male students $(21.5 \%)$ to have ever been on academic probation. Further, the data also report 
that $13 \%$ of white students have ever been on probation as compared to $24.2 \%$ of Latino students. In general, students on probation have more D or F grades, more incompletes, and more academic advisory referrals than students who are not on probation. Academic advisory referrals serve as checkpoint for faculty to alert a student's academic advisor of the issues that may be impacting success in a course. Latino students are more likely to have ever been on academic probation than White students at RHC.

The average cumulative GPA at graduation (four-year graduation rate of $46.2 \%$ ) for the general student population is 3.19. Female students graduate with a cumulative GPA of 3.23, while male students graduate with a cumulative GPA of 3.11. For Latino students, the GPA at the four-year graduation rate $(45 \%)$ is 2.9 , while white students (51\%) graduate with a 3.24 GPA. This small, though meaningful difference in GPA at graduation can mean the difference between being eligible for graduate school, many of which require a minimum 3.0 GPA. This difference also impacts the financial aid eligibility of students, especially the Cal grants, which are based on GPA throughout the time that students are enrolled in higher education.

When I started to analyze the data by first-generation status, I realized that the data on this student population is quite messy. Prior to fall 2004 , the only identified first-generation students were those who were conditionally admitted through the Aim High Program (AHP) into RHC. Therefore, there is no clear way of identifying those 
students who were first-generation but not part of AHP. The remaining data analysis includes students entering as cohorts in fall 2004, fall 2005, and 2006. This ensures the integrity of the data when analyzing for first-generation status. In reviewing the data, it became clear that Latino/a students are a growing population for RHC, as well as overrepresented in the first-generation to college students.

First-generation students are more likely to be from low SES families, from minority ethnic groups, multilingual, women, and tend to work 2-3 times as many hours as non-first generation students (Bui, 2002; Choy, 2001, Nunez \& Cuccaro-Alamin, 1998; Pike \& Kuh, 2005; Pascarella, Pierson, Wolniak, \& Terenzini, 1994; Terenzini \& Rendon, 1994). At RHC, there are consistently more women than men who are firstgeneration, $63 \%$ to $37 \%$ respectively. There are almost twice as many Latinas $(30 \%)$ who are first-generation in each entering class as compared to white women (12\%). As Latinas make up only $8 \%$ of the total population of RHC students, these patterns indicate an overrepresentation of Latinas who are also first-generation.

RHC's overall four-year graduation rate for first-generation students is $39 \%$. First-generation students who are also Latino have a four-year graduation rate of $36.7 \%$ compared to $51.6 \%$ four-year graduation rate of first-generation white students. When disaggregating by gender, first-generation Latinas have a four-year graduation rate of $39.3 \%$ compared to first-generation women whose four-year graduation rate is $57 \%$. 
The nearly $20 \%$ difference between female students who are Latina compared to white women is disconcerting.

T-tests showed that RHC Latino students earn a cumulative GPA that is 0.50 grade points lower than white students (0.44 SD). Similarly, Latinas earn GPAs (2.81) that are 0.24 grade points $(0.38 \mathrm{SD})$ lower than white women (3.05). Although, Cohen (1969) would characterize these differences as small effect sizes $(0.5<p>.2$ SD), the difference between having an overall GPA above versus below 3.0 has large implications on whether or not students are eligible for certain financial aid funds (Cal grants, scholarships). Cumulative GPAs that fall below 3.0 also limits students' options for graduate education. Therefore, although the actual difference in overall GPA may be seen as small, the fact that Latino/as and whites fall on either side of 3.0 makes big differences, both immediately for completion of the degree, and long term if students seek additional educational opportunities. White women who are also first-generation to graduate from RHC with a cumulative GPA of 3.38, while first-generation Latinas graduate with a cumulative GPA of 2.81 (0.53 SD), illustrating a medium effect size $(0.8<p>.5$ SD) as described by Cohen (1969). Overall, the data show that firstgeneration Latinas take longer to graduate, are on probation at higher rates than white women, and graduate with a lower cumulative GPA than do white women. At the fouryear graduation, the cumulative GPA for first-generation white students is 3.16 , while only 2.65 for first-generation Latino students. This data is consistent with research that 
supports that once enrolled, first-generation students are less successful from term to term, often because of academic preparation leading to college and are less likely to complete a degree (Ishitani, 2003; 2006).

Section 3 - Quantitative to Qualitative Data: Transformational Resistance Survey Analyzing the longitudinal data alongside findings from the Campus Climate Survey, where students of color and women were more likely to hear or experience disparaging remarks as part of their college experience, provided an opportunity to see how their educational experiences are impacted by their race and/or gender. For firstgeneration Latinas the data revealed that they must consistently navigate through both of these forms of oppression in order to persist in college. Upon completion of analyzing the quantitative data provided to me by the institution, it became evident to me that follow up with qualitative data would provide more insight into the experiences of first-generation Latinas at RHC.

Mixed methods studies focus "on collecting, analyzing, and mixing both quantitative and qualitative data... Its central premise is that the use of quantitative and qualitative approaches in combination provides a better understanding of research problems than either approach alone" (Creswell \& Plano Clark, 2007). As described in chapter 1 , research on the academic persistence of first-generation students is primarily quantitative. Therefore, using a mixed methods approach was critical for me to get at 
the nuanced experiences of first-generation Latinas. And as revealed in chapter 2, research on the persistence and resistance strategies of Latinas is not typically included in the student retention literature, which further supports how the findings of this study are critical as mixed methods.

As I continued to focus on the first-generation Latinas at RHC, I found that as a group, they make up $81.8 \%$ of the Latina student population and only $8.0 \%$ of the total student population. Table 4.1 shows the overall number of Latinas enrolled at RHC, as well as the numbers of those are also first-generation

\section{Table 2 Enrollment of First-Generation Latinas at RHC}

\begin{tabular}{llll}
\hline $\begin{array}{l}\text { Rolling Hills } \\
\text { College }\end{array}$ & $\begin{array}{l}\text { \# of } \\
\text { Latinas }\end{array}$ & $\begin{array}{l}\text { \# First- } \\
\text { Generation }\end{array}$ & $\begin{array}{l}\text { Resulting \% of } \\
\text { Overall Student Population }\end{array}$ \\
\hline $\begin{array}{l}\text { Data from } \\
2010-2011\end{array}$ & 309 & $253 / 81.8 \%$ & $8.00 \%$ \\
$\mathrm{~N}=3,145$ & & & \\
\hline
\end{tabular}

This overrepresentation of first-generation students in the Latina student population provided a guiding assumption for learning more about the persistence and resistance strategies these mujeres use to remain in school. I use the term mujeres interchangeably with Latinas because it captures the nuance of language and culture in describing these young women. Therefore, this study aimed to look at the educational experiences of first-generation Latinas as a way to better understand the persistence strategies of this 
student population and to inform how educational institutions can work from a strengths-based framework when implementing persistence strategies and initiatives.

The quantitative data from the previous two sections provide some context and insight into the educational experiences of first-generation Latinas at Rolling Hills College. However, as I described above they are not sufficient to provide an in-depth nuanced understanding of the educational experiences of first-generation Latinas. Therefore, I developed an online survey to better understand the experiences of this student population by collecting both quantitative and qualitative data as part of the survey. Aside from collecting demographic information, the survey also included 9 likert-scale questions, which aimed to get the key characteristics of transformational resistance. Respondents were provided multiple points to provide open-ended answers to most of the questions in the survey, yielding the beginning of rich qualitative data about the mujeres' experiences at RHC. The online survey also served as a mechanism for identifying participants for the focus group interviews, further adding to the qualitative data findings. The following section provides the details of the survey's data findings in this study, including both quantitative and qualitative data.

Transformational Resistance Survey

As indicated in chapter 3, an online demographics questionnaire and Transformational Resistance (TR) survey were sent to all first-generation women $(\mathrm{n}=253)$ who self-identified as Latina during the 2010-2011 academic year, yielding a 
$59 \%$ response rate $(n=141)$. The TR survey yielded quantitative data, including demographic data such as year in school, major, minor, caregivers' educational levels, educational aspirations, and ethnic self-identification. The TR survey also yielded quantitative data on the likert-scale questions describing the respondents' beliefs and perspectives around issues of social justice and oppression, two key characteristics of transformational resistance. The quantitative data from the survey are reported in this section followed by a transition into the qualitative data findings reported in chapter 5 .

Of the 253 women who are first-generation and Latina, $141(n=141)$ responded to the survey, representing a $59 \%$ response rate. There was a proportionate distribution of the respondents' distribution by year in school. The following percentages indicate the class demographics of the respondents: $28 \%$ Seniors (expected graduation spring 2011); 25\% Juniors (expected graduation spring 2012); 24\% Sophomores (expected graduation spring 2013; and 23\% First Year Students (expected graduation spring 2014).

The mujeres who responded had some distinctions in how they identified ethnically. Most of the mujeres identified as "Latina" $(42.6 \%, \mathrm{n}=60)$, with 'Hispanic' identification $(34.8 \%, n=49)$ closely following. The remaining respondents identified as either 'Chicana' $(8.5 \%, \mathrm{n}=12)$, Xicana $(1.4 \%, \mathrm{n}=2)$, or 'Other' $(12.8 \%, \mathrm{n}=18)$. Upon further review of the 'Other' category, 8 identified as "Mexican-American," 7 as 
'Mexicana', and 7 as 'Multi-racial.' Table 4. 3 illustrates the ethnic breakdown of the 141 respondents.

\begin{tabular}{lll}
\multicolumn{2}{l}{ Table 3 Mujeres' Ethnic Identification $(N=141)$} \\
\hline Ethnicity & Percent / Number \\
\hline & & \\
Latina & $42.6 \% \quad(\mathrm{n}=60)$ \\
Hispanic & $34.8 \% \quad(\mathrm{n}=49)$ \\
Chicana & $8.5 \% \quad(\mathrm{n}=12)$ \\
Xicana & $1.4 \% \quad(\mathrm{n}=2)$ \\
*Other & $12.8 \% \quad(\mathrm{n}=18)$ \\
*Includes: 8 Mexican-American; 7 & \\
Mexican; 7 Multiracial & \\
\hline
\end{tabular}

With the terms Latino and Hispanic used interchangeably throughout the literature and most official documentations, it is not surprising that there is almost an even split between these two categories. Until the 2010 census, Hispanic was the only label used for 'Hispanic, non-White' individuals (US Census Bureau). Although I did not set out to study Chicanas, or solely mujeres of Mexican descent, all of the respondents reported identifying at least in part as Mexican in descent. Notable as well in terms of the validity of the sample, the demographic make-up of the respondents is closely aligned with the ethnic breakdown among all RHC Latino/as, of which $59.9 \%$ report of some variation of Mexican, 10\% report as Central American, and 7\% report as South American. In an effort to honor the mujeres who identified as multi-racial, although they did report identifying as part Mexican, I will use the general term, Latina interchangeably with Chicana/Mexicana. 
When asked to identify their primary caregiver while they were growing up, $81 \%(n=114)$ of the Latinas indicated that their mother held this role, while $69 \%(n=97)$ listed their father as the secondary caregiver. Thirty-six of the respondents $(25 \%)$ indicated that they come from a single mother household and either did not list a second caregiver or listed an abuela/o (grandmother/father) or tía/tio (aunt/uncle) as their secondary caregiver. The highest level of education for most respondents' primary caregiver was a high school diploma $(26.2 \%, \mathrm{n}=37)$ followed by the next highest level of some elementary school $(24.1 \%, n=34)$. The remaining respondents reported their primary caregivers' highest level of education as follows: $6.4 \%(n=7)$ no formal education; $19.1 \%(n=27)$ some high school; and $22 \%(n=31)$ some college education. For the secondary caregivers, the highest percentage for level of education is elementary school $(25.5 \%, n=36)$ with a high school diploma following at $22 \%(n=31)$. Latina respondents reported that they generally live on campus $(64.5 \%, \mathrm{n}=91)$. Among the Latinas living off-campus, they are approximately evenly split between those living at home with family $(14.9 \%, \mathrm{n}=21)$ and those living with roommates $(17.7 \%, \mathrm{n}=25)$. The high numbers of Latinas on campus may provide some insight into the high percentage of engagement with campus clubs and activities $(84.4 \%, n=119)$. The two groups with the highest levels of engagement are Hermanas Unidas (HaU) with $22 \%$ and the Catholic Institute for Lasallian Social Action (CILSA) with $21 \%$ of the 
Latinas reporting engagement. Both of these organizations are high profile groups for community building and working for social justice.

Educational aspirations for these young women are quite high. Forty-three percent of the mujeres surveyed indicate that the highest degree they want to earn is at the doctoral level (including M.D. and J.D.), while $42.5 \%$ indicate that they would like to earn a master's degree. The remaining $14.8 \%$ indicate that a baccalaureate degree is their highest aspiration for education.

The women who aspire to earn a doctoral degree describe a sense of pride and honor that their family would have as a result, as well as the benefit to their larger Latino community. As one mujer wrote as an open-ended response, "I would like my law degree and a Ph.D. because I want to teach about things that I am passionate about like issues of social justice. I think it would be a great example for the students in my community who do not see that kind of example around very often...," (Junior Respondent, TR Survey). Another young woman wrote, "I want to get an Ed.D or Ph.D. because I want to gain the tools and knowledge to hopefully have authority to empower future students of color on a larger spectrum" (Respondent, TR Survey). These young women shared personal aspects of wanting to improve their families' lives and future generations in their communities. "I want a Ph.D. to show that even if your parents didn't get as great an education doesn't mean you can't" (Sophomore Respondent, TR Survey). 
When asked why they have remained at RHC, most of the young women $(87 \%)$ shared that substantial financial aid makes it possible for them to remain. They also indicated that the small community environment and class sizes are appealing to them because they receive intentional and individualized support from faculty and staff. They reported feeling valued and respected as a whole individual and not just seen as a number. They also indicated that the quality of education, in terms of the college's recognition and its academic programs have encouraged them to remain.

Almost all of the women (94.3\%) stated that their familia and relationships with faculty and staff were the biggest support systems for them to stay in school, as well as the motivating factor that helped them get through difficult times. One of the women wrote, "My mami is my biggest motivation and support. She works two jobs so I can be here and when I feel like I can't do it anymore I think of her and her two jobs. That gets be back on track real quick." There were many others that echoed this sense of understanding that their presence in college is not without esfuerzo (hard work) from their parents. It's a sobering reminder to think of how hard many of the RHC Latino parents work at low wage jobs, which result from their lack of education, to provide for the mujeres ' education.

Most of the young women wrote about experiences of having established at least one close relationship with a faculty or staff member whom they saw as a mentor or role model. "It makes all the difference that my faculty know me by name [...] that's 
important to me [...] to be known for who I am and for what I think," (Senior Respondent, TR Survey). Additionally, $78 \%$ of the respondents $(n=110)$ indicated that the person that they saw as a mentor was a person of color or a woman. Most of the young women name the same 3 faculty/staff Latinas whom they see as mentors because these women share similar backgrounds, and have been open about sharing those experiences with students. As bell hooks says, "When professors bring narratives of their experiences into classroom discussion it eliminates the possibility that we can function as all-knowing, silent interrogators" (1994, p.21). Building genuine relationships with "authentic care" (Valenzuela, 1999) for and with students, allows students to see and feel that they are not being treated as "other people's children" (Delpit, 1995). It is important to note that the young women in this study express the importance of having a faculty/staff mentor who serves as a role model as a woman of color. However, hooks, Valenzuela, and Delpit's work is not specific only to educators of color; they all build upon Freire's (1970) work of providing an education which combats the "dehumanization" of an oppressed group of people and advocate for all educators to embrace this liberatory stance.

The women also expressed a sense of cultural pride in representing the Latino community. As one wrote in the survey, "It is a private school where I should stay and represent my family and represent that minorities can also attend this type of school." There was a general sense of feeling at home when they saw other Latinas in their 
classes, clubs, or residence halls, such as, "I am one of three Latinas on my floor (residence hall) and it helped me to feel better knowing that I wasn't the only one." They wrote about experiences in which they saw older students in leadership positions that were Latinas and felt like they, too, could be involved at that level.

Interestingly enough, almost half (47.5\%) of the women wrote that at some point in their time in college they thought of leaving RHC. When asked to describe why they thought of leaving, issues of discrimination and racism, followed by lack of sufficient financial aid, and pressing family issues were at the top of students' responses. Because issues of financial aid are common for most first-generation college students, I focused on the comments about discrimination and racism, as well as those about critical family issues.

Racial microaggressions impact students of color on a level that impacts not only their personal and psychological well-being, but also their academic performance (Sue et al., 2009). Of the 67 mujeres who expressed a desire to leave RHC, 61 (92\%) indicated that they had a desire to leave because they felt marginalized, neglected, and also targeted because of their race. "My freshman year I was living in a triple with two roommates, both of them white. They always complained about my Spanish music and the fact that my mom left long voice messages in Spanish on our phone. I felt as if they were judging me for who I was, Mexican." (Junior Respondent, TR Survey). This type of racial microagression impacts students on a daily basis because it strips away the 
very fabric that they shared motivates them through difficult times. When our family, our mamás are being ridiculed, our source of strength and motivation are being ridiculed. There is also an expectation that adhering to the values and norms of the dominant culture is necessary to be seen. "There are times when I feel that I don't really belong in this school because I feel that in order to get recognized I have to publicly recognize that I am from a different culture. Then I feel like I have to 'act' a certain way around the white students in order to get acknowledged," (Senior Respondent, TR Survey). This student's experience resonates with struggle of acknowledging cultural heritage, while also enacting the dominant values and norms in order to be acknowledged in an academic setting.

Another young woman shared an incident of being told by an advisor "that a four-year college isn't for everyone," and that "there are a lot of Latino students in community colleges, which might make you (student) feel more comfortable." This particular incident highlights one of the key findings in this study which describes how students of color are often placed in role of having to change environments to feel comfortable, rather than having the educational environment change to make students of color feel more welcome. Further, the lack of diversity in the classroom settings heightens the awareness of students of color to know that they are in the minority and might encourage them to seek community in another educational institution with more diversity. 
I have thought of leaving RHC and transferring to a school where there were more people like me. There are very VERY few people who can understand why I am the way I am. My professors have never fully been able to relate to me because none of them seem to have experienced the level of racism and discrimination that I have experienced. For example, throughout my four years at RHC, I have taken courses in the science field and never have I been in a classroom with 2 or more minorities (race)... and they are usually the first ones that drop the class. And of course, most people in my class are male.... (Senior Respondent, TR Survey).

This was a common thread throughout the 141 Latinas. They expressed a sense that as they increased in their level of education, the numbers of the students of color around them decreased. For the mujeres who are in the STEM programs, they shared a resounding experience in feeling like one of the only students of color, and especially a woman of color. Each of the 18 mujeres $(13 \%)$ who identified her major in the school of science, described feeling isolated especially when it came to choosing lab partners. "I hate when we have to choose lab partners because it makes me feel like no one wants to be with me at first, until they see that I'm really good especially in the lab write-ups" (Junior Respondent, TR Survey). All the other mujeres are in majors across the departments and expressed a sense that there were not many of them in their classes and felt as if they had to support one another to get through each semester. "I'm a sophomore and I felt like if Karina (pseudonym), she's a senior, hadn't helped me to study for that class...I would've dropped it already. I'm really grateful for her." 
(Respondent, TR Survey). This type of experience exemplifies the hermandad (sisterhood) that is described in more detail later in chapter 5.

From a perspective of being first-generation college Latinas, $34 \%(n=48)$ of the young women expressed that because of critical family issues, they almost had to transfer schools or stop going to college altogether. "I have thought of dropping out of college overall because I feel that college is not for people like me who have bigger life, family problems as a priority. Mi $A$ má always calls on me to deal with family issues back at home and when she calls I have to go, I just have to," (Junior Respondent, TR Survey). As described in chapter 2, research supports the multiplicity of roles that Latinas hold in their families, especially those who are considered to be successful at fulfilling family obligations and navigate higher education successfully (Delgado Bernal, 2001; Hernandez, 1997). I incorporate this perspective when reporting the findings of the focus groups interviews in the Familia section of chapter five. The values of Latino families of respeto and confiánza often hold first-generation Latinas to constantly straddle their two worlds; the world of familia and the world of the academy. In reviewing what the mujeres shared in their responses to the online survey, I have come to see that their experiences as first-generation Latinas at RHC are both beneficial and challenging. One student summarizes best when she wrote, "Everything is well, but I feel like I don't belong here. Something just doesn't feel right; something 
is missing. I like it here, but I definitely can't say I love it," (First Year Respondent, TR Survey).

Overall, the mostly quantitative data (with the beginnings of qualitative data) in this chapter revealed that there is always more to the story and the young women who participated in the focus groups provided even more insight into the educational experiences and resistance strategies first-generation Latinas use to navigate Rolling Hills College. The TR survey data contribute to the findings that emerged from the focus group interviews. It was an essential part of the mixed methods study design because it provided the framework, from which, to design the interview protocol for the focus groups. At the beginning of each focus group, I began by sharing the data from the TR likert-scale.

Table 4 illustrates the results of the questions, which aimed to operationalize what transformational resistance looked like for the respondents. The question that yielded the longest discussion was the statement, "In order to earn my degree means that I have to be more masculine than feminine in class settings." The focus group discussions revealed that had the language been changed to, "In order to earn my degree means that I have to me more assertive in class settings," the mujeres would have agreed with the statement. They did not believe that they have to more masculine, but that they do need to be more assertive in order to be heard in class discussions. 
"Sometimes I feel like if I don't come into the discussion with my guards up and more, like, well, assertive...then I would never be heard," (Focus Group participant).

Table 4 Transformational Resistance Results ( $N=136 ; 5$ skipped survey section)

\begin{tabular}{|c|c|c|c|c|c|}
\hline Statement & $\begin{array}{l}\text { Strongly } \\
\text { Agree }\end{array}$ & Agree & $\begin{array}{l}\text { Neither } \\
\text { Agree } \\
\text { Nor } \\
\text { Disagree }\end{array}$ & Disagree & $\begin{array}{l}\text { Strongly } \\
\text { Disagree }\end{array}$ \\
\hline $\begin{array}{l}\text { Educational institutions provide an } \\
\text { equally fair pathway for all students } \\
\text { to succeed }\end{array}$ & $\begin{array}{l}13.2 \% \\
(18)\end{array}$ & $\begin{array}{l}39.0 \% \\
(53)\end{array}$ & $\begin{array}{l}17.6 \% \\
(24)\end{array}$ & $\begin{array}{l}23.5 \% \\
(32)\end{array}$ & $\begin{array}{l}6.6 \% \\
(9)\end{array}$ \\
\hline $\begin{array}{l}\text { If I work hard enough, I can } \\
\text { accomplish anything regardless of } \\
\text { my background. }\end{array}$ & $\begin{array}{l}60.0 \% \\
(81)\end{array}$ & $\begin{array}{l}27.4 \% \\
(37)\end{array}$ & $\begin{array}{l}5.9 \% \\
(8)\end{array}$ & $\begin{array}{l}6.7 \% \\
(9)\end{array}$ & $\begin{array}{l}6.6 \% \\
(9)\end{array}$ \\
\hline $\begin{array}{l}\text { In order to earn my degree means I } \\
\text { have to know how to act white. }\end{array}$ & $\begin{array}{l}.7 \% \\
(1)\end{array}$ & $\begin{array}{l}14.0 \% \\
(19)\end{array}$ & $\begin{array}{l}19.1 \% \\
(26)\end{array}$ & $\begin{array}{l}25.7 \% \\
(35)\end{array}$ & $\begin{array}{l}40 / 4 \% \\
(55)\end{array}$ \\
\hline $\begin{array}{l}\text { In order to earn my degree means } \\
\text { that I have to be more masculine } \\
\text { than feminine in class settings. }\end{array}$ & $\begin{array}{l}1.5 \% \\
(2)\end{array}$ & $\begin{array}{l}6.6 \% \\
(9)\end{array}$ & $\begin{array}{l}21.3 \% \\
(29)\end{array}$ & $\begin{array}{l}35.3 \% \\
(48)\end{array}$ & $\begin{array}{l}35.3 \% \\
(48)\end{array}$ \\
\hline $\begin{array}{l}\text { My college education will allow me } \\
\text { to impact my home community in a } \\
\text { positive way. }\end{array}$ & $\begin{array}{l}61.0 \% \\
(83)\end{array}$ & $\begin{array}{l}32.4 \% \\
(44)\end{array}$ & $\begin{array}{l}6.6 \% \\
(9)\end{array}$ & $\begin{array}{l}0.0 \% \\
(0)\end{array}$ & $\begin{array}{l}0.0 \% \\
(0)\end{array}$ \\
\hline $\begin{array}{l}\text { My cultural values influence my } \\
\text { choices. }\end{array}$ & $\begin{array}{l}44.9 \% \\
(41)\end{array}$ & $\begin{array}{l}30.9 \% \\
(42)\end{array}$ & $\begin{array}{l}24.3 \% \\
(33)\end{array}$ & $\begin{array}{l}0.0 \% \\
(0)\end{array}$ & $\begin{array}{l}0.0 \% \\
(0)\end{array}$ \\
\hline $\begin{array}{l}\text { Becoming educated is a form of } \\
\text { social justice. }\end{array}$ & $\begin{array}{l}30.1 \% \\
(41)\end{array}$ & $\begin{array}{l}45.6 \% \\
(62)\end{array}$ & $\begin{array}{l}24.3 \% \\
(33)\end{array}$ & $\begin{array}{l}0.0 \% \\
(0)\end{array}$ & $\begin{array}{l}0.0 \% \\
(0)\end{array}$ \\
\hline $\begin{array}{l}\text { It is important to me to be informed } \\
\text { of the social injustices that impact } \\
\text { groups of people. }\end{array}$ & $\begin{array}{l}42.6 \% \\
(58)\end{array}$ & $\begin{array}{l}44.9 \% \\
(61)\end{array}$ & $\begin{array}{l}11.0 \% \\
(15)\end{array}$ & $\begin{array}{l}.7 \% \\
(1)\end{array}$ & $\begin{array}{l}.7 \% \\
(1)\end{array}$ \\
\hline $\begin{array}{l}\text { It is important to me to be actively } \\
\text { involved in addressing the } \\
\text { injustices that impact groups of } \\
\text { people. }\end{array}$ & $\begin{array}{l}34.6 \% \\
(47)\end{array}$ & $\begin{array}{l}40.4 \% \\
(55)\end{array}$ & $\begin{array}{l}22.8 \% \\
(31)\end{array}$ & $\begin{array}{l}2.2 \% \\
(3)\end{array}$ & $\begin{array}{l}0.0 \% \\
(0)\end{array}$ \\
\hline
\end{tabular}


Table 4 also illustrates how the TR survey respondents agree that their college education will impact their home communities in a positive way, as well as that their cultural values influence their choices. These two areas are supported in chapter 5 when describing how familía is a source of support and cultural pride. The respondents also reported that becoming educated is a form of social justice and that is important for them to be actively involved in addressing the injustices that impact people. These findings provided the opportunity to center the discussion of the focus groups in the critique of oppression, as well as their motivation rooted in social justice.

Throughout the focus groups, the mujeres came back to the statements about how their college education will allow them to impact their home communities in a positive way. Their testimonios about their educational experiences at RHC are described in chapter 5 within the context of highlighting the major findings of this study. 


\section{Chapter Five: Las Mujeres' Testimonios}

"It's not just about getting a college degree. It's the whole package, education, morals, values, cultural pride, and... oh yeah being una mujer." (Maria Luisa)

For first-generation Latinas, being educated is a complex existence that challenges them to look at the intersection of what it means to be a first-generation Latina trying to earn a college degree.

She strengthens her tolerance (and intolerance) for ambiguity. She is willing to share, to make herself vulnerable to foreign ways of seeing and thinking. She surrenders all notions of safety, of the familiar. Deconstruct, construct. She becomes a "nahual," able to transform herself into a tree, a coyote, into another person. She learns to transform the small "I" into the total Self. Se hace moldeadora de su alma. Según la concepción que tiene de si misma, asi sera" (Anzaldua, 1999, pp.104-105).

Anzaldua's words capture the nuance of what it means to exist within two worlds. In the case of first-generation Latinas, they exist in the world of their families' cultural values and traditions, while at the same time trying to find existence in the culture of higher education. And while the educated Latina crosses in and out of multiple worlds, she is strong, reflective, and ever present of where she walks in life.

\section{Focus Group Findings}

As described in chapter three as part of the methodology, there were 24 young women who participated in one of four focus groups. They shared with one another and 
with me a variety of experiences, which highlight the transformational resistance strategies they have used in their transition into and persistence in higher education. The focus groups provided the time and space for first-generation Latinas to share stories, listen to their hermanas, and to reflect on what they believe has allowed them to succeed at a predominantly white institution (PWI). The thematic findings from this study are told from the perspectives of four first-generation Latinas at RHC, which are autobiographical and organized in a counterstorytelling (Delgado \& Stefanic, 2001) method to tell their experiences at RHC. The voices of these four young women, voices that are often silenced or marginalized as women of color, will provide the perspective from which the findings are reported.

Each of the following mujeres represents one of the four focus groups, as well as each of the four class levels. These young women were selected as the focals during the member-checking process of the data analysis, in which I provided them with a summary of the key findings to ask them if they were an accurate reflection of their experiences. They were selected as exemplars for this study because of their ability to express the sentiments and experiences of each of their respective focus groups. And while their individual story may not be identical to that of all first-generation Latinas at RHC, they do provide insight into the nuanced experiences of this student population. Throughout the remainder of this chapter, I incorporate their voices to illustrate the key findings of this study. While they were not in a focus group together, their words often 
flow off one another, as if they were in conversation. This format reinforces the strengths of focus group interviewing, which aims to find the common themes across different groups or normative experiences. This also further reinforces that the interview questions and format were aligned in such a manner so as to capture the same discussions across each of the groups. Table 5 provides key descriptors for each of the four focal mujeres.

\begin{tabular}{|c|c|c|c|}
\hline Table 5 & Focal Mujere. & escriptors & \\
\hline Focal Mujer & Year at $R H C$ & Major/Minor & Self-identifying quotes \\
\hline Gaby & First Year & $\begin{array}{l}\text { Accounting/ } \\
\text { Sociology \& } \\
\text { Women's Studies }\end{array}$ & $\begin{array}{l}\text { "Latina from the city (San } \\
\text { Francisco) who wasn't supposed to } \\
\text { make it to college but did anyway, y } \\
\text { qué (and what)?" }\end{array}$ \\
\hline Esmeralda & Sophomore & Psychology & $\begin{array}{l}\text { "I do what I do for my family, so my } \\
\text { sister doesn't have to suffer like I } \\
\text { did." }\end{array}$ \\
\hline Suzie & Junior & Health Science & $\begin{array}{l}\text { "fighter who doesn't give up, ever. I } \\
\text { got a lot of fight in me." }\end{array}$ \\
\hline María Luisa & Senior & $\begin{array}{l}\text { Sociology/ } \\
\text { Women's Studies }\end{array}$ & $\begin{array}{l}\text { "I'm loud, brown, round, and } \\
\text { proud!" }\end{array}$ \\
\hline
\end{tabular}

Gaby is a first-year student who prefers to wear jeans, solid t-shirts, with matching sneakers, gold-hooped earrings, and her hair naturally long and curly. She wears minimal make-up, except for the prominence of her eyeliner and a wrist full of bangle bracelets. Her parents are currently in the process of becoming naturalized 
citizens of the United States. She describes herself, as a "Latina from the city (San Francisco) who wasn't supposed to make it to college but did anyway, y qué (and what)?"

Esmeralda, a psychology major, is a sophomore from northern California, who is known as quiet to those who don't know her and as an advocate for students of color to those who do. She wears her thick, dark hair often pinned half-up, often dresses better and wears make-up when she feels like she is having a good day. She comes from a single-mother household and sees herself as a living breathing example of how Latinas can and do make it to and through college, but not without sacrifices. "I do what I do for my family, so my sister doesn't have to suffer like I did."

Suzie is a junior from the greater bay area who is a health science major and sees her older brother as a model of how she can improve her life and that of her family by getting an education. She describes her upbringing as disjointed because she spent time with her mom and dad individually, a product of a "Latino divorce." For Suzie, "Latino divorce," means that her parents are considered divorced in her family and Latino culture, although by American standards they are still married but separated. She refuses to be labeled, especially in terms of her sexual orientation. She self-describes as a "fighter who doesn't give up, ever. I got a lot of fight in me."

Maria Luisa is a senior, self-described as, "loud, brown, round, and proud!" She is from the central valley and sees her mother as her primary caregiver, since her father 
spends long periods of time away from the family because of work. She indicates that she wears jeans, shirts, sweatshirts, and usually flip-flops because this is what she can afford. When she dresses up, she describes her style as retro and honoring the beauty and "non sexualized symbolism" of the pin-up girls, with big curls and red lipstick. As a major in sociology with a minor in women's studies, she sees herself as a student leader when it comes to issues that impact women of color at RHC.

\section{Introducing the Concept Ser Educada}

The major finding of this study is the concept of Ser Educada, which when translated into English means "to be educated." However, I chose to keep the concept in Spanish to preserve its nuanced meaning, which is more complex than the literal English translation. I conceptualize Ser Educada to include the following sub-themes: 1) Familía 2) Educación, 3) Femininity, and 4) Hermandad (sisterhood). A common thread throughout the sub-themes and the concept of Ser Educada is the integration of a new mestiza consciousness and acts of transformational resistance, which allow the mujeres in this study to persist at RHC. These three themes each hold un fondo of knowledge (Andrade \& González Le Denmat, 1999; Fernandez, 2002; and Gonzalez \& Moll, 2002) that further shows the nuances of the educational experiences of firstgeneration Latinas and their resistance strategies at RHC as they each strive to Ser Educada. In the center is the first-generation Latina who must navigate transitioning between the four key areas of her life that assist her in succeeding in college. Ser 
educada calls for the first-generation Latina to be in a constant state of transition, in which her transformational resistance strategies and new mestiza consciousness, are key to helping her successfully navigate moving through these four areas of her life.

Throughout the remainder of this chapter, the language is kept authentic to the women's words. Each of the young women provides rich descriptions on her experiences and often flows in and out of Spanish. Translation for the portions in Spanish is not always provided literally so as to honor their words, their lenguaje [language]. Square brackets are included when readers who are not fluent in Spanish might miss the main point. This back and forth exemplifies a form of code-switching and the nuances of the experiences of the Latinas in this study.

\section{Familia}

For me, I think being Latina is a privilege...that's just me....People might say, 'oh but being white is a privilege'...Nah, being Latina is a privilege because my whole background is a privilege, like what my family taught me about communidad, familia, la raza... (Esmeralda)

As Latinas, there are cultural values and traditions rooted in generations of sharing stories, lived experiences, and intergenerational wisdom, that is the dichos (sayings) that are passed on through the generations. Latino families challenge the nuclear family unit of two parents and children because it includes grandparents, aunts/uncles, cousins, and even close neighborhood friends. Yosso's (2005) definition 
of familial capital is illustrated when a family "models lessons of caring, coping, and providing. Family lessons help shape us emotionally and give us moral guidance" (p.46). The young women in this study spoke of family as being both the nuclear and extended family of support that provided them with the foundational knowledge of consejos y coscorrones [advice and love taps on the head].

Suzie: Well, I didn't really have my mom growing up, so it was just my dad, my brother and my dad's family. I had all kinds of tios, tias, primas, and all that who, you know, were my family. But mostly I would have to say that my brother is the one who gave me the most support and encouragement. We've always said that we got each other's back. It's his voice that I hear when I think about giving up.

Gaby: Damn, my family. They're, like everything to me. I live and breathe my family. My mom.......she's our backbone.... keeps us strong, keeps me strong. She always told me I was fuerte y terca como mi abuelita [strong and stubborn like my grandmother].

Esmeralda: O pues, mi familia, my mom and my sister... and our church community. That's who I consider my family. Mi amá is the one who has taught me so much about who I am. I think I even sound like her. Even though I've had to, like, be a grown up with her, I wouldn't change it for anything. That's just who we are.

Funds of knowledge are those characteristics that are understood as historically developed and accumulated strategies or bodies of knowledge that are vital to a family's survival (Andrade \& Gonzáles Le Denmat 1999; Delgado Bernal, 2001; Vélez-Ibánez \& Greenberg, 1992). Delgado Bernal (2001) builds upon Andrade \& Gonzáles Le Denmat's (1999) “Chicana feminist pedagogies focus on the teaching and learning of the home allows Chicanas to draw upon their own cultures and sense of self to resist 
domination along the axes of race, class, gender, and sexual orientation"(p.624). For the young mujeres in this study, this fund of knowledge runs deep into the stories of their ancestors, their trials and tribulations to survive.

Maria Luisa: I know that I come from a long line of strong women. My mom always told me that we come from sangre fuerte y corazones amables[strong blood \& generous hearts]. I never knew what that meant really, until I got here and realized that I was always talking about my family, my culture. Pues eso es como veo la vida. Por los ojos de mi familia. [Well that's how I see life.... Through the eyes of my family].

Esmeralda: My amá always tells the story about how she was the one that the family paid los coyotes [border smugglers] so she could cross over here first. She tells us about how she left and didn't know if her tia was going to be en el otro lado esperandola o no[on the other side waiting for her or not]. It took two weeks riding in the back of a van with no windows before she got to Salinas. My mom said she was lucky because she knew how to show that she was not afraid of the coyote. She was always alert and ready to protect herself.... and how she kept telling herself that she was strong.... she just remembered how she used to wake up at four in the morning to help out on el rancho before she went to school. Only my mom! Of course she would think about that when these coyotes could have harmed her. But that's my amá.... she always says, 'Trabajar duro es lo que nuestra familia sabe hacer bien. Somos trabajadores' [Our family knows hard work. We're workers].

These stories provide a communal cultural history that informs the young women's perspectives in college. Family stories and traditions are laced with values of hard work, generosity, and the strength of being a woman. Mother-daughter pedagogies (Villenas \& Moreno, 2001) include how mothers teach their daughters "contradictory and yet interruptive lessons of how to be a woman" (Elenes, González, Delgado Bernal, \& Villenas, 2001, p.597). Latina mothers teach explicit and implicit lessons of 
appropriate and resistant behaviors to teach daughters how to be mujeres. Shared cuentos serve as a form of ancestral wisdom that are taught from generation to generation, which are "powerful pieces of our legacy... healthy... and necessary for survival" (Lawrence-Lightfoot, 1994, p.27).

Esmeralda: Back home, I'm like my mom's partner, her friend, like a second mother to my sister. Mi Amá taught me how to cook, take care of the house, value myself as a young woman. You know, like, how to respect myself and not let los chavos think that they could get at me And now, well, it's difficult for me being here. It's difficult because back home my mom doesn't understand what I have to go through here and the challenges...or even how much time college takes. Like, she just doesn't get the workload that I have. My mom gets frustrated because she wants to help me but she doesn't know about college stuff because she's only, like, barely completed elementary school. But she pushes me. Me da consejos y apollo [she gives me advice and encouragement].

Esmeralda's role in her family is crucial to the family's survival and poses both a challenge and a benefit to her college experience. Every time there is an issue or emergency back at home, she leaves immediately. Given the urgency of issues such as her mother being evicted from their apartments or her sister being harassed in school, rarely does Esmeralda stop to think about the consequences of leaving school in the middle of the night or in the middle of class for that matter. As her mother's partner in holding the family together, this pull is stronger than any consequence she might face in missing a class, an exam, or a study session. Latina/o college students at PWIs have to navigate simultaneously the obligations and expectation of their families or communities, as well as the culture of higher education (Torres, 2006). However, it 
also serves as a benefit because Esmeralda has learned to channel the intensity of this energy to support her mother and sister towards her academics, a common experience for first-generation Latinas. This was a resounding theme across the focus groups, which supports the findings of the Transformational Resistance survey results - that of family responsibilities being both a source of stress and of motivation.

Familia Role Models - Pride and Pressure

Modeling new behaviors for family members, especially siblings is an expectation that all of the women in the focus groups shared. They discussed how they felt their families support them, but also expect them to teach their younger siblings and cousins about pursuing a college education.

Maria Luisa: The added responsibility and extra pressure to take care of not just yourself and make sure you succeed but putting a good example for others, making sure that they succeed as well as make sure that my siblings are alright. It's like I have to show them that we're going to be okay and that I know they can do it, even when I doubt if I can do it, you know?

Esmeralda: I have always been told that I have to set an example for my sister, so I had to work, go to school and help take care of the house. I always tried to do as much as I could at home because mi Amá had three jobs and we wanted my sister to be able to focus just on school. I had to miss so many days of school to help my Amá with going to the doctor, pay bills, basically whenever she needed me to translate for her. And then I was always responsible for my sister at home because my mom worked late nights. So I usually did my homework after I made dinner and helped her with her homework...so yeah, she was usually asleep when I started my homework. 
Serving as role models is not limited to teaching their younger family members. The mujeres also described how they were seen as role models by their older siblings and neighborhood friends. They expanded the understanding of what constitutes a Latino family to be more than just the nuclear family (Cuádraz, 2005).

Suzie: Even though my brother is older than me, I'm the one that's expected to be a role model for him.... to show him how someone from our family can get a college education. On my dad's side of the family, they talk to my cousins about me and how I'm in college and how they should be like me. I don't even know some of them!

Gaby: My girls back home. Most of them did not go the path of going to college, so their moms talk to my mom to hear about how I'm doing. My mom tells me that the other moms tell my girls how I'm in college doing this for me, my family, out of respect for what my parents did for me. That's just weird, but I see what they mean.

Maria Luisa: It's a responsibility. I can't just be here getting my college degree and not think about my sister. I know that I am the one, and my brother too, the ones who are doing things different than my cousins and friends back home...And I, like, pues ya se que lo hago aqui es para mi raza [well, I know that what I do here I do for my people].

Each of these young women illustrate what all 24 women of the focus groups described as their burden to bear. They all shared examples of how them being in college is used as a form of educating their hermanas/hermanos, primas/primos, anyone who might benefit from learning that they are pursuing their education. These findings reinforce the TR survey findings of the mujeres also including non-parent, family members as their primary care providers, as well as the general family benefiting from them being in college. There is a sense of pride that they are able to pave a new path for 
their families. Yet, this path they walk is a difficult and sometimes lonely one, especially as a first-generation college student.

Gaby: When I try to tell my parents about what I'm learning sometimes they just don't want to hear it. Or they question me, like, they say they're going to wait and see how I do in school to see if I'm really learning what I say I'm learning.....Yeah, so when I ask them just support me, my dad is like 'I do support you! I help pay for you to be at that school!'.... and that's not even what I'm talking about.....

Maria Luisa: The first-generation part is what's really tough sometimes.... sometimes I just want them to ask me how things are going so I can tell them all about it. Pero...como que no quieren saber. I don't know... maybe it's just too hard for them to have their daughter know more about this college stuff than them. I...I just don't know what to think about it. I know it makes me feel hella bad sometimes.

As first-generation college students, their educational experiences include feeling, at first, distant from their families. Among all of the focus groups, the mujeres talked about how it was difficult to be in college and not have, in some cases, anyone from the family to help them navigate higher education. However, there was also resounding pride in knowing that as first-generation college students, they provide new ways of bridging the culture of their family to the culture of higher education.

Suzie: I know that I'm the one, that like, has to be this link...It's like I'm this link or this like bridge from my family to here. And even though I wish it were easier sometimes, I know that I can, like, be that bridge because of where I come from. Like, I come from something real, even though it's different than here. 
A common theme was an awareness or consciousness that the role they play in being in college is one that brings two worlds together, sometimes even crashing into one another.

\section{Living in the Borderlands - Mestiza Consciousness}

Much has been written and discussed about Gloria Anzaldúa's (1987)

description of Chicanas as defining the new mestiza consciousness. "The term mestiza

has come to mean a new Chicana consciousness that straddles cultures, races,

languages, nations, sexualities, and sprititualities - that is, living with ambivalence

while balancing opposing powers" (Delgado Bernal, 2001, p.626).

Esmeralda: As I mentioned before, I feel like its not my first semester because I feel like I just started, because I haven't got used to it and I feel like a big part of that is the fact that I think there is a boundary between my family and my school. Like, I am still in the same position I was at home, I am still going to school, working two jobs, and not really earning any money for myself because it's all for them. And I feel, como no se, come que me siento desesperada (like I feel desperate) because I don't really have a choice. They need it and I know they need it [money] so I send it to them. So it's like I put that expectation on myself and they have the same, like, higher expectations that I can do it all. And well, that's muy dificil because for me personally there is no boundary. Like how can I just leave them and forget who I came from, you know? I have to be there and here.... because being here will give me the opportunities to change what there looks like for my family. I don't know if it makes sense to you, but it makes sense to me. This constant back and forth, that is my life... that is who I am.

The mujeres ' experiences and words provide a real sense of what it means to be caught in a space that further complicates the intersections of how first-generation 
Latinas view themselves in their family culture and the culture of higher education. Esmeralda uses the word boundary, which I see as a description of an actual border she, like many other first-generation Latinas, must straddle. She is what Anzaldúa would call a new mestiza, which describes the process by which Latinas, namely Chicanas or Mexican-Americans, come to a state of consciousness that fuels their desire to break down the dualities (e.g., gender, sex, language) that keep women of color from claiming their space in the world. As I listened to the women in the four focus groups, I heard over and over again phrases such as, "caught between two worlds," "confused about which behaviors to use," "struggling to switch," "ni de aqui ni de alla [neither from here nor there]," and "siempre pensando en donde estoy [always thinking about where I am]." I have come to understand and view that first-generation status is yet another layer to add to the complexity of being a mestiza in the land of higher education.

\section{Familia-Mestizaje as Resistance}

The findings revealed that the mujeres view themselves as mestizas, from both the culture of their familias and the culture of higher education. They refuse to choose to be one or the other, and in doing so, enact in transformative resistance because they hold a critique of the social oppressions that force them to choose the culture of higher education over that of their family. Delgado Bernal (2001) stated, "the mestiza identity 
is a dual identity that is located at the cross roads of racism, sexism, classism, homophobia, and patriarchy found in the dominant society an in Chicana/o communities" (p.626). These multiple forms of oppression call for a mestiza consciousness to be able to fight against the daily forms of discriminations that they encounter, which become more evident as they become educated.

\section{Educación}

Colleges and universities begin to connect with students long before their first day of school, through recruitment efforts and communication from the admissions offices. Admitted students receive packets of information telling them how to register for orientation days, sign up for campus housing, and even whether or not they will need a parking permit. And although orientations are to welcome and orient new students to the culture, there seems to be nothing more memorable than realizing on move-in day that you are in fact different.

Maria Luisa: Move-In weekend was crazy. My whole family came with me to help me move in and we were dressed ready to move stuff, you know? Pues, en realidad, we looked hella casual compared to all the other girls and their families moving in. I think... yeah, I think we were like one of three Latino families moving in and it's funny because we were all speaking Spanish. And then at one point, I saw my dad talking to this other girl's dad and they were chopping it up in Spanish about how both of our families were dropping off the first daughters to college.

Gaby: Move-in weekend was crazy hectic with lots of people and family, except I didn't have hella family with me. Only my mom helped me move in... But I did notice how all the white girls had tons of stuff...like one girl even had a u-haul! 
What's up with that? I was like, damn, what the hell did she bring? I had like one suitcase, a box of sneakers...cuz yeah, I love my sneakers and just some bedding and personal stuff... Well, and my stereo.. but I'll tell you more about that later...And they were all dressed really nice..como que iban a misa or algo asi (like they were going to church or something like that)...

Suzie: Dang! That weekend was doing too much. My brother helped me move in and, yeah, like I was the only one of my roommates that didn't have parents there. They just weren't able to come...So, yeah, like my brother, even though he was sick...he's the one who helped me move in... We just kept saying how different it was here...they were different...I was different...I mean, literally, I was the dark one of all my roommates. My stuff, it was obvious that I had generic labels for soap, clothes, and stuff... My cobija (blanket) is the, like traditional, fuzzy blanket with a lion on it. I saw my roommates straight trippin'... Shit, I was trippin'.

These young women all share a perspective of what it means for their cultural upbringing to no longer be visible in their new college surroundings. However, they felt visible, even exposed because now they stand out in a different way from being in their home environment. What they were used to seeing as the norm was now the anomaly, different, the outsider.

Esmeralda: Well even though I am in my third semester, I still feel like I just began. I guess coming from a different culture than the majority of the people here is really obvious to me. I mean, not only are there a lot of white people..and don't get me wrong, I know there are a lot of minorities and firstgeneration students here, but like la gente aqui son muy gringos, muy Americanos (the people here are so white, so American)...And well, I just can't seem to get used to it..I'm used to being surrounded by Latinos, mi cultura, mi musica, mi comida, you know?

Suzie: I felt so out of it, so different when I first came here. Everything about me was so different. I talk different. I act different. I dress different...but I'm still here to get my education... to get ahead and help out my family. But damn, it's like having to break a code and stuff... like they (white students) have all the 
codes and people like me, students of color and especially first-gen students, we need to break into it.

Esmeralda: Yeah, there's a huge cultural difference from my hometown to RHC. Like it's all about who can learn their (dominant culture) rules faster so we can level the playing field with the white students, the rich students and well, all the students that aren't first-generation. Like, they had parents and family members that went to college and know this stuff already. They learned it as part of their upbringing, como que ya estan primados para ser, you know, successful. Pero, yo tambien, eh! Mi mama, well, she was, like,... she is the one who taught me that I can get a college education and that I should para nuestra raza.

Suzie and Esmeralda describe how their cultural capital might not have fully prepared them for the culture of higher education, yet they also speak from a perspective that wants to honor their cultural traditions and the traditions of higher education. These are emerging signs of young women who want to challenge that they have to become "like" the system in order to be successful.

\section{Educación - Race and Gender Matter}

Developing an educación that will allow these young women to succeed at RHC requires that they constantly reflect on their experiences as women of color at a PWI. They share about what it means to have to literally stop and think before speaking or acting on a decision, especially in a classroom setting.

Gaby: I was thinking about how being in this new space, this new life. I was thinking like not flashing on people and like being educated enough to know when to put out my point and stuff without getting mad, like being smart about what I am saying. And you know how that's not easy for me...I can just flash on people, like my face gets all heated and I don't see no rhyme or reason. All I see 
is that someone just said or did something that is offensive, or disrespectful, or whatever. It's a lot of work to not use the code of the streets, you feel me? Me puede [it's hard work] Like, back at home, when I flash on you it's on, you know it's on, and we go at it until I win. Here, that just doesn't work, you know? Like what am I gonna do? Flash on my professor? ...that'll get me in hot water, you feel me? So, I, like need to stop. Literally I stop and I hear Angélica's voice in my head," take a breath..take another one..think about what you want to say, what you are feeling." [long pause]... and that is work, you feel me? Like that takes some real work!

Exhibiting appropriate behavior is a top priority for Gaby and many of the young women who took part in the focus groups. They shared how figuring out what behavior is deemed appropriate and which will have you look bad, takes so much energy. They talk about how it seems so "natural and easy" for most other students. But for them, it's a combination of exercising what they have learned as part of their communication skills.

Esmeralda: It's hard for me sometimes, you know? Como que no puedo encontrar mi voz cuando estoy en clase y todos estan contribuyendo y yo como muda! [Like I can't find my voice when I'm in class and everyone is participating and there I am like a mute!] And well, when the professor doesn't make sure to include me, then...como que...like no one else is going to check to make sure my opinion is included, you know?

Gaby and Esmeralda share different experiences that both make them stop and think about how to communicate in class. While Gaby is usually a bit more forceful in sharing her opinion, she is constantly aware of how she needs to temper her energy so as to not give more reason for her to be seen as an "angry woman of color." Yet, Esmeralda shares the experience of feeling silenced in class discussions, especially 
when professors do not make space for all students to be heard equitably. This includes those young women who feel that their voice does not matter because they have been taught in their schooling that the professor is always right (Valenzuela, 1999). It takes growing into the new mestiza consciousness to see that the very act of challenging what is considered the norm for communicating with professors and peers can be seen as changing the way that women, namely women of color communicate in higher education.

This is further compounded by the incidents of perceived racism that these young women described having experienced by their peers and professors. Minority students' fear of being viewed through a negative stereotype or confirming a negative stereotype about their marginalized group add to the level of sensitivity to how they interact with their peers and professors.

Esmeralda: There are times when you have to keep your thoughts to yourself, especially when we talk about anything related to diversity because I can just feel how they are all listening, waiting for me to mess up, to confirm that minority students shouldn't be here. It drives me crazy that I have to think about that, but I do. It's like if I make a mistake or do poorly on an exam or in class, it's not just about me. I honestly believe that the professors and other students will say, 'See, they [Latinos] are not smart enough to be here.' '....And well, I don't want to give them any more reason to think bad about us. And don't even get me started on being a first-gen student. Just the other day, this guy in my psych class was talking about how RHC is letting too many low-income students and first-gen students in, and how that is probably making the curriculum less rigorous or something like that. Can you believe that? Somehow because I'm poor and the first one in my family to go to college, that means I'm lowering the bar. Would he say that if poor and first gen students were mostly white? 
Racism impacts minority students in a manner that is insidious. The persistent preoccupation with thinking that how their race, gender, ethnicity, sexual orientation, or any other membership that is considered oppressed might be held against them, can negatively affect students' academic success (Mendoza-Denton \& Aronson, 2007). Suzie's experiences as a student in the school of science capture this very notion being one of few women of color in advanced science classes. "I always have to be on point. I can't make any mistakes because I'm it. I'm the only woman of color in my human biology course. If I mess up then it's about another minority student, another woman not being able to handle the science curriculum," (Suzie). Suzie, Gaby and Esmeralda provide personal experiences that illustrate what stereotype threat might look like for first-generation Latinas as they navigate RHC.

\section{Finding Their Way-Educación in Seminar}

Another common example that the mujeres described in the process of developing their Educación was their experience with the seminar courses, the Great Books curriculum, which all students must complete as part of their general education requirements. Seminar courses are an integral part of the curriculum at RHC and challenge students to engage in academic discourse that is Socratic, student-led, and where grades are based heavily on active participation in class. Regardless of major, 
every student must complete four seminar courses, as part of the common liberal arts curriculum. Throughout each of the focus groups, the young women described the level of frustration, anxiety, and determination to succeed in these courses.

Maria Luisa: Oh lovely seminar! I'm not even exaggerating when I say that I used to hate... I mean hate seminar. I didn't like how all of a sudden I had to learn how to seminar. Yes, it's a verb! Like, I would think I need to hella seminar to get a good grade.... Well, it's not easy. Como que se me hiso dificil buscar la forma to, you know, like find a way that worked for me in seminar. Girl, I hella had my books all written in, post-it notes everywhere. I had to be ready to defend my point. I was not gonna just let them shut me out.

From the perspective as a senior, María Luisa describes what most of the senior focus group participants shared in terms of finding a way that worked for them. Yet, within these shared experiences, all of the mujeres talked about how self-conscious they feel about participating in class discussions. They described feeling shoved out, shut down, and sometimes ignored over other students, namely white students.

Gaby: I know I bring it to seminar. I'm ready to throw down and get my point across, especially because, like I notice that my professor always looks to the same three people. They're all white and two of them are dudes. So, I'm always, like, busting into their discussion and I put my point across. And well, I guess I do this kind of stare down.... Yeah, like I stare at whoever is talking, like to get their attention... and then they pause long enough for me to jump in!....I'm telling you, y'all should try the stare down...

Esmeralda: I have to review my questions several times the night before each class. I have to, like, write them down like, how I would try to say it in class. That's the only way I can feel comfortable speaking up.

Suzie: Man, it hella bugs me that just when I'm gonna jump in and participate the stupid discussion jumps to something else. And I'm like, damn, can I have a minute to think please? 
The shared stories about seminar were endless in each of the focus groups.

Discussions about seminar ranged from frustration with it, to strategies to be successful, to a dialogue about how different the communication style was for them as Latinas.

They described how it seemed that the other students, namely white students, seemed to know how to engage in this type of communication. Essentially, they are describing the cultural capital that is traditionally validated in the culture of higher education.

Gaby: It was so hard for me. It makes me so frustrated to see other students, like, mostly the white students or the boys, be able to just talk. And most of the time, I feel like they're not really even saying anything important, you know, like they have no point.

Maria Luisa: When the professor just sits there and lets one or two people dominate the whole discussion, it just doesn't make sense. Like, how are you gonna sit there and put checkmarks next to people's names every time they talk and count that as participation. You know, I only say one or two things, but they really get people going. Like, why can't I get credit for starting a good discussion? It's like even if you're just talking to talk, that's good!. [throws her hands up exasperating]

\section{Educación - Resistance as Capital}

The culture of higher education is structured to value the cultural capital of middle- and upper-class families, a capital that carries status and power. And with the status and power comes access to opportunities for generational advancement in society, or in this case, advancement in the culture of higher education (Terenzini \& Rendon, 1994). It is in the process of learning the culture of higher education that first- 
generation Latinas in this study reflect on how their behavior, norms, and values of their cultural capital rub against those of the academy, yet also help inform how they resist the dominant culture as they develop their Educación.

Resistance theorists analyze how marginalized people navigate with the societal oppressions of poverty, racism, sexism, and heteronomativity (Bernal, 1997; Fine et al., 2004; Forham \& Ogbu, 1986; Giroux, 1983; Macleod, 1986; Solorzano \& Delgado Bernal, 2001; and Willis, 1977). Resistance includes how students use their human agency - the confidence and skills to act on one's behalf (Solorzano \& Solórzano, 1995) as they develop their Educación and educational success.

I use Solórzano and Delgado Bernal's (2001) framework of transformation resistance to analyze how the Latinas in this study use resistance as they develop their Educación. With a deliberate CRT lens, the framework calls for an analysis of how students' critique of social oppression and whether they are motivated by an interest in social justice. This framework resonates with how I come to see the first-generation Latinas define and develop their Educación. Figure 4 is the graphic representation of how Solórzano and Delgado Bernal's (2001) define the concept of resistance. The yaxis represents the degree to which there is a critique of social oppression, while the $\mathrm{x}$ axis represents the degree to which one is motivated by social justice when exhibiting oppositional behavior. The four quadrants each hold a varying degree of resistance, 
ranging from self-defeating resistance, which does not critique social oppression, nor is it motivated by social justice, to transformative resistance, which holds both.

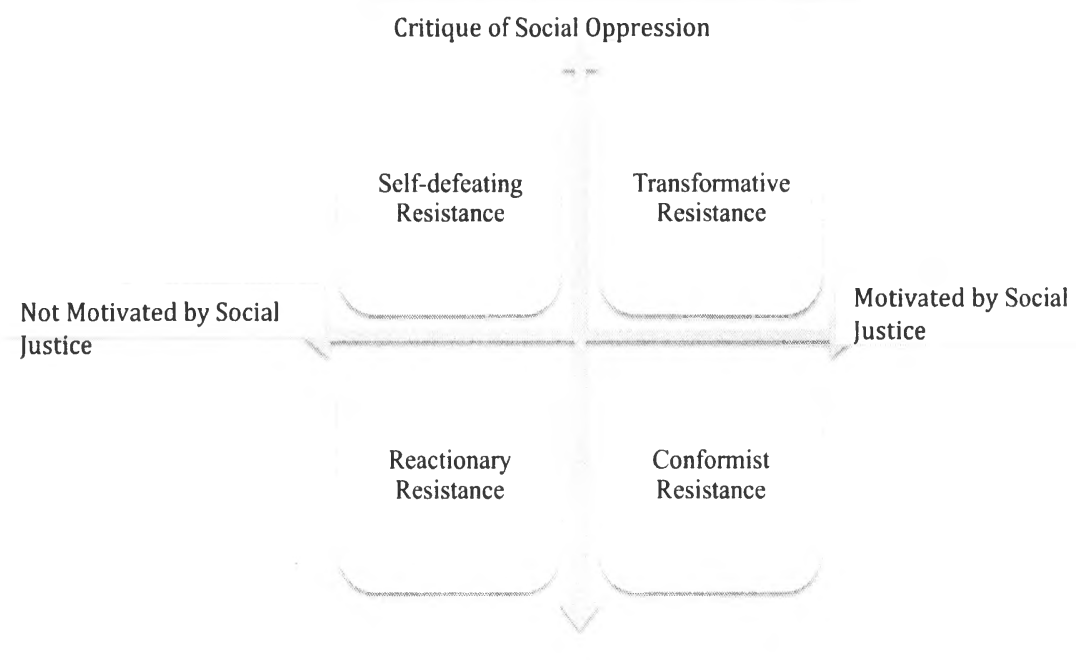

No Critique of Social Oppresion

Figure 4 Transformational Resistance Quadrants

Reactionary Behavior

Oppositional behavior is considered reactionary, not resistance behavior because

there is lack of a critique of oppression and motivation that is not rooted in social

justice. Many of the young women described how the Latinas who perpetuate

stereotypes about this student population cause more damage than they realize.

Maria Luisa: I have so many experiences with Latinas acting out. My sophomore year, I used to be friends with this one Latina. And she loved that all the white girls were afraid of her, you know? No le importaba si la querian o no. So, anyway...damn, long story short, instead of dealing with a conflict by talking it out, she did every kind of stereotype about hood Latinas that you can think of...she yelled at this white girl, then started pushing her, then she just went after her, like basically she beat the crap out of her, yelling how she was gonna kill her, and that where she comes from you get killed for acting stupid.... And 
the whole time, there was, like me and another friend that were trying to get her to calm down and other people were just watching and, like, encouraging her to keep fighting....All over a guy....

Suzie: There's this guy....he's Latino, but well I guess he doesn't consider himself Latino. Anyway, every time he doesn't do his work for class...he's always cracking jokes about Latinos being lazy or on cpt [color people timecode for late] shit. He's basically clowning on himself and making us all look bad because he's a Latino hating on Latinos. And when you ask him why he does that, he says it's no big deal...

Both of these excerpts exemplify what the young women discussed in each of the focus groups about students who perpetuated stereotypes about Latinos. In both cases, there is a Latino student who is illustrating oppositional behavior that lacks the critique of the social oppressions that perpetuate the stereotypes of Latinos. In both cases, the student acting out did so as a reactionary behavior that might have been for self-preservation; however, it further illustrates the pervasiveness of racism. In all of the focus groups, the young women described how angry it made them feel to see another Latino behave in a manner that maintains the status quo.

\section{Self-Defeating Resistance}

Students enacting self-defeating resistance might include the student who is critical of the dominant culture in higher education, but engages in behavior that leads to inadequate academic success or even dropping out of school.

Gaby: I come from the city, from the hood. And I came across a lot of girls that were gang affiliated and even though I wasn't in the gang, I was seen as one of 
them because I kicked it with them. Anyway, some of them were hella smart and all about talking back to the educational system, you know? Like they would challenge teachers and talk about how the types of books we read in school were whack and not about us folks of color... and I think back to them and I think of all the wasted promise. They could have been here with me, challenging this system.

Maria Luisa: That reminds me of how many raza I've seen leave RHC over the last 3 years. Hella people have left because they either didn't feel like they fit in or they didn't do the work. You know, like you can't be talking up a storm in a seminar class about discrimination and the institutional structures that keep our gente down and then get busted for actin' a fool or selling weed. That just proves the point that we don't belong here!

Gaby's experience of seeing her gang-banger friends "waste their talent, their promise," reinforces how students' self-defeating resistance actually reinforces the status quo. María Luisa's reflection gets at the nuances of self-defeating resistance strategies. On the one hand, students exhibit the ability to critique structures that perpetuate social oppressions, yet they also choose to act in a manner that reinforces stereotypes of students of color, of non-majority students, as "hood" and not serious about succeeding in higher education.

\section{Conformist Resistance}

Student who exhibit conformist resistance are motivated to increase the quality of their individual lives and that quality of life for their entire community. Yet, they do not critique the social oppressions or racist structures that act as a barrier to enhancing their quality of life. These students often are represented as those who seem to go 
through their daily college experiences, doing whatever they need to do to succeed. Some of the mujeres that responded to the online survey indicated that issues of racism, sexism, and hegemony are no longer an issue for minority students. They feel that because they have made it this far, then those forms of discrimination must no longer exist.

I don't think that there is racism and discrimination and stuff here at RHC. Look at me, I'm Latina and I'm about to graduate because I worked hard. I am the one who worked for it... and I think that us Latinos can prove that if you work hard enough you can accomplish getting a college degree (Senior Respondent, TR Survey)

This young woman's response was the most direct at describing how the system of meritocracy is alive and well. She firmly believes that her success is based solely on her work ethic. She does not acknowledge that there may be a chance that structures of institutional oppression exist to keep the status quo. The conformist resister is the one who believes that it is her individual hard work and determination that has allowed her "to beat the odds," (Wang \& Castañeda-Sound, 2008).

My goal is to become a pediatrician, so I want to get my M.D. I want to show the world that we're not all lazy, on welfare, or pregnant. (Sophomore Respondent, TR Survey)

On the surface, this young woman's comment seems to be about critiquing the social injustices and prejudices held against Latinos. But, this young woman is emulating the meritocratic analogy of pulling herself up by her bootstraps because she blames the lack 
of desire to pull up the boots rather than questioning the structural inequalities that exists when there are no boots.

Contrary to that example is Suzie's perspective of the benefits and sacrifices are to emulating the dominant culture.

Suzie: I feel like the people who are assimilating do have it, like, easier because, like, they do assimilate and, well...so you are losing yourself, like they lose but they win, too because they act like they're not really Latino, you know? They act like they're white, they dress differently, talk differently, and even cap on their own people. It's like they're hella proud that they are not like 'those minorities over there making it obvious that they are not white, not like the majority.'

She describes how these assimilating students may succeed beyond even her white counterparts in terms of academic and social successes, but their conformist resistance is based on further embedding the dominant hegemonic culture at RHC.

\section{Transformational Resistance}

When discussing curriculum and course selection, most of the young women shared how they look for courses in ethnic studies, women's studies, and sociology to get courses that are specifically about people of color, especially women of color.

Maria Luisa: My first soc course sealed the deal for me. It was my freshman year, spring semester, I think... and I had seminar and then would go into my social problems class. Talk about night and day, like, in seminar we were analyzing St. Augustine and then I would roll into my soc class, which had a diverse group of students and we would analyze issues like racism, sexism, classism, and all that stuff I felt, like, empowered in that class... and pues, desde ese tiempo ya era una soc major [well, since that time I have been a soc major]. 
Gaby: Since I started out as an accounting major, damn, like we only talked about ledgers and stuff. [laughing] Talk about not having anything do with our gente, people in general. So, when I took and intro to soc course, I was like, what the hell!...I like this, being able to connect to real-life issues that impact my community, you know? And now I'm trying to figure out if I can do a double minor in sociology and women's studies, so I can balance my accounting major.

As described earlier in this chapter, it is not uncommon for students of color to look to programs, such as Ethnic Studies and Women's Studies to find the academic space where they can feel empowered and learn about how to better their own communities. RHC requires that students take one diversity course as part of the general education requirements. Therefore, unless students make the effort to choose courses that are about people of color or women, they could technically just take one course and meet the diversity requirement.

Often it is the students who are enacting transformational resistance, that drive institutions to review the institutional curriculum to provide more courses in issues of equity, diversity, and inclusion. Since the early 1960s when students protested to demand for Ethnic Studies programs in California, students continue to pressure institutions of higher education to meet the curricular needs of diverse student populations. RHC has had Women's Studies as a major for just over 10 years and Ethnic Studies has only been a minor for the past two years. Women's Studies has grown as a major with a wide diversity of course offerings. Outside of the core major Women's Studies courses, students in this major must take courses in multiple 
disciplines, emphasizing the importance of inter-departmental collaborations. Students

who are current Ethnic Studies minors are presenting at academic senate meetings to persuade RHC faculty and administrators to make it possible for them to have it as a major.

Esmeralda: You know, that's why there was a group of us that got together last year... and we camped out on the main lawn. We stayed out there for over a week. We did many things to try to get it better for all of you who came after us. And you know, you shouldn't care just because you're Latina, but because of regardless of how long you've been here or if you're a student of color or if you're poor or even a first-generation student...we...well, we sacrificed ourselves, our grades, our health. All of us came together, GSA, LASA, HaU, $B S U, A P A S A$, all of us... We fought for OUR voices to be heard, so we could be on campus committees that plans all the diversity programming...so we could know what to do when someone acts with discrimination against us, or anyone... Like, we even have an official 'Acts of Intolerance' protocol for the college now. We fought to have more resources given to the ethnic studies program and for more intensive recruitment of faculty of color. We even fought of a student-led peer facilitation class so that we can teach ourselves how to be agents of change, to help one another build a multi-cultural community....I don't regret it at all. I'm proud of what we did, even if some people thought it was too extreme.

Esmeralda describes here a student protest led by diversity student organizations came together after a series of racist, homophobic, and xenophobic acts against students, mostly by other students, were made public. Their protest slogan, "Our Struggle is Tied With Yours," illustrated to the larger campus community how marginalized students were standing together fighting for social justice and equity. For over one week, they held daily open sessions sharing their personal experiences of discrimination, marginalization, and alienation. Esmeralda does not describe herself as a 
political activist, but rather as "a student who cares deeply about the social injustices that impact people of color, women, and marginalized groups in general" (Focus Group Interview 1). Yet she and the other students welcomed anyone who wanted to sit down and join them to hear about their perceptions of injustice that were taking place at RHC. Each day they would invite, or challenge, an administrator to come out and join them for an open discussion session. Behind the scenes were faculty and staff members assisting the students in their discussions and negotiations with campus administrators. Among their list of demands was the creation of an ethnic studies major/minor, increased diversity in the core curriculum, student-led/designed courses, and increased diversity in the faculty, staff, and administration. Currently, a proposal for ethnic studies to become a major is before the academic senate and a new tenure track faculty member was recently hired to be the Director of Ethnic Studies.

Throughout the focus groups, members who were at RHC during this studentled protest shared how that event impacted them.

Suzie: I didn't know what was going on at first. I just saw tents, a bonfire ring, and whole grip of students who were out there talking, chanting, even singing. I avoided the whole scene for a couple of days because it just felt like too much, you know? Anyway, when I finally stopped in late one night to talk to them, I immediately knew that I needed to be a part of it all. That night, I packed a bag, borrowed a sleeping bag and moved into El Campo.

Gaby: I really wish that I had been here when this was all going on. I hear about it [Our Struggle protest] in a lot of my classes and from friends who are older. They talk about how hard it was to do that and still do school. Like, this one girl told me how they would have study sessions at night to still handle their business..... didn't want to give anybody any reason to not listen to them. 
Maria Luisa: I supported the Our Struggle students, but didn't join them in El Campo. I went everyday to the open circle talks and would stop by and say hi.... but I had to keep working. I work at the IC [diversity office on campus] and needed to keep my check coming in. So, I would bring them food from Saga [campus dining hall] and some food that I would cook at night. That was my part...I' $m$ grateful for what they did and that I could be involved, even if I wasn't one of the ones who was living in tents.

Students engaged at different levels and there was an understanding that however anyone could contribute was sufficient. Esmeralda was deep in the organizing group and shared about how even her health was impacted by the action, yet still believes this sacrifice was worth shedding light on the lack of diversity in the curriculum.

Gaby, along with many first year students in the focus groups, shared how they wish they could have been here to be a part of it all. They also recognize that they have opportunities today because of the hard work and sacrifices of students who came before them. Many of the junior and senior women in the focus groups who did not participate actively in the student protest, shared experiences of how they would support the student protestors by standing up for them in classes when they were being criticized. I see these acts as transformational resistance because they interrupted the daily discourse in the classroom to advocate and support their hermanos/as who were camped out on the lawn. They exhibited what Anzaldúa (1987) calls la facultad, which is "the capacity to see in surface phenomena the meaning of deeper realities, to see the deep structure below the surface" (p.38). By speaking up in their classes about the cause of "Our Struggle" they challenged their faculty and peers to stop and think about how 
minority students live at the margins in a predominantly white institution. All of these different levels of engagement and responses show how resistance takes many forms, especially for first-generation Latinas at RHC.

"With a deeper level of understanding and social justice orientation, transformational resistance offers the greatest possibility for change," (Solórzano \& Delgado Bernal, 2001, p.319). There is something in the process of integrating the theoretical (academic) and the social (cultural) experiences that enable the firstgeneration Latinas in this study to view their education as a form of resistance.

Gaby: Just this past Tuesday, the Mesherle case (well-known Bay Area case of the shooting of Oscar Grant by BART police officer Johannes Mesherle) came up in my English class. I got so heated because these two guys, white guys, eh, were going on about how Mesherle was innocent and that Oscar Grant was just another 'thug' from the hood. Girl, I came so unglued! I was, like, do you even know what you're talking about? Have you been following the case and know about it or are you just talking out of your ass? I know I shouldn't have said 'ass' but I was heated.

Maria Luisa: Like, the Mesherle case.... We were talking about social perceptions and some people in my class said that some people just take the race thing too far...I literally had to take a deep breath and tell myself, don't go off on them, just school them. So, I brought up the fact that the issues of poverty, racism, and white privilege were a part of this whole case. It matters that a white officer shot a black man because that's what society expects...that black men are dangerous criminals...

Gaby: Oooh, I was fuming! .... because they were just talking without any kind of consciousness about the, like, institutionalization...Is that a word?...you, know, the role that racism and white privilege have in our society. It's no hidden secret that most of the poor people are folks of color...that they live in Oakland, and not the hills, but down in the bottoms and West Oakland. It's because of racism and white privilege that fewer people of color own homes, that fewer people of color get a quality education, that fewer people of color actually get to 
a point in their lives where they can climb out of a deep hole...Nah, they (white students) don't want to hear about that because then they have to question if they really 'earned' what they have, you know?

Transformational resisters will challenge not only themselves but those around them. "They oppose a schooling process that disrespects them; they oppose not education but schooling," (Valenzuela, 1999, p.5). They will keep the dialogue about social oppressions and injustices on the forefront of every conversation, recognizing that there is a larger system at play. Gaby's passion about issues of discrimination is further fueled by the fact that she comes from a community where class and race cannot be separated. María Luisa's words and actions are a direct challenge to white women, men, all those in positions of privilege. Audre Lorde addressed this issue in an essay published nearly 30 years ago. She wrote, "my anger is no excuse for not dealing with your blindness, no reason to withdraw from the results of your own actions," (Lorde, 1984, p.67).

As the young women discussed how they felt the need to temper their thoughts and reactions, especially with such a controversial case, they began to challenge one another to no longer be silent. They started to encourage one another to find their voices as women of color to stand up for issues that intersect at the very core of what it means to be a person of color in this society. It was at this point in every focus group that I witnessed these young women engaging in transformational resistance. I began to see and hear how, as first-generation Latinas, they were defining how their Educación as a 
college student is rooted in bridging their family, their communities, and their lived experiences with the academic expectations at RHC. This intersection provides the foundation for the next theme on owning their femininity.

\section{Feminidad}

Each of the young women shared personal stories about their experiences as women of color and the impact it had on them at RHC. They discussed how the different parts of their identity, including how they understand what it means to be women, pose serious challenges to their success in higher education. Within a CRT lens, the objectification of women can be seen as women being considered property. And while a CRT lens holds that race trumps all when it comes to oppression, the mujeres in this study described how their feminidad is challenged to fit the essentialized notion of Latina women.

The stereotype that Latina women are curvy, sensuous, and voluptuous is problematic because it romanticizes what femininity looks like for an entire cultural group of women, while preying on the cultural norms and traditions of the Latino community.

Suzie: Oooh, I hate how because I'm Latina, I'm somehow supposed to be all sexy and shit. Um, hell no! That's not me. I wear make-up when I feel like it, do my hair when I feel like it, and I'm sure in the hell not gonna dress all different because that's what people think I should wear. Seriously, I've seen some females wearing tight, short dresses with big ass heels who can barely walk. What is that about? Not me. And, please... don't assume I'm straight! 
Gaby: You know, it's only been since I've been here that I'm more aware of it all. Like back in the city [San Francisco], you dress to get around. So I hella wear sneakers, jeans, hoodies and yeah my big hoop earrings, make-up and stuff. I think I've only worn heels once for prom and a couple of times for some bailés or a quinceañera or something like that. And damn, yes my booty has gotten me lots of attention, too much attention. Just because I have a big booty doesn't mean you can comment on it, slap it, touch it. No, it is a part of me, yes a beautiful and sexy part of me but it doesn't define me, who I am, what I'm about, you feel me?

Research on the objectification of women is not a new phenomenon (Cleaver, 2003; Mohanty, Russo, and Torres 1991; Lorde 2002; Tintiangco-Cubales, 2007; and Wing, 1999). Moreover, Latinas' portrayal as the stereotypical curvaceous and exotic women, contributes to a superficial understanding of Latinas in general. Beauty and strength are defined by the physical attributes of women, including their hair, size, style, and the manner in which they move. Admiring the beauty of women, especially women of color has become about sex and often reduced to that which only takes place in the bedroom. Audre Lorde (2007) described how women have been taught to ignore all of the erotic that comes with being a woman. She wrote, "When I speak of the erotic,...I speak of it as an assertion of the lifeforce of women; of that creative energy empowered, the knowledge and use of which we are now reclaiming our language, our history, our dancing, our loving, our work, our lives," (p. 55). Lorde challenged the notion that the erotic and sensual is just physical, and that it includes the emotional, which is the deepest, strongest within ourselves. 
There is a deep connection for women when they allow themselves to feel this inner eroticism, this inner space and belief that they are worthy of what truly brings happiness. "For once we begin to feel deeply all the aspects of our lives, we begin to demand from ourselves and from our life-pursuits that they feel in accordance with that joy which we know ourselves to be capable of" (Lorde, 2007, p.57). The young Latinas in this study all shared aspects of their lives that describe the binary of being a woman and being strong.

María Luisa: I'm know how being a mujer can bring me....pues mucha felicidady orgullo. Guys say they want a strong woman to be their partner, but when they get that strong Latina... well when they get me, all they want to do is squash who I am and make me weak and small. I used to think that making myself small...literally and figuratively.... that somehow that would mean that I would always be happy. But it's not like that. Guys back home are intimidated by the fact that I'm in college and the guys here are all caught up in having the prettiest girl, that they often just see me as an angry woman of color or a manhater. And you know what? I used to let them. Not anymore. I want to be loved because of mi cultura, mi lenguaje, mi familia, quien soy, eh..... and the fact that I'm trying to become educated and earn my college degree. Why do I have to choose between one or the other?

María Luisa captures the nuance of what it means to honor the eroticism in being a woman, while also honoring that she wants more out of her relationships with partners, with the world. She allows her identity as a woman, as a Latina to begin to inform how she views the world. This lens is one that is unique to her and only her. Yet the more she shares her perspective, the more she will challenge those who want to be in relationship with her to see women differently. The mujeres in the focus groups shared 
so many instances that resonate with María Luisa's experiences. Loving María Luisa means loving all the parts of who she is, including her identity as a Latina, a college student, a poet, a sociologist, and a strong woman. Ultimately, loving a first-generation Latina in college means loving all of the intersecting parts that inform how she views and moves throughout the world.

\section{Good Daughter and Educated Woman}

There are cultural expectations in a Latino family that young women are well behaved, well dressed, and of high moral values. Often, the behaviors associated with being bien educada (well educated) hold Latinas to more traditional gender roles of behavior and appearance (Rodrigúez Martin, 2010). Esmeralda's experience captures what a majority of the focus group participants revealed about their transition into college and the impact it had on their identities as young Latinas.

Esmeralda: I grew up being told that I needed to be una hija buena [ a good daughter] that dresses properly, is well groomed, and behaves with high morals. Mi amá would always tell me that she didn't want us to be all greñudas [uncombed] because then people would think bad things about us. Siempre tenia que estar bien vestida y bien peinada [I always had to look well dressed and well combed]. She didn't want any bad attention drawn to our house. If we looked good then everything would be okay and we would be left alone from the school, de las chismosas[from those who gossip], and boys would respect me. Mi amá would never let me wear anything revealing or tight, even when all the other girls in town where doing the opposite. That was for las andareagas [girls who hung out in the streets]. My mom thought she was teaching me about being modest, but what I took from it was be quiet and invisible as much as possible...try to blend in... 
Unfortunately, Esmeralda voices what many of the young women in the focus groups shared about receiving conflicting messages about their college endeavors. They shared how they were told to dress, behave, and speak properly, to reflect positive images about their families. Yet, they were also told to do well in school, without realizing that often the behaviors of being bien educada are in direct contradiction with being a successful student, which often require breaking the "good behavior" rules to be heard in an academic setting.

Suzie: It was hard for me at first to get into the whole discussion, like seminar style classes. I wasn't used to being forceful with my opinions. And by forceful, I don't mean like making other people think like me. I'm just talking about the whole get your voice out there in the discussion kind of forceful....

Esmeralda: Most of my classes are discussion based, so I have to think about speaking up all the time. My voice is naturally soft and people think that because I have a soft voice, I don't have anything to say.

Maria Luisa: My mom tells me that all the time que no soy la misma muchacha que se vestia bien all done up with make-up and stuff. I mean, I've always been pretty open about my ideas, but only since I've been here at RHC...it's been these past three and a half years that I've learned to speak up more about people seeing me for who I am on the inside not just the outside. Why do I have to be all peinada y vestida bien para que me escuchen [combed and dressed well in order to be heard]?

Utilizing a critical race feminism lens, it is necessary to problematize these contradictions and view how they further push Latinas into the margins. "The fact that women of color are situated within at least two subordinated groups that frequently pursue conflicting political agendas...is a dimension of intersectional disempowerment which men of color and white women seldom confront" (Crenshaw, 1995, p.360). 
Montoya (1999) and González (2001) further provide insight into the "braiding" of the personal, academic, and cultural traditions of Latinas, known as a concept of trenzas (braids). The term trenzas truly captures the linguistic nuance of Latinas "braiding" their multiple identities.

\section{Feminidad: Oueer Latinas}

Although I did not specifically ask the mujeres to identify their sexual orientation, it was something that came out in each of the focus groups as they talked about being a woman. In retrospect, I am pleased that it came out organically because the young women who "came out" as not being heterosexual broadened the discussion around the concepts of feminidad and bien educada.

Suzie: I don't consider myself straight or gay, really. I'm queer..trying to figure myself out. This is the first time that I've been able to talk about my sexuality and not feel like I have to talk about guys. It's just not okay, back home, being a lesbian would bring so much shame...I just don't think I could ever tell my family that I think I might be into girls...And you think it wouldn't be a big deal, you know, being here and stuff... But, like it takes so much energy to figure this all out...

Suzie's words provide an insight into the amount of time and energy, queer or questioning Latinas described during the focus groups. One young woman from the focus groups describes "feeling trapped into a box where her family is telling her that to be a woman means wearing dresses, make-up, and liking boys." Another mujer told the story of being given the silent treatment for six months from her family when she told 
them she might be queer. As the discussions continued, I began to notice that the young women were describing being Latina as being a "good girl" who follows the rules and makes her family proud, which would not include anyone who did not identify as heterosexual.

Suzie: I just didn't do all the things Latinas were supposed to.... like, I didn't cook and clean for my dad and brother. I didn't worry about being out in the streets hanging out with my friends. I just did me... but quietly, I guess.

As a practitioner scholar, I would not consider my work genuine without sharing a part of my own lived experience that surfaced as I reviewed the data index for this particular section. And while I have much to say about the experience of being a Latina woman who is married to another woman, I will be brief so as to keep the voices of the mujeres strong and loud. The experience that resonated for me as the ultimate intersection of feminidad and sexual orientation was during my senior year of college. There we were, my "friend" Maria and I home for the weekend. As far as my family knew, she was my best friend and her presence at another family event was not unusual. This particular visit home was different because my Ita was ordering me to be up early the next day to make breakfast for the son of a family friend who was in town from Mexíco. When I refused, I was promptly scolded by my Ita, the matriarch of our family, my mother, and all of my tías for not being una buena hija. This was supposed to be an opportunity for me to be courted by an eligible bachelor, get married, and have kids. There I was, standing in the middle of the kitchen, being scolded by my family about 
what it means to be a woman in our familía, while looking at the bewildered and hurt expression on my girlfriend's face. I felt raw and exposed and reminded of this painful experience as I listened to the queer or questioning Latinas talk about the diversity in their own perspectives as mujeres.

\section{Transformational Resistance Through Feminidad}

Chicana feminist scholars view the conceptual grounding of trenzas as the social process of la cultura mestiza (Delgado Bernal, 2000; Hernández-Truyol, 1997;

González, 1998b, 2001). It is the work of these feminist scholars that paved the way for me to conceptualize Ser Educada as the state of being for first-generation Latinas as they become college educated. Ser educada is about Latinas harnessing the energy that comes from their rich lived experiences as women of color and bleeding it into the culture of higher education.

The young women in this study shared experiences that I consider as examples of transformational resistance, (Solórzano \& Delgado Bernal, 2001), examples of the straddling of multiple cultures and identities in Anzaldúa's (1987) description of mestiza consciousness.

Maria Luisa: Last year, we had a speaker come on campus during Women's History month. I can't really remember which department brought her, but I had to go for one of my women's studies classes. Anyway, we went and I was so pissed! This lady, some doctor or Ph.D or something, came and talked about having that surgery, como se llama?.... that ... ay yay ay!.... oh yeah, gastric bypass! She actually talked about how that was healthy, especially for women 
who come from communities where the food is not that healthy! I was like, 'what the hell did she just say?' Anyway by the end of the presentation, all I pretty much heard was blah, blah, blah...women of color were trying to have this surgery in larger numbers proving that obesity is an epidemic for us Latinas. I remember writing my critical analysis for my class and just going off on a woman, a white woman, talking about what was healthy for women of color. And my professor, she talked to me after class one day and told me that she appreciated my perspective and that she wanted me to lead the class discussion next time. ..basically, set up a lesson that would talk about the health and body issues for a future class. At first, I didn't want to do it, but then after talking to a couple of my mentors, here on staff, I realized that I just had to do it. Anyway, that talk, lesson... whatever you want to call it, that work led to the Counseling Center wanting to set up a group just for women of color around body image and issues. And they asked me if I would help, you know, like run it. Me? I'm not even a psych major! I'm a soc major!

When I think about the amount of strength and courage it took for María Luisa to write about her experience at that campus wide presentation, and then to run a class lesson with her peers, I am reminded of how resilient our students are. She may not have camped out in an all out protest, but she seized the opportunity to challenge the norms about what women should look like and challenged that all women want and should be thin. She provided a genuine reaction to her experience as a Latina, a selfproclaimed, "brown, round, and proud" woman. This act of transformational resistance (Solórzano \& Delgado Bernal, 2001) directly addressed the a system that has oppressed women into believing that being thin is the standard of beauty Audre Lorde (1984) provided a nuanced insight into the intersection of being a woman and a person of color. "As women, we must root out internalized patterns of oppression within ourselves if we are to move beyond the most superficial aspect of social change" (p.69). 
The type of change that María Luisa was demanding of the speaker, her professor, her peers, and ultimately the institution of the college is one that called each of them to question their own assumptions. For the administrators, faculty, and staff who bring speakers to our campus, she challenged them to think of their assumptions of women of color and what they believe these women most struggle with. For her peers, especially those who believe that beauty is not round and curvy, she challenged them to think about the differences between women. Not all women are the same, especially when you look at the intersection with race. María Luisa expressed her anger in a manner that made the whole experience raw. This act of transformational resistance resonates with Audre Lorde's (1984) perspective on women, anger, and guilt: "I cannot hide my anger to spare you guilt, nor hurt feelings, nor answering anger; for to do so insults and trivializes all our efforts. Guilt is not a response to anger; it is a response to one's own actions or lack of action.

Maria Luisa: The professor who brought that speaker... she came up to me a few weeks later. I guess my women's studies professor told her about my anger and stuff....and well, Professor Davis [pseudonym] came up and said that she was very sorry and that she felt guilty for putting me through that. I told her, don't feel guilty, do something....Si, eso le dije! ... and after I said it, I kept thinking about my mom telling me to respect my elders, my teachers. And then, I checked myself...I deserve to respect myself and women of color everywhere, so I'm glad I said what I said.

The process of María Luisa being able to state, "I deserve to respect myself and women of color every, so I'm glad I said what I said," is a kind of pedagogy that Elenes et al. 
(2001) describe as one that instructs a channeling of female energy into self-

direction/self-determination for living and practicing ethical standards, respeto, and educación (Delgado-Gaitan, 1990; Valdés, 1996). The young women in this study describe how they constantly have to bridge the cultural values of familia, respeto, $y$ communidad, with the values of higher education.

In each of the focus groups, I kept hearing how being educated, for firstgeneration Latinas, is so much more than simply earning a degree. And it even is more than the expectations of being bien educadas. The concept of Ser Educada is the daily experience of having to navigate being a first-generation, person of color, who is a mujer, as she works to be successful in higher education.

Suzie: It's, like, very emotional and that emotion is a lot of energy that is tiring. Switching from being what I was told I had to be, you know, like bien vestida, peinada, y con much respeto, to being here and literally battling to get my voice heard in class discussions. That's just tiring and challenges me to cope with it.

Esmeralda: There is so much emotion with making our transition between the type of life and existence that you come from and then having to figure out the type of life that college is like. My amá would flip out if she saw me dressed in sweatpants and stuff for class. You just don't do that. And I'm like, I don't have time to get all dressed because I need to study and read to get ready for class. It's like a different kind of ready, me entienden?

Gaby: You don't have to be masculine, but you do have to be aggressive. But the fact that you are a Latina and that you are a minority and a woman in the whole class which is mostly white and full of men, so yeah, you really have to get out there. If my family, especially my mom, saw how I am in class they would probably think that I am being rude and disrespectful and stuff But if I don't get into the discussion then it's over for me in some classes. Participation is big here. 
As young Latinas, the young women share about how the cultural expectations to be respectful and well behaved do not align with the college's expectations of being active in class discussions. For many of these young women, and students of color in general, they are less comfortable with voicing their thoughts and ideas because norms of academic discourse are so different from what is expected from them from their family culture. This is also evident when they return home for weekends or for a break during the school year.

Maria Luisa: Now that I'm a senior it's different because my parents have seen me grow over the years. But before, I can remember feeling weird when I went home because I got so used to analyzing and discussing ideas in class and then I would go home and try and talk like that... My parents were, like, que es eso? Porque estas hablando asi, muy no se como, como creida [What's that? Why are you talking, so, so conceited?]. And I remember feeling hella embarrassed, like, damn, I just tried to shut my parents up by critiquing their side about why they didn't want me to stay out late or something stupid like that.

Gaby: Yeah, so I'm kind of, well, I don't like what just happened like this past weekend. I went home and was hanging out with some of my girls... and yeah, so they started asking me about boys and if I was getting hit on or if I hadn't gotten together with anyone. Three of my girls are prego.....I started going off about how women are objectified as sex symbols and how just because everyone else is getting pregnant that doesn't mean that all Latinas have to get pregnant and stuff. Anyway, long story short, they started calling me white-washed and saying que era muy creida y quien sabe que otra cosa [that I was stuck up and who knows what else]. And I just kept saying that I wasn't being creida, but that I see now how woman are being trained, you know, to be homemakers and the rule followers. Like...our brothers aren't being told any of this....

When María Luisa and Gaby took their newfound skills of critical thought and discourse, they were seen as being creidas [conceited] and disrespectful, complete 
opposites of being bien educadas. However, the young women in the focus groups also shared how they kept sharing their thoughts and ideas even if, they were first met with disapproval that is described by Gaby and María Luisa. All of the young women described how they were persistent in not "giving up on family or friends from back at home."

Suzie: Now when I go back home, I'm aware that how I talk and discuss things with people here are just as valuable as how I talk about things back at home. Like, before I used to think that my friends and brother didn't want to hear it.... didn't want to hear about college and stuff....but I realized that he just wants to relate to me, you know?.... like know that I'm still me...still Suzie....

Gaby: I just gotta bring it.... when I'm home or here...I gotta bring it and talk about how I see things. I really try to figure out how what I'm learning in my soc classes and even accounting relates to my community back home. Yeah...that's what I have to do because I am here and there.... a la mismá vez [at the same time]....

Here is where I see Ser Educada as a concept that is in motion, never quite

complete. First-generation Latinas constantly navigate the expectations of women

depending in which world they walk.

Maria Luisa: If you asked me this when I was a freshman or even a sophomore, I probably would have told you that I'm just here to get my college education. Now...I'm about to graduate... and I don't think you can just be in one place at any point in time when you have knowledge. Knowledge is about learning all the time, so you can just be okay ya termine porque se esto o eso otro. I am in the progress of gaining knowledge, every day all the time. Y todos los dias, pienso en como es ser una mujer, una hija, una hermana, una mujer educada.....dang! that's a lot of thinking! [laughs]....con razón estoy cansada y no me peino todos los dias! [And every day, I think about what it means to be a woman, a daughter, a sister, an educated woman....dang! that's a lot of thinking! [laughs] ...no wonder I'm so tired and I don't comb my hair everyday!] 
In reviewing the mujeres' experiences and how they might be seen as forms of resistance, there were a plethora of examples that show how each and every day, they are placed in situations where they are aware of issues of social justice and inequality. While they might not describe themselves as social activities, their words, their experiences, show how they move throughout the quadrants of resistance (2001). Their lived experiences are never static, always presenting them with situations in which, they are reminded of what it means to be a first-generation college student, who is also a woman and Latina. It is the intersectionality of these aspects of their identity that lead to the next finding of hermanad (sisterhood).

\section{Hermandad - Sisterhood}

In all four of the focus group interviews, the mujeres exclaimed that this was the only time they were in a room full of Latinas in a non-social setting. There was an immediate sense of relief in having a safe space to share their experiences as women of color, as Latinas.

Maria Luisa: I feel hella comfortable being here right now, maybe cuz I came from a school that was mostly Latinos. I' $m$ mad happy right now to be here because I'm surrounded by white people, white women all day long. Don't get me wrong, I appreciate being in classes and stuff with them, but this right here, this is the real deal. Like, I feel like I can just break it down and each of you would understand me. Pues, como que being here and seeing all these Latinas in one room, I feel comfortable... like to just put my voice out there... 
Gaby: This is good, you feel me? Like, I feel hella comfortable and I don't feel like my guards are up, como que hasta puedo hablar en español or even Spanglish...that's nice for a change, you know?

Esmeralda: Siento familia. I feel like even though I didn't know all of you before today, we are sisters, hermanas...getting our education on...

"The paradox of life on the Borderlands for the mestiza is that this place, this free space of consciousness, is the site of her worst battles with racism, sexism, classism and heterosexism, but paradoxically, it is also the place of her greatest strength" (Martínez, 1999, p.47). I repeatedly heard the young women share how even though there were challenges with being a woman of color at RHC, there were also so many blessings. They talked about how being in a room full of Latinas with permission to talk about issues that impact them as a group and individually was "empowering," "comforting," and "affirming."

Suzie: Being here with a group of Latinas means that I don't have to explain too much...that I can just speak freely...en Inglés or en Español... you know...I feel really strong right now....

Esmeralda: I feel like I can be open and talk about everything Latino.... musica, comida, valores, todo....

Although the women do not state it directly, what they allude to is the safe space to be bi-cultural. They can be both the Latina from home and the Latina in college within this space. Delgado Bernal (2001) provides a unique analysis of how biculturalism and bi-lingualism are aspects of the mestiza identity. She provides a Chicana feminist perspective that honors the culture of the home and the culture of the 
academy. "As a mestiza, standing at the crossroads and trying to balance different cultures can be challenging, exhausting, and sometimes isolating" (Delgado Bernal, 2001, p. 631).

Gaby: Before I came here I was literally tired ....tired from lack of sleep because I was doing homework....tired of having to work and go to school... and mostly tired of having to hold it all together...I finally, well, pues I feel like I can just let go and do me with all of you Latinas.

Most of the young women who responded to the online TR survey $(n=141)$ stated that they were involved in some type of campus group or organization. One of the most prominent groups on campus is Hermanas Unidas (HaU), which is part of a national group that provides support and advocacy for Latinas in higher education. Many of the young women shared how being a member of this group makes them feel comfortable, even with the drama that comes with student organizations. The "drama," as the young women referred to, describes the in-fighting that sometimes happens among the Latinas at RHC.

Maria Luisa: I don't know why it happens, but you know that some females be talking hella shit. Don't we have enough stacked against us that we don't need to bring each other down. I've lost too many friends, too many Latina friends because of drama and gossip over stupid stuff that doesn't even matter....

Esmeralda: I feel like other Latinas talk about me because I'm more traditional in some ways. Like, I'm never going to be one of those girls that dates a lot of guys at once. And just because I want to get married and have a family after I get my education doesn't mean that I don't care about breaking gender stereotypes and stuff 
Gaby: I'm not even gonna front about this.... I just got over a big fight with another Latina over some mess with a guy. And I wish that I was over it enough so we could talk and figure stuff out, but I'm not....

Suzie: [Sigh].....there's just too much shit-talking between Latinas. If it's not because someone doesn't wear make-up, it's because someone wears too much make-up. Or like when some Latinas make fun of Carmen because she matches all of her clothes and piochas como las humildes muchachas del rancho [and hair accessories like the humble girls from the ranches in Mexico].... that's just cutting up another Latina because they're different...

Every single one of the young women shared an experience of the drama that exists among the Latinas at RHC. It is the conditioning of years of racism, classism, and sexism that attempt to keep women from liberating themselves of the patriarchal structures in society. Although there was much discussion of how much conflict exists within the Latina community, the mujeres also described how having strong mentors has helped them work through difficult situations.

Hermanas Unidas is one of several student-driven groups and programs on campus that provide support and mentorship to marginalized groups of students. The mujeres in the focus groups described how being mentored by older female students of color helped them learn how to navigate RHC.

Gaby: My peer mentor, she was my peer mentor in Aim High [pseudonym] ...was, like someone I could go and talk to, you feel me? Like, I could relate to her. She taught me about how to use the resources on campus and how to ask for help. I guess, I'm one of the lucky ones who had a mentor. Because even last weekend when a friend of mine got transported to the hospital for alcohol poisoning, even then, she was the first person I called... 
Gaby's experience exemplifies the strength of support and encouragement that many of the young women described in having a mentor they considered una hermana. However, they were adamant to include Latina faculty and staff as key sources of mentorship and hermandad.

Maria Luisa: I don't even want to think of how alone I would have felt if I didn't have the mentors and role models that I do in women like, Juana and Marisol [pseudonyms]. They, like show me how being a strong, educated Latina can look different for all of us. I wish we had more of them...porque, well if y'all call on them as much as I do... they must be hella busy!

Esmeralda: I know that the Latina faculty and staff that I have met here are going to be women that I keep in my life. I respect and appreciate their guidance and support.

Suzie: Dang! Like, it feels real good and comforting to have a female, an older Latina show me something different. Like, I mean, it's tight to think about how they used to be like us starting in undergrad and stuff... and now, they have like Ph.Ds and stuff...

Gaby: They get it, you feel me? I don't have to, like, explain about coming from a Latino family because they get it... all of it, the pressure, the pride, the expectation that family has on us and the expectations that we put on ourselves. I really need that in my life...someone who truly gets it because they, like, lived it...

First-generation Latinas want and need faculty and staff who are representatives of them and serve as mentors and role models. I have come to understand hermandad as the relationship between first-generation Latinas in general, regardless of social location. This form of feminist critical pedagogy is what Adriana Hernández (1997) describes as a "life project producing diverse forms of knowledge, theory, and multiple subjectivities contesting domination and oppression while also working through the tensions among 
them," (p.19). By acknowledging that there is opportunity for hermandad in relationships with their peers and with faculty and staff, Latinas are able to recognize "emancipatory feelings, and the freedom not just from power over us, but much more, freedom of our power over others" (Hernández, 1997, p.22). The young women described how having the freedom embrace their home culture with their academic culture is made possible because of the hermandad they have experienced.

\section{Summary and Synthesis}

The educational experiences of first-generation Latinas at Rolling Hills College provide a unique perspective on the resistance strategies these mujeres use to persist in a PWI. Chapter four of this mixed methods case study started with a report of the quantitative findings from the Campus Climate Survey and the RHC Longitudinal Data, which provide insight into the experiences of oppression, as well as the academic persistence of first-generation Latinas at Rolling Hills College. First-generation Latinas represent $81.8 \%(n=253)$ of the overall Latina student population, which totals 309 women. Overall, the quantitative data show that first-generation Latinas take longer to graduate, are on probation at higher rates than white women, and graduate with a lower cumulative grade point average than do white women.

The testimonios of Gaby, Esmeralda, Suzie, and Maria Luisa represent the lived experiences of the 141 first-generation Latinas who responded to the Transformational 
Resistance Survey. More specifically, these four exemplars provide the voice for the 24 mujeres who took part in 1 of 4 focus groups over the fall 2010 semester at RHC. It was through their voices that I was able to articulate and define the concept of Ser Educada, which is the daily work of being a new Mestiza, who is conscious about harnessing the cultural energy and wisdom of being a Latina to help navigate the culture of higher education.

I conceptualize Ser Educada to include the following sub-themes: 1) Familía 2) Educación, 3) Feminidad, and 4) Hermandad (sisterhood). A common thread throughout the sub-themes and the concept of Ser Educada is that of resistance and consciousness. These three themes each hold un fondo of knowledge (Andrade \& González Le Denmat, 1999) that further shows the nuances of the educational experiences of first-generation Latinas and their resistance strategies at RHC as they each strive to Ser Educada.

Anzaldúa (1987) described la facultad as "the capacity to see in surface phenomena the meaning of deeper realities, to see the deep structure below the surface" (p.38). Elenes et al. (2001) further described how it "is the ability to create knowledge and theory out of the everyday experience of those who live on the margins of society" (p.598). The first-generation Latinas who participated in this study shared their joys, successes, struggles, and wisdom on their educational experiences at Rolling Hills College. Rather than focus on the failures of Latino students, this study focuses on the 
strengths that the mujeres brought from their families and communities. These testimonios will forever live in the walls of the academy because they have allowed me witness the dialogue between women, el poder de la mujer Latina. 


\section{Chapter Six: Discussion and Conclusions}

\section{Overview}

The culture of higher education remains one that holds the values of the middleto-upper middle class culture, such as individuality, social capital, and academic discourse, along with the norms that are considered male, white, and heterosexual. Most colleges and universities are considered to be predominantly white institutions (PWIs) because of the historical and institutional racism upon which they were built. Even when an institution of higher education undergoes a demographic shift in the number of minority students it enrolls, the culture of higher education may remain predominantly white.

The primary purpose of this study was to highlight the educational experiences of first-generation Latinas as they successfully navigate and persist in higher education, and to add their testimonios to the literature on education through the lenses of LatCrit, $\mathrm{CRF}$, and borderlands. This case study incorporated a mixed methods sequential design to incorporate both quantitative and qualitative data. Quantitative data included RHC's Campus Climate Survey, Longitudinal Data from 2000-2010, and the results of the Transformational Resistance survey. Qualitative data included the Transformational Resistance survey open-ended responses and the focus group transcripts. Out of the 
population of 253 first-generation Latinas that were enrolled at RHC for the fall 2010 semester, 141 (56\% response rate) responded to the Transformational Resistance. survey. Of the 49 that indicated interest in participating in a focus group, 24 were selected to create groups that were balanced in terms of year in school in which the women were enrolled. Upon reviewing the transcripts, one woman from each group was selected as a focal student to report the findings of this study in her own words.

The biographical testimonios of these four focals provided a rich account to the lived experiences of first-generation Latinas persisting at a four-year PWI. This study focused on the role of hearing the voices of these young women as they shared the importance that their identities as a woman, a person of color, and a first-generation college student played in their educational experiences. These counterstories also emphasized the constant state of transition that they must endure in their academic persistence and success, which is characterized by the construct of borderlands (Anzaldúa, 1987).

\section{Interpretation of Findings}

Most of what we know about first-generation college students of color comes from empirical data that focuses on national, longitudinal data. This study aimed to answer the research questions: How do Latina, first-generation college students persist in the normative, predominantly white culture at a private, four-year college? What resistance strategies, if any, do these young women enact to persist? The primary 
significance of this research is that it looked at the intersectionality of first-generation status, race/ethnicity, and gender, told from the perspectives of the mujeres themselves. Their testimonios contribute to the predominantly male, white, heterosexual literature on student retention, as well as contribute to the existing literature on LatCrit and Critical Race Feminism (CRF). Introducing a LatCrit and CRF perspective into the literature on student retention provides an opportunity to stretch the discussion beyond that of diversity and more towards one of equity. Within this approach, the findings of this study challenge how the collection of quantitative and qualitative data is imperative to better understand the experiences of marginalized students, especially first-generation Latinas. This study puts at the center the first-generation Latina to highlight her borderlands existence.

In hearing the experiences of the young mujeres I was able to develop a conceptual model that describes how first-generation Latinas persist at a four-year PWI. These findings also provide a platform from which to critically analyze how retention practices can be enhanced by infusing an intentionally racialized and gendered perspective. This conceptual model suggests that first-generation Latinas who seek their education as a form of transformative resistance live in a constant state of transition known as Ser Educada. 


\section{Conceptual Model of Ser Educada}

This research found that the educational experiences of first-generation Latinas in higher education include the constant state of transition and navigation of four key areas that define Ser Educada: Familía, Educación, Feminidad, and Hermandad. Within this constant state of transition and navigation, the mujeres use their new mestiza consciousness (Anzaldúa, 1999) and transformational resistance strategies (Delgado Bernal, 2001) to preserve their sense of cultural self and expand their academic self.

Figure 5.0 illustrates the expansion of the concept Ser Educada, which includes the location of the institution of higher education in the conceptual framework. At the center of this figure is the first-generation Latina college student. Based on the mixed methods data, especially from the transformational resistance survey (TR survey) and the focus groups, the mujeres reported being in a constant state of transition. They are constantly at a crossroads and their experiences as first-generation women of color will impact how they engage the institution and its faculty, staff, and students. As mestizas, they must develop a consciousness that straddles "cultures, races, languages, nations, sexualities, and spritualities - that is, living with the ambivalence while balancing opposing powers" (Delgado Bernal, 2001, p.626). The outer ring represents the institutional culture they must navigate in order to persist in higher education. At each 


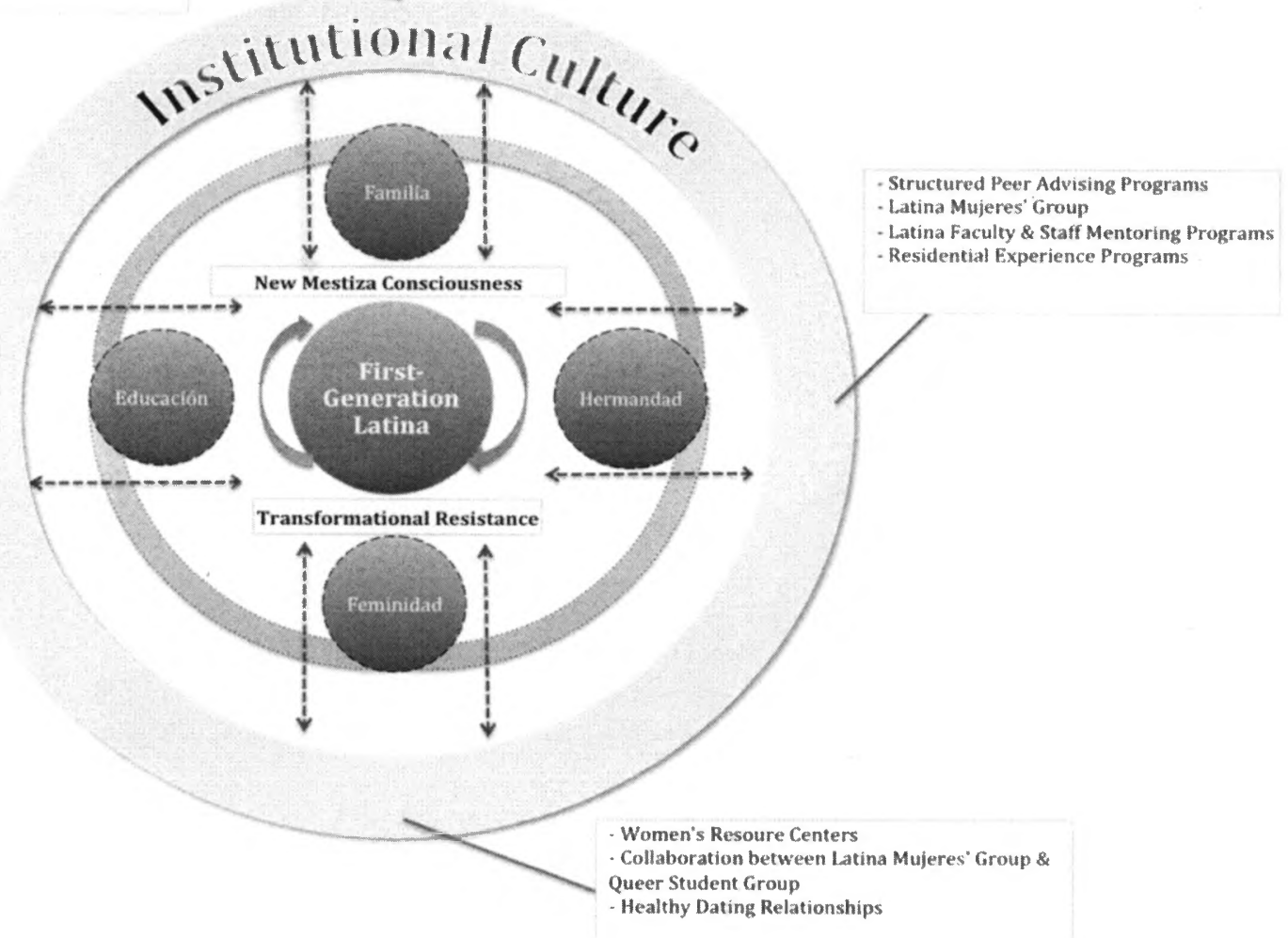


end of the four themes, there is an entry point for the institution to connect with its firstgeneration Latinas; and the boxes outside of those entry points provide some examples of institutional programming that can be initiated.

The first-generation Latina engages in resistance behaviors that range from the subtle internal resistance, such as making it to class after solving a family crisis, to the overt external resistance of helping to organize a student-led protest. The constant shifting of their new mestiza consciousness and transformational resistance strategies make-up the layer of protection that immediately surrounds the mujeres. They also serve as the tools by which the mujeres are able to successfully transition and navigate among familia, educación, feminidad, and hermandad.

Successfully navigating the culture of higher education means that the mujeres must be aware of the oppressive institutional and societal forces that impact them. As discussed in chapters four and five, the first-generation Latinas in this study described how each of the four themes of Ser Educada provides a source of support yet also is a source of stress. For example, many of the women described how their families supported, inspired, and encouraged them to get a college degree. However, they also discussed how they experienced immense pressure to continue to serve the roles they had long-established in their families as mediators, translators, and even sometimes as parent to younger siblings and other family members. Such demands put a strain on the mujeres' ability to continue to develop their educación. Another example is the young 
women sharing experiences of racial microaggressions, and even outright racism, when roommates expressed annoyance at music and voice messages that were in Spanish, or classmates who claim that with more first-generation and low-income students being admitted into the college, the rigor of the curriculum is being diluted. These are the experiences that first-generation Latinas, and many students of color, must navigate to persist in college.

The young women also shared how feminidad and hermandad were sources of support and of stress. As mujeres they described the struggle arising from fighting the cultural norms of women in Latino families being mothers, homemakers, and the primary care person for children and elders. They shared how they were expected to be una hija bien educada (a good daughter) over being educada. Yet, they also described how the lessons they learned about being mujeres fuertes (strong women), such as owning your place as the matriarch of the family, learning how to communicate with all community members, and being able to teach others how to get things done, served them well in college. The constant tension between the pedagogies of the home (Delgado Bernal, 2001) and the pedagogies of the academy creates a space that the young women of this study describe as the "place to navigate to be successful. I have to be about and for my family... and I have to be about and for my education" (María Luisa). The mujeres in this study revealed that they enact in transformative resistance 
by refusing to choose between the key parts of her identity (familia, educación, feminidad, and hermandad).

Additionally, the findings of this study contribute to the literature on student retention by adding a racialized and gendered lens to traditional student retention theories. These young women consistently described their need to be actively engaged in their educación and with their familía to preserve their sense of identity. Therefore, their testimonios challenge long held beliefs that students must become independent from their home culture in order to succeed in higher education. Instead, the mujures' counterstories show that their strong connections with their families though tenuous at times, help them to persist in college. And while student retention literature holds that engagement, defined as active involvement in the campus community is the highest indicator for student persistence in higher education, this study pushes the nuances of engagement for first-generation Latinas. Engagement in the college community is not sufficient. Instead, these young first-generation Latinas describe engagement rooted in their familia, educación, feminidad, and hermandad as keys to retention.

\section{Educational Equity Issues}

The lack of equitable persistence and graduation rates of first-generation college students is often described as impacted by the student's inability to engage in the college community (Bean \& Eaton, 2001; Cabrera, Nora, \& Castaneda, 1993; Tinto, 1988). Too often, marginalized students are expected to be the ones who change, often 
radically, to acculturate to the culture of higher education. The findings of this study suggest that educational institutions should analyze campus climate survey data to determine how and where an institution can implement change to better serve students at the margins. The first-generation Latinas in this study expressed that it is crucial they have the necessary support in each of the four areas to persist at RHC. Therefore, the findings also suggest how looking at the intersections of students' identities can provide a more nuanced perspective on their educational experiences, thereby informing the retention practices in higher education.

\section{Implications for Theory, Policies, and Research}

The concept Ser Educada is a complex existence that challenges first-generation Latina college students to live at the intersection of what it means to be first-generation, female, and a Latina seeking to earn a college degree. As a new conceptual model for student retention, it challenges educators and scholars to reconceptualize how familía, educación, ferminidad, and hermandad are cultural resources that contribute to this student population's persistence in higher education. More importantly the conceptual model of Ser Educada demonstrates that the successful mujer navigates all four of these dimensions of her identity when she is able to persist as a first-generation Latinas in higher education. 
Each of the four themes are described by the mujeres in this study as having a paradoxical relationship, where they are both a source of support and encouragement, yet also major points of stress. This study revealed how first-generation Latinas negotiate, through their mestiza consciousness (Anzaldúa, 1999) and their transformational resistance (Delgado Bernal, 2001) within the culture of predominantly white institutions of higher learning.

The testimonios in this study also illustrate how first-generation students should not be essentialized, but acknowledged as a diverse group of students, rich with cultural wisdom. The findings also contribute to the LatCrit and CRF literature by directly liking race and gender to first-generation college students' transformational resistance strategies. Educators and scholars are challenged to look at the intersectionalities of the identities of marginalized students to better understand students' educational experiences and the challenges that may keep them from earning a college degree.

If educators and scholars gain a better understanding of students' experiences at points of intersection - race, ethnicity, socioeconomic status, gender, language, sexual orientation, and spirituality - they can more effectively inform policy. For example, the US Department of Education could better address educational equity gaps if policy makers would demand that all applicants for federal funds intentionally address the intersections of marginalized student identities. Latino college students, first-generation women in particular, would benefit from having federally funded retention programs, 
such as Upward Bound, Student Support Services and McNair's Scholars, implement programming that holds race as central to students' experiences. This would call for proposals to challenge Tinto's $(1988,1998)$ theory of student departure and provide a theoretical and programmatic foundation rooted in addressing the intersectionalities of marginalized student populations.

Additionally, state legislators in a state like California, with a high concentration of Latino students, must acknowledge that as the student population shifts, educational policies must also shift to meet their needs. California reports that $37.6 \%$ of its population identifies as 'Hispanic or Latino' (US Census Bureau, 2010). According to NCES (2010) data, California still records a $12.6 \%$ equity gap between the $34.8 \%$ Latinos, predominantly first-generation to college, earning a college degree versus the $47.4 \%$ of white students earning a degree. Quantitative data alone is no longer enough to inform and justify our current practices. Policy makers have the ability to call for and support the mixed methods research that can provide insight into the nuances within marginalized groups of students.

Policy makers must send a message centered on student success being everyone's responsibility. If we are to ensure that students are graduating, student success should include students persisting from year to year in good academic standing. Furthermore, graduation alone should no longer be considered baseline; rather the baseline for student success should be that students graduate with options for graduate 
school, competitive career placements, or paid internships. Focusing on student success, via persistence and graduation rates, ensures that all students receive an equitable education. Legislation on the campus, state, and national level must be concerned with the academic success of marginalized students, specifically firstgeneration Latinas.

Overall, the findings of this study calls for implementing strategies and programs that are rooted in the intersectionality of students' identities, namely firstgeneration Latinas. Ser educada describes the constant state of transition and navigation that first-generation Latinas must execute in their persistence at a four-year PWI. The quantitative data revealed that there is a need for educational institutions to disaggregate data by intersecting data points, such as race, ethnicity, gender, SES, firstgeneration status, language, sexual orientation, and religious/spiritual identification. These data also revealed that alone, they cannot provide insight into the experiences of marginalized students. Therefore, qualitative data collection is critical to highlight the voices and experiences of historically marginalized students, such as students of color, women, and first-generation students. Publishing reports with both quantitative and qualitative data will fill in the gaps where one data set is lacking. 
Implications For Institutional Leaders

The findings of this study reveal that first-generation Latinas navigate a complex existence, which I have termed Ser Educada: familía, educación, feminidad, and hermandad. It is imperative that institutional policy makers and leaders recognize the critical areas of support that the mujeres in this study have described. The following section provides recommendations for educational leaders, faculty, and staff who seek to improve the persistence and retention rates of first-generation Latinas.

\section{Bi-lingual and Bi-cultural Presence in Campus Leadership}

Educational institutions must have a cultural presence of bilingual and bicultural administrators, faculty, and staff. Implementing and maintaining a cultural presence of Spanish-speaking, first-generation Latinas among administrators, faculty, and professional staff provides a direct link to the Latino community. This type of cultural presence allows for families to hear from campus leaders who can speak from direct experience to Ser Educada. It further provides a cultural presence that can provide educational opportunities for Latino families to learn about what their daughters might experience being a first-generation college student. Cultural presence is exemplified through the visibility of Latina administrators, faculty, and professional staff at orientation programs, cultural celebrations, and web and printed materials. 
More specifically, offices that work with students and their families, such as Admissions, Orientation Programs, Financial Aid, Business Office, Registrar, Campus Housing, Academic Advising, Counseling, and Health Centers must have at minimum a bi-lingual, Spanish-speaking person, if not ideally a bi-lingual and bi-cultural person. Currently, at RHC there is a small group of about 9 Spanish-speaking professionals in a faculty and staff of over 300 . We are regularly consulted for translation services when students' family members communicate with the college. Not only does this limit the opportunities for Latino family members to gather direct information from specific offices, it calls for Spanish-speaking staff members to set aside their work, and to learn broadly about campus functions so they can provide information that goes well beyond their job descriptions. For the bi-lingual and bi-cultural staff members, these demands serve as an additional layer of work because Latino family members often continue to make contact with them, long after their particular question has been resolved.

Educational institutions should be explicit about sharing how transitioning into higher education is a challenge for most students and their families, especially historically marginalized students. And should ensure that all key offices (if not all of them) have a Spanish-speaking person readily available to work with Latino family members. Providing multiple touch points for Latino family members to engage with the college would provide more opportunities for them to become involved in their daughter's educación. 


\section{Know Academic Success and Retention Rates of Marginalized Students}

Educational leaders must know the data on their students' academic achievements. Offices of Institutional Research should standardize disaggregating data by points of intersections. It is no longer sufficient to disaggregate data by race, gender, SES, or academic program. Rather, it is critical to disaggregate data at the intersecting points, such as first-generation, ethnicity, gender, and academic success. The findings in this study revealed that analyzing data at the intersectionalities of students' identities provides a much richer foundation from which to assess and develop programming.

As a practitioner and supervisor of professional advisors, I am extremely interested in how research can inform our practices, and as such, have started to implement some changes as a result of this study. As the supervisor of academic advising services and programs that outreach to first-generation and low-income college students, the findings of this study called me to launch a strategic plan for supporting the academic achievement of marginalized students at RHC. The findings reveal that it is crucial for educational leaders to know the data about student success and persistence, especially for marginalized students. Therefore, my staff and I plan to work collaboratively with the Office of Institutional Research to collect and analyze data about our marginalized student populations. Part of my staff's responsibility will be to continue this inquiry each term so that we are ready to provide specific emphasis for 
students who are on or close to being on academic probation. This quantitative data in conjunction with our internal data collection (via advising notes), will inform how we can continue to improve our practice. Additionally, this integration of mixed methods provides outcome measures that help institutions to base programmatic decisions and a range of qualitative data that helps us understand the particulars. Such practices can be implemented at any academic advising or counseling office that works directly with student success and retention.

While the example I provide is about my department, it serves as a reminder that educational leaders have to be intentional about collecting and analyzing multiple forms of data that are available on the persistence and experiences of marginalized students, especially first-generation Latinas. The findings also suggest that the responsibility of student retention and persistence issues must be everyone's responsibility. In the following sections, I describe new roles and practices key stakeholders should adopt. These include administration, faculty, staff, parents/families, and students alike. This transparency would provide the opportunity to set clear outcome goals and objectives within each area, as I have described in my particular office.

\section{Curriculum \& Research on Feminidad Mestiza}

Feminist scholars must be encouraged to include critical race analysis in their curriculum and in their research on women. Moreover, research on women of color in 
higher education should include the intersection of first-generation status, as this study has revealed the impact it has on further marginalizing Latinas. It is especially crucial to address the diversity among feminist scholars and include into the curriculum the work of current Chicana/Latina feminists (e.g., Delgado Bernal, 2000; Gonzáles, 2001; Hernández-Truyol, 1997; Montoya, 1999). These same Chicana feminist scholars view the conceptual grounding of trenzas (braiding) as the social process of la cultura mestiza. Women are not the same, and Chicana scholars problematize the intersecting point of race within feminist thought and research.

The findings of this study, including the testimonios of the mujeres, revealed how the concept of Ser Educada contributes to the feminist literature by identifying how feminidad is a key characteristic for the persistence of first-generation Latinas. The young women shared how having the space to discuss and analyze their femininity, as it relates to their culture, was something they wish they could experience more frequently. As a conceptual model, Ser Educada illustrates how the first-generation Latina is never static, always presenting them with situations in which they are reminded of what it means to be a first-generation college student who is also a woman and Latina. I recommend that Chicana feminist scholars include first-generation status as a critical element to the mestiza identity because it includes an additional layer of identity that Latinas must navigate if they are to persist in higher education. 


\section{Pedagogy That Integrates Students' Lived Experiences}

Colleges and universities begin to connect with students long before their first day of school, through recruitment efforts and communication from the office of admissions. Once admitted, students continue to receive communication and messages from additional departments such as academic programs, advising, student affairs units, and from their individual professors. The mujeres in this study described how engaging in their educación brought the other aspects of their identity as first-generation Latinas to a head. Institutions of higher education should engage and hold onto the tension between the cultural identity first-generation Latinas bring with them, while trying to establish their educación.

The findings revealed that first-generation Latinas sought classes in Ethnic Studies and Women's Studies courses to learn about the history and experiences of marginalized groups of people. Outlining the courses in the curriculum that specifically address issues of oppression for marginalized populations would benefit students' knowledge of the diversity of courses available to them. Most institutions, such as RHC, often have a "diversity requirement," which mandates that students complete 1-2 courses to fulfill this area requirement, limiting diversity to very few courses. The mujeres in this study described the need to have more courses available to them in all academic areas that provide them opportunities to connect the pedagogy of the classroom with real communities. 


\section{First Year Experience Courses}

Faculty who teach first year experience courses, a programmatic tool for improving student retention, should be explicit about what it means to integrate academics as part of students' identities. At RHC, first year students are enrolled in a first year advising course, in which students are organized by intended major of study and coupled with a faculty from that major. The course is for partial credit and meets sporadically throughout the students' first year at RHC. These courses currently include a curriculum that addresses issues that arise when transitioning into college such as, communication with faculty, the rigors of higher education, and using their resources. While the curriculum also calls for a unit on issues of diversity, there is little evidence to suggest it is being taught by the faculty effectively, if at all. Fortunately, the first study on the program is underway, and results will be available for fall 2011 implementation strategies.

Directly addressing the diversity among the student population, including the strengths that historically marginalized students bring, such as strong familial capital, bilingualism, and biculturalism, can provide the safe space for minority students to be included. These first year experience courses should provide a classroom environment that allows students engage in discussions about how oppressions such as poverty, racism, sexism, language, and immigration status impact their education. This type of 
educational space calls for faculty who teach first year experience courses to acknowledge that culture matters. While this study did not seek to identify effective teaching practices, it did provide insight that culturally relevant education LadsonBillings, 1994 "aims and transforms shifting responsibility into sharing responsibility" (p. 15). My interpretation of how Ladson-Billings describes teaching as a shared responsibility is included here to state how first year students should be invited to share themselves within this educational space, to gain better insight into how to successfully navigate the culture of higher education.

\section{$\underline{\text { RHC Seminar (Great Books) Program }}$}

Another striking example of how the academic setting impacts the mujeres' educación plays out in their seminar classes. As discussed in chapter five, seminar courses are part of the Great Books curriculum that all RHC students must complete, and is foundational to RHC's liberal arts education. The courses are taught using Socratic discourse, which calls for students and faculty to engage in shared inquiry. One of the critical elements of seminar is that as a shared inquiry course, $50 \%$ of the overall grade is based on class participation. The young women in this study described how the current structure of seminar seems to benefit those who come from white, middle- toupper middle class backgrounds, where more direct and open communication is valued, as well benefit the voices of a predominantly white culture. With the exception of one 
elective course, the majority of seminar courses are predominantly about male, white, religious, heterosexual culture. The mujeres described feeling tired of "reading about old white men" and tired of "being overlooked by the professor" because they were not as forceful in joining the class discussions. One recommendation for this area is to review the Socratic method of shared inquiry and reinforce the "shared" part. If one student is silenced, then the space is no longer shared and that student can no longer be successful in the course, especially given the heavy emphasis on class participation.

I suggest that faculty leaders of programs and courses, such as seminar, refer to Duncan-Andrade's (2007) articulation of Socratic sensibility as a pillar of effective teaching. According to Duncan-Andrade (2007), Socratic sensibility is lived when teachers strike "a delicate balance between confidence in their ability as teachers and frequent self-critique" (p.632). He stresses the point that effective teaching requires self-analysis, in conjunction with pedagogies that connect to the realities of students' prior lived experiences. And while his study focuses on effective teachers in urban schools, it emphasizes the importance of connecting the content to students' lives. In this case, RHC seminar faculty must create a learning space that connects the writings of Plato, St. Augustine, Sophocles, and Marx to the experiences of first-generation students, women, and students of color. 


\section{Advising That Addresses the Intersectionalities of Students}

Advising for first-generation Latinas must be inclusive of all aspects of their identity. Culturally rooted academic advising is an integral part of guidance these mujeres to develop and articulate their educación. Kuh (2005) describes how academic advising is a mechanism by which an institution of higher learning can communicate to its students that their success is a priority. The mujeres in this study shared how being able to go to the Academic Advising Center (AAC), which identifies one of its advisors as the Latino Student Achievement advisor, enabled them to continue to plan for academic success. Valenzuela (1999) articulated the concept of cariño (caring) as a central tenet of good teaching; and the young women in this study clearly articulated how the care and concern they received from advising staff members were critical to their persistence.

Advising this student population must address their familia, educación, feminidad, and hermandad to capitalize on their transformational resistance strategies that enable them to persist in higher education. Therefore, advising models must include the professional development of staff and faculty that provide advising to students. Guiding students to declare a major and achieve academic success, cannot be in isolation from the cultural elements of students' identities. Instituting peer advising programs addresses the necessary theme of hermandad that the mujeres in this study described. Peer advisors that are trained, regularly supervised, and provided regular 
professional development can serve not only as important elements to current advising models, but can also serve as paraprofessionals during these times of economic hardship.

Colleges and universities must identify an individual or departments such academic advising, to be responsible for knowing the academic achievement of marginalized student groups, such as students of color, women, and first-generation students. First-generation Latinas evidence their independence in that they are seeking to earn a college degree, something that has not been done in previous generations of their families. At the same time, the testimonios in this study describe how the mujeres are both independent and interdependent with their families. Therefore, advising models should include discussions and experiences to enhance their academic identities must include an analysis of the role familia plays in their educational journey.

Academic advisors can serve as key collaborators to bridge students and faculty, students and family, family and institution, privileged students and marginalized students, so that they all have a role to play in student retention, graduation, and overall success. They must become experts at knowing the data on student academic success to communicate and personalize the experiences of marginalized students to key campus leaders. 


\section{Mentoring Programs that Promote Hermandad}

In all four of the focus group interviews, the mujeres exclaimed that this was the only time at RHC that they had found themselves in a room full of Latinas in a nonsocial setting. There was an immediate sense of relief in having a safe space to share their experiences as women of color, as Latinas, as hermanas. Harnessing the positive energy that the mujeres described would likely enhance their educational experiences and academic achievement. The general understanding of hermandad (sisterhood) describes a familial kind of relationship, such as between siblings. However, this study found that first-generation Latinas expand this understanding to include not only their peers, but also Latina faculty and staff. Currently at RHC, there are no Latina administrators, that is, at the Provost or Dean levels. Furthermore, the number of Latinas at RHC who are tenure line faculty or staff is also limited. First generation Latinas want and need faculty and staff who are representative of them to serve as mentors and role models. I have come to understand hermandad as the relationship between first-generation Latinas, regardless of their social location.

Educational institutions should implement or expand upon current student diversity organizations that are specific to Latinas, such as the Hermanas Unidas organization the mujeres described. Women's groups such as these, especially those who have a Latina faculty or staff as their advisor, would provide an opportunity for shared inquiry, mentorship, and guidance. Such collaboration between student and 
academic affairs helps to design programs and interventions that meet students exactly where they are.

The findings in this study also suggest the need for mentoring programs that connect Latina faculty and staff with first-generation Latinas. However, this poses serious challenges given the low numbers of female Latina faculty and staff in comparison to the student populations at most four-year colleges and universities. Yet, this type of shared space challenges the traditional views of faculty and staff as experts and encourages what the young women described as having the freedom to embrace their home culture with their academic culture in the safe space guided by fellow hermanas. Capitalizing on existing resources, Latina faculty and staff members can become more involved with Latina student groups, such as Hermanas Unidas.

At the very minimum, the message of intervening whenever possible is critical for this student population. Therefore, all faculty and staff need to be proactive, inviting, and available to students. In practical terms, be in your office when you say you're going to be there and return phone calls and emails promptly.

\section{Collaboration of Academic and Student Affairs}

Crucial to the success of first-generation Latinas is a strong collaboration between academic affairs and student affairs. Many of the challenging experiences the young mujeres described happened in the residence halls, during campus social events, 
or during academic events across campus. Administrative leaders from both of these areas must have a forum by which they bring all of their respective direct reports to the proverbial table to implement strategies for student success. This is especially for colleges that have living learning communities, community based research learning, capstone research projects, first year seminars, and study abroad programs.

The more educators and scholars know about the experiences of students at the margins, the better informed they can be when developing curriculum. The mujeres in this study revealed how they sought out courses in Ethnic Studies, Women's Studies, sociology, history, and Spanish to learn about their cultural communities. Faculty leaders must incorporate these histories and perspectives as part of the core curriculum that all students must take, so as to articulate the priority of giving "voice" and "space" to the experiences of all of the cultural groups enrolled as students.

The mujeres described how their persistence in college challenged them to reflect on the intersection of being female and a person of color. There are cultural expectations in Latino families that young women are well behaved, well dressed, and of high moral values, that is bien educada (well educated). Often, the behaviors associated with being bien educada hold Latinas to more traditional gender roles of heterosexual behavior, virginity, and feminine appearance (Rodrigúez Martin, 2010). These cultural norms influence a first-generation Latina's transition into developing an educación that is often in direct contradiction to the behaviors expected from their 
families. Yet, they were also told to do well in school, which often meant having to break from being bien educadas to become successful academically. Therefore, when working with first-generation Latinas, educators must check their own biases about students who might be quietly in the background of class discussions or residence hall meetings if they label them as disinterested or unprepared. Rather they should work to provide a safe space in which young women can find and share their voices so that they develop a more prominent presence in academic and student life settings.

Furthermore, the mujeres described the tension between the behaviors of those young women who come from urban communities and the perception that they are "street" or from the "hood," designating them as "mean" or "bitches." This type of labeling or stereotyping further marginalizes first-generation Latinas who are perceived to come from urban communities. Gaby's experiences capture this most strongly when she describes how students who live in her residence hall or who are in classes with her, fear her. Her behavior is often seen as oppositional and outright defiant because her communication style is a bit more aggressive than the culture of higher education. The impact that it has had on her is that she silences herself in academic settings, such as seminar courses, so as to not be labeled defiant. This is problematic because, again, the institution is perpetuating a culture in which students must change to succeed, rather than the institution identifying what structures, policies, and programs it needs to change to support student like Gaby. 
As Latinas, the young women in this study described feeling caught between the woman their family wants them to be, and the woman they want to become. More specifically, the young mujeres described how they had to balance being the responsible and virtuous women they were raised to be with the assertive, independent, and sensuous women they want to become. Educational leaders must demand that campus departments such as Women's Resource Centers, Counseling Centers, and Multicultural Centers collaborate with academic programs to generate programming that is relevant to the intersectionalities of first-generation Latinas, and women of color in general experience. Such reforms can include support groups on healthy relationships, body image in a Latino cultural setting, collaborative programming between Latino student clubs and queer student clubs, counseling services that are bi-lingual and bi-cultural, and opportunities to conduct academic research in each of these areas as part of the curriculum.

\section{Limitations of the Study}

The mixed methods explanatory design of this case study provides a nuanced insight into the educational experiences of first-generation and the resistance strategies they enacted to persist at a four-year PWI. Mixed methods research requires both collecting and analyzing quantitative and qualitative data (Creswell \& Plano Clark, 2007). The data for this study were collected using a sequential design, in which the 
quantitative data were collected and analyzed first, followed by the collection and analysis of the qualitative data. While the research is strengthened by the integration of both quantitative and qualitative data and provides transferability, it may not be generalizable to the experiences of first-generation Latinas in all institutions of higher education. Generalizability may be limited by the fact that the research was conducted with women at one institution, which is also a private, non-profit four-year college. The limitations of this study are outweighed by the power of the words and experiences of the women in this study. They have challenged me to take the findings and answer the question, "So now what?"

\section{Recommendations for Disseminating Ser Educada}

The findings from this study will be shared with a number of key members of the Rolling Hills College community, such as the Campus Diversity Committee, academic advising, academic departments, Student Affairs - orientation programs, first year experience, residential program, and student leadership programming. I have already had the opportunity to share preliminary findings with student leaders of Latino diversity clubs during an all day training program. All of the student leaders present asked me to come to one of their general club meetings to share the findings with their members. I will begin to facilitate these workshops beginning fall 2011. 
I also plan to make the findings of this study available to all interested parties at Rolling Hills College, including the faculty of the School of Education. I have been asked to teach the College Student Services course for all graduate education and counseling students interested in higher education. Within this teaching role, I plan to disseminate the findings as well as the research methodologies used for this mixed methods study.

With a targeted audience in mind, I plan to submit articles to the Journal of Hispanic Higher Education and The Hispanic Outlook in Higher Education, as the findings of this study directly addresses the Latino student community. Future plans include submitting a paper to the National Conference on Race and Ethnicity for the 2012 annual conference. The findings of this study can provide additional insight to the experiences of first-generation Latinas, which are rooted in the centrality of race to their experience.

For a wider audience of practitioners, I plan to submit a proposal for the findings to be shared at the Student Success Conference, sponsored by the Research and Planning Group of the California Community Colleges, scheduled to take place later this fall. While the study does not include community college students, the findings can inform how the conceptual model Ser Educada can enhance college advising and counseling services for first-generation Latinas. Additional conferences that focus on practitioner research include the National Academic Advising Association, which is the 
professional community of college advisors and counselors. There are often calls for papers and presentations that focus on issues of diversity, which the findings of this study include. And given my interest to bring about more collaboration between academic affairs and student affairs, I also plan to submit a paper to the NASPA Student Affairs Administrators in Higher Education national conference for fall 2011.

Finally, I hope to influence and contribute to scholarship by sending manuscripts to peer reviewed journals. The theoretical concept of Ser Educada would be of interest to publications such as Qualitative Inquiry, Teachers College Record, American Educational Research Journal or Harvard Educational Review, especially because of this study's focus on CRT, LatCrit, and borderlands.

\section{Recommendations for Further Study}

Recommendations for further research including looking at how the research question on the educational experiences of first-generation Latinas at a small, private institution might differ from those mujeres who attend a large, public four-year university. Replicating the study within a two-year college setting would also benefit future study. Also, the generalizability of the concept Ser Educada would be strengthened if this mixed methods research design were conducted at multiple fouryear and two-year colleges and universities concurrently. 
The expansion of this study design to include a longitudinal perspective would also strengthen the reliability of the findings of Ser Educada, as well as provide insight as to how it develops over the course of a first-generation Latina in her undergraduate career. It would also be possible to include those first-generation Latinas who have continued on to graduate school and how the concept Ser Educada is relevant to their educational experiences and persistence in higher education.

Further research also should include looking at the specific role that academic advising interventions impact the persistence and resistance strategies of firstgeneration Latinas, as well as the role it plays in the concept Ser Educada. There are a variety of models of advising, including a faculty based model, a professional staff model, a peer advisor student based, and often hybrids among these models. Additional research on the advising models that prove to be the most effective with this student population would add to the literature on advising, a well as provide possible implications for practice.

\section{Reflections on the Research Process}

It is important that I disclose that as a first-generation Latina, this research process has been indescribable. Of course I have possible biases, given that my educational experiences as a first-generation Latina resonates strongly with the findings of this study. It is because of these biases that I intentionally undertook a mixed 
methods study that challenged me to collect and analyze both quantitative and qualitative data. Working with critical colleagues also challenged my potential biases, as there were three key colleagues who reviewed my data memos, transcripts, and summaries. I purposefully selected three critical colleagues who are familiar with the literature on CRT and LatCrit and with my research, but who do not directly identify as first-generation and Latina. They challenged my thinking and data analysis in ways that made me even more attentive to the nuanced experiences the mujeres shared with me.

I ventured into this study seeking to learn about the educational experiences and resistance strategies first-generation Latinas enact to persist in higher education. What I learned throughout the process is that their educational experiences include being in a constant state of transition that requires a mestiza consciousness and transformational resistance strategies to successfully navigate the culture of higher education. Although I treated the women as study participants and sought to amplify their voices through my work, I did not expect for the young women to describe their participation in this research as an important piece of their educational experience. Yet even after I collected and analyzed data, members of the focus groups as well as women who had only completed the online survey came to my office to check in about issues that continue to impact them. Seventeen of the 24 mujeres who participated in the focus group have come to see me individually since the focus groups. Oftentimes they want to check-in, problem-solve, or gain some advice on how to deal with a particular tension 
between school and family. I see now that some might have experienced the focus groups an intervention in and of itself.

The relationship that I have built with my graduate advisor is one of the most influential relationships I have formed. When I first asked Barbara to be my advisor, I knew that she would challenge me as a researcher and a practitioner. Her ability to call me out on things throughout the research process has been key to ensuring successful completion of this study. She met with me almost weekly towards the last three months of this process, reviewing data memos, providing comments on my drafts, and sharing her thoughts and ideas with me. I see now that she modeled for me the hermandad that the mujeres in this study described. Even though she is not Latina, she is a critical colleague who created the space for me to explore, think, and challenge my own issues with persisting in graduate education.

I truly believe that this research process has been an intervention process for me as well. When I first started my undergraduate education, I had no idea of what I was doing. I was aware that getting a college degree would provide me opportunities, but I never imagined that I would be sitting at my computer right now completing a dissertation. As I reflect on the relationships that I have built with critical colleagues, professors, and the participants in my study, I am humbled. I am humbled because I had the honor of simply listening and telling the story of young women who are not often included in education literature. My role in this research was to simply capture 
and write what the mujeres shared with me to the best of my ability. However, the role this research has played in my life is that for the first time, I no longer believe I'm a fraud in education. I believe that I do deserve to be here and that I earned every bit of the pain, struggle, and triumph this research process has provided me.

If I could go back to the $9^{\text {th }}$ grade when I was about to get kicked out of high school for oppositional behavior (talking back to a nun) and tell myself un dicho (wise saying), I would tell myself that I deserve a quality education and will benefit greatly from what the mujeres in this study have taught me about Ser Educada. In essence, the dicho that I would share with myself is that I can be Latina, be educated, and still be authentically me.

\section{Conclusion}

The testimonios of Gaby, Esmeralda, Suzie, and María Luisa represent the educational experiences of first-generation Latinas at Rolling Hills College. Students whose parents did not earn a college degree are one of the most frequently target groups, along with low-income students and minorities, for access programs into higher education (Swail et al., 2004). While access to higher education has increased for marginalized student groups, the persistence and graduation rates of first-generation students of color are alarmingly low in comparison to white students. The quantitative data in this study revealed that first-generation Latinas are more likely to have been on academic probation, consistently earn an average GPA that is .25 below that of first- 
generation white women, and take an average of two additional terms to complete their degrees.

The qualitative data provided a nuanced insight into the educational experiences of first-generation Latinas that led to the conceptual model I termed as Ser Educada, the constant state of transition they must navigate to successfully persist in a four-year PWI. The four themes that comprise Ser Educada include: Familia, Educación, Feminidad, and Hermandad. The rich testimonios of the mujeres in this study illustrate how they had to use their new mestiza consciousness to navigate the borderlands of their identity by enacting transformational resistance strategies. María Luisa's words capture the essence of Ser Educada, "It's not just about getting a college degree. It's about the whole package, education, morals, values, cultural pride, and...oh yeah, being una mujer." 


\section{References}

A Framework for Retention (2003). ASHE-ERIC Higher Education Report, 30(2), 75112.

Akom, A. A. (2003). Reexaming resistance as oppositional behavior: The Nation of Islam and the creation of a Black achievement ideology. Sociology of Education, 76(4), 305-325.

Akom, A.A.(2008). Black metropolis \& mental life: Beyond the "burden of 'acting white" toward a third wave of critical racial studies. Anthropology \& Education Quarterly, vol. 39, issue 3: 247-265.

Alexander, J. S., \& Gardner, J. N. (2009). Beyond retention: A comprehensive approach to the First College Year. About Campus, 14(2), 18-26.

Andrade, R., \& González Le Denmat, H. (1999). The formation of a code of ethics for latina/chicana sholars: The expereince of melding personal lessons into professional ethics. Frontiers: A Journal of Woman Studies, 20, 151-160.

Anzaldúa, G. (1987). Borderlands la frontera: The new mestiza ( $2^{\text {nd }}$ ed.). San Francisco, CA: Aunt Lute Books.

Anzaldúa, G (1990). Haciendo caras/making face, making soul: Creative and critical perspective by women of color. San Francisco, CA: Aunt Lute Press.

Aronowitz, S. \& Giroux S. (1991). Postmodern education: Politics, culture, and social criticism. University of Minnesota Press.

Astin, A.W. (1970). The methodology of research on college impact, part two. Sociology of Education, 43(4), 437-450.

Astin, A. W., \& Oseguera, L. (2004). The Declining "Equity" of American Higher Education. Review of Higher Education, 27(3), 321-341.

Bartolomé, L. (2009). Beyond the methods fetish: toward a humanizing pedagogy." In Darder, A. Baltodano, M.P., and Torres, R.D. (Eds.) The Critical Pedagogy Reader, $2^{\text {nd }}$ edition. (pp. 338-355). New York: Routeledge.

Bean, J. \& Eaton, S.B. (2002) The psychology underlying successful retention \& practice. Journal of College Student Retention: Research, Theory, and Practice, $3(1), 73-89$.

Benmayor, R. (2002). Narrating cultural citizenship: Oral histories of first-generation college students of Mexican origin. Social Justice, 29(4), 96-121.

Berger, J. B., \& Lyon, S. C. (2005). Past to present: A historical look at retention. In A. Seidman (Ed.) College student retention: Formula for student success, $1-29$. Westport, CT: Praeger.

Bernal, D. (2002). Critical race theory, Latino critical theory, and critical racedgendered epistemologies: Recognizing students of color as holder and creators of knowledge. Qualitative Inquiry vol. 8, issue 1: 105-126. 
Bhandari, H. \& Yasunobu, K. (2009) What is social capital? A comprehensive review of the concept. Asian Journal of Social Science, 37(3), 480-510.

Bloom, A. (1987). The closing of the American mind. How higher education has failed democracy and impoverished the souls of today's students. New York: Simon and Schuster.

Bogdan, R. C., \& Biklen, S. K. (2008). Qualitative research for education: An introduction to theories and methods (5 ed.). Boston: Allyn and Bacon.

Bonilla-Silva, E. (2001). White supremacy and racism in the post-civil rights era. Boulder, CO: Lynne Rinner Publishers, Inc.

Bourdieu, P. (1973). Cultural reproduction and social reproduction. In R. Brown (Ed.), Knowledge, education, and social change: Papers in the sociology of education (pp. 71-112). London: Tavistock.

Brayboy, B. M. J. (2005). Transformational resistance and social justice: American Indians in Ivy League universities. Anthropology \& Education Quarterly, 36(3), 193-211.

Braxton, J. (2000). Reworking the student departure puzzle. Nashville, TN: Vanderbilt University Press.

Braxton, J.M., Hirschy, A.S., \& McClendon, S.A. (2004). Understanding and reducing college student departure (ASHE-ERIC Higher Educational Report, 30(3); A.Kezar Series Ed. San Francisco: Jossey-Bass.

Bui, K. V. T. (2002). First-generation college students at a four-year university: Background characteristics, reasons for pursuing higher education, and first-year experiences. College Student Journal, 36(1), 3-11.

Cabrera, A, Nora, A, \& Castañeda, M. (1993). College persistence: Structural equations modeling test of an integrated model of student retention. The Journal of Higher Education, 64(2), 123 - 139.

Cabrera, N. L., \& Padilla, A. M. (2004). Entering and Succeeding in the "Culture of College": The Story of Two Mexican Heritage Students. Hispanic Journal of Behavioral Sciences, 26(2), 152-170.

Cabrera, A., Nora, A., Terenzini, P. T., Pascarella, E., \& Hagedorn, L. S. (1999). Campus racial climate and the adjustment of students to college: A comparison between white students and African-American students. Journal of Higher Education, 70(2), 134-160.

California educational opportunity report (2007). UCLA Institute for Democracy, Education, and Access.

Cammarota, J. (2004). The gendered and racialized pathways of Latina and Latino youth: Different struggles, different resistances in the urban context. Anthropology \& Education Quarterly, 35(1), 53-74.

Cammarota, J. (2006). Disappearing in the Houdini Education: The Experience of Race and Invisibility among Latina/o Students. Multicultural Education, 14(1), 2-10. 
Cerna, O. S., Pérez, P. A., \& Sáenz, V. (2009). Examining the Precollege Attributes and Values of Latina/o Bachelor's Degree Attainers. Journal of Hispanic Higher Education, 8(2), 130-157.

Chang, M. J., Astin, A. W., \& Kim, D. (2004). Cross-Racial Interaction Among Undergraduates: Some Consequences, Causes, and Patterns. Research in Higher Education, 45(5), 529-553.

Chen, X., \& Carroll, C. D. (2005). First-generation students in postsecondary education: A look at their college transcripts. postsecondary education descriptive analysis report. NCES 2005-171. Washington D.C.: National Center for Education Statistics.

Choy, S. (2001). Students whose parents did not go to college: Postsecondary access, persistence, and attainment. National Center for Education Statistics, Washington, DC.

Choy, S. P., Horn, L. J., Nunez, A.-M., \& Xianglei, C. (2000). Transition to College: What Helps At-Risk Students and Students Whose Parents Did Not Attend College. New Directions for Institutional Research, 2000(107), 45.

Cleaver, K. (2003). Racism, civil rights, and feminism. In Critical Race Feminism (2 ${ }^{\text {nd }}$ ed.) New York, NY: New York University Press.

Cohen, J. (1992). A power primer. Psychological Bulletin, 112(1), 155-159.

College Experiences (2007). ASHE Higher Education Report, 33(3), 41-4.

Collier, P. J., \& Morgan, D. L. (2008). "Is that paper really due today? ": Differences in first-generation and traditional college students' understandings of faculty expectations. Higher Education: The International Journal of Higher Education and Educational Planning, 55(4), 425-446.

Crenshaw, K. (1989). Demarginalizing the intersection of race and sex: A black feminist crtique of antidiscrimination doctrine, feminist theory and antiracist politics. University of Chicago Legal Forum, 139-167.

Crenshaw, K. (1993). Mapping the margins: Intersectionality, identity politics and the violence against women of color. Stanford Law Review, 43, 1241-1299.

Crenshaw, K., Gotanda, N., Peller, G., \& Thomas, K. (1995). Critical race theory: The key writings that formed the movement. The New Press: New York, NY.

Creswell, J. \& Plano Clark, V., (2007). Designing and conducting mixed methods research. Sage Publications: Thousand Oaks, CA.

Cuádraz, G. (1996). Experiences of multiple marinality: A case stufy of chicana scholarship women. In. C. Turner, M.García, A. Nora, \& L. Rendón (Eds.), Racial and ethnic diversity in higher education, 210- 222. New York: simon \& Schuster.

Darder, A. (1997). Creating the conditions for cultural democracy in the classroom. Latinos and Education. 
Delgado Bernal, D. (1997). Chicana school resistance and grassroots leadership: Providing an alternative history of the 1968 east los angeles blowouts, Unpublished doctoral dissertation, University of California, Los Angeles.

Delgado Bernal, D. (1998). Using a chicana feminist epistemology in educational research. Harvard Educational Review, 68(4), 555-582.

Delgado Bernal, D. (2002). Critical racy theory, latcrit theory and critical racedgendered epistemologies: Recognizing students of color as holders and creators of knowledge, Qualitative Inquiry, 8(1), 105-126.

Delgado Bernal, D. (2002). Living and learning pedagogies of the home: The mestiza consciousness of chicana students. International Journal of Qualitative Studies in Education, 14(5), 623-639.

Delgado-Gaitan, C. (2001). The power of community: Mobilizing for family and schooling. Boulder, CO: Rowman and Littlefield Publishers.

Delpit, L. (1988). The silenced dialogue: Power and pedagogy in education other people's children. Harvard Educational Review, 58(3), 280-298.

Denzin, N. K., Ed., \& Lincoln, Y. S., Ed. (2000). Handbook of Qualitative Research. $\left(2^{\text {nd }}\right.$ ed $)$.

Duncan-Andrade, J. (2007). Gangstas, wankstas, and ridas: Defining, developing, and supporting effective teachers in urban schools. International Journal of Qualitative Studies in Education, 20(6), 617-638.

Duncan-Andrade, J. (2009). Note to educators: Hope required when growing roses in concrete. Harvard Educational Review, 79 (2).

Duncan-Andrade, J. \& Morrell, E. (2008). The Art of Critical Pedagogy. New York: Peter Lang.

Duster, T. (1991). The diversity project: Final report. Institute for the study of social change. University of California, Berkeley.

Duster, T. (1995). They're taking over! and other myths about race on campus. In Berube, M., \& Nelson, C. (Eds.), Higher education under fire: Politics, economics, and the crisis of the humanities. New York: Routledge.

Elenes, C.A., Gonzalez, F., Delgado Bernal, D. \& Villenes, S. (2001) Introduction: Chicana/Mexicana feminist pedagogies: Consejoes respeto, y educación. International Journal of Qualitative Studies in Education, 14(5), 595-602.

Engle, J. \& Tinto, V. (2006). Moving beyond access: College success for low-income first-generation students. The Pell Institute for the Study of Opportunity in Higher Education.

Engle, J., Tinto, V., \& Pell Institute for the Study of Opportunity in Higher, E. (2008). Moving Beyond Access: College Success for Low-Income, First-Generation Students: Pell Institute for the Study of Opportunity in Higher Education. 
Fernández, L. (2002). Telling stories about school: Using critical race and latino critical theories to document latina/latino education and resistance. Qualitative Inquiry, $8(1), \mathrm{pp}, 45-63$.

Fine, M., Burns, A., Payne, Y. A. P., \& Torre, M. E. (2004). Civics lessons: The color and class of betrayal. Teachers College Record, 106(11), 2193-2223.

Fischer, M. J. (2007). Settling into campus life: Differences by race/ethnicity in college involvement and outcomes. Journal of Higher Education, 78(2), 125-161.

Flores, J. \& Garcia, S. (2009). Latina "testimonios": A reflexive, crtical analysis of a "latina space at a predominantly white campus. Race, Ethnicity and Education, 12(2), pp. 155-172).

Foley, D.E. (1997). Deficit thinking models based on culture: The anthropolgoical protest, in: Valencia, R. (Ed.) The evolution of deficit thinking: Educational thorught and practice. London: The Falmer Press, 113-131.

Foley, D. (2005). Elusive Prey: John Ogbu and the Search for a Grand Theory of Academic Disengagement. International Journal of Qualitative Studies in Education, 18(5), 643-657.

Fordham, S., \& Ogbu, J. U. (1986). Black students' school success: Coping with the "burden of 'Acting White'". The Urban Review, 18(3), 176-205.

Freire, P. (1970). Pedagogy of the oppressed. Continuum International Publishing Group Inc. New York: NY.

Gándara, P. (1982). Passing through the eye of the needle: High-achieving chicanas. Hispanic Journal of Behavioral Sciences, 4, 167-179.

Gándara, P. (1995). Over the ivy walls: The educational mobility of low-income chicanos. Albany, NY: State University of New York Press.

García, M.A., (2009). Experiences of low-income students at a private liberal arts college. Unpublished paper, San Francisco State University, San Francisco, CA.

Giroux, H. (1983). Theories of reproduction and resistance in the new sociology of education: A critical analysis. Harvard Educational Review, 55, 257-293.

Giroux, S. \& Simon, R.I. (1989). Schooling, popular culture, and a pedagogy of possibility. Journal of Education, vol. 170 (1): 9-26.

Gonzalez, N. \& Moll, L.C. (2002) Cruzando el puente: Building bridges to funds of knowledge, Educational Policy, 16(4), 623-641.

Health Care and Education Reconciliation Act http://www.whitehouse.gov/issues/education. Retrieved on March 2, 2010.

Hernandez, A. (1997). Pedagogy, democracy, and feminism: Rethinking the public sphere. New York, NY: SUNY Press.

Hernandez-Truyol, B. (1997). Borders (en)gendered: Normatives, Latinas, and a latcrit paradigm. 72 N.Y.U. Law Review. 882.

Hill, M.L. (2009) Wounded healing: Forming a storytelling community in hip-hop lit. Teachers College Record, vol. 111 (1): 248-293. 
Holguín, G.C. (2005). Chicanas and Higher Education: Three Decades of Literature and Thought. Journal of Hispanic Higher Education, 4(3), 215-234.

hooks, b. (1994). Teaching to transgress: Education as the practice of freedom. New York: Routeledge.

Hurtado, S., \& Ponjuan, L. (2005). Latino educational outcomes and the campus climate. Journal of Hispanic Higher Education, 4(3), 235- 251.

Ishitani, T. T. (2006). Studying Attrition and Degree Completion Behavior among FirstGeneration College Students in the United States. Journal of Higher Education, 77(5), 861-885.

Kellner, D. (1995). Media culture: Cultural studies, identity \& politics between the modern \& the postmodern. Taylor \& Francis e-library (2003).

Kim, Y., \& Sax, L. (2009). Student-faculty interaction in research universities: Differences by student gender, race, social class, and first-generation status. Research in Higher Education, 50(5), 437-459.

Kuh, G. D. (1995). The other curriculum. Journal of Higher Education, 66(2), 123-155.

Ladson-Billings, G. (1998). Just what is critical racy theory and what's it doing in a nice field like education? Qualitiave Studies in Education, 11(1), 7-24.

Ladson-Billings, G., \& Tate Iv, W. F. (1995). Toward a critical race theory of education. Teachers College Record, 97(1), 47-68.

Lawrence-Lightfoot, S. (1994). I've known rivers: Lives of loss and liberation. Reading, MA: Addison-Wesley Publishing.

Leonardo, Z. \& Hunter, M. (2007). Imagining the urban: The politics of race, class and schooling. In W. T. Pink and G. W. Noblit (Eds.), International handbook of urban education, 779- 802. New York, NY: Springer.

London, H. B. (1992). Transformations: Cultural challenges faced by first-generation students. New Directions for Community Colleges(80), 5-11.

Lorde, A. (1984, 2007). Sister, Outsider: Essays and Speeches. New York, NY: Crown Publishing Group.

Lundberg, C. A., Schreiner, L. A., Hovaguimian, K., \& Miller, S. S. (2007). Firstgeneration status and student race/ethnicity as distinct predictors of student involvement and learning. NASPA Journal, 44(1).

Macleod, J. (1986). Ain't no makin' it. Boulder, CO: Westview Press.

Mason, M.A., \& Goulden, M. (2002). Problems in the pipeline: Gender, marriage, and fertility in the ivory tower. The Journal of Higher Education, 79(4), 388- 405.

Mendoza- Denton, R., \& Aronson, J.A. (2007). Psychosocial processes in the cultivation of itellective competence. In E.W. Gordon \& B.D. Bridglall (Eds.), Affirmative development: Cultivating academic ability, 189-209. Lanham, MD: Rowman \& Littlefield.

McKinsey \& Company (2007). How the world's best-performing school systems come out on top. 
McLaren, P. (1999). Research news and comment: A pedagogy of possibility: Reflection upon Paulo Freire's politics of education. Educational Researcher, vol. 28 (2): 29-56.

Mohanty, C., Russo, A., \& Torres, L. (1991). Third world women and the politics of feminism. Bloomington, IN: Indiana University Press.

Montoya, M. (1994) Mascaras, trenzas, y grenas: Un/masking the self while un/braiding Latina stories and legal discourse, Chicano-Latino Law Review, 15, 1-37.

Moraga, C. (1983) La güera, in: Moraga, C. \& Anzaldúa, G. (Eds). This bridge called my back: Writings by radical women of color $\left(2^{\text {nd }}\right.$ ed). New York, NY: Kitchen Table, 24-33.

Naumann, W. \& Banalos, D. (2003). Identifying variables that predict college success for first-generation college students. The Journal of College Admission (Fall), pp. 2-9.

Nora, A. \& Cabrera, A.F. (1996). The role of perceptions of prejudice and discrimination on the adjustment of minority student to college. Journal of Higher Education, 67(2), 119-148.

Nuñez, A., \& Cuccaro-Alamin, S. (1998). First-generation students: Undergraduates whose parents never enrolled in postsecondary education. College Student Journal, 33(2), 198 - 205.

Ogbu, J. (2004). Collective identify and the burden of "acting white" in black history, community, and education. The Urban Review: Issues \& Ideas in Public Education, vol. 36 (1): 1-35.

Ogbu, J. \& Fordham, S. (1986). Black students' school success: Coping with the "burden of 'acting white." The Urban Review, vol. 18, (3): 176-206.

Olivas, M. (1997). Research on latino college students: A theoretical framework and inquiry. In A.Darder, R. Torres, \& H. Gutiérrez (Eds.) Latinos and education: A critical reader (pp.468-486). New York: Routledge.

Pascarella, E., Pierson, C., Wolniak, G., \& Terenzini, P. (2004). First generation college students: Additional evidence on college experiences and outcomes. Journal of Higher Education, vol. 75 (3)249-284.

Pascarella, E. \& Terenzini, P. (2005). How college affects students: A third decade of research vol. 2. Indianapolis: IN: Jossey-Bass.

Perez, E. (1999). The decolonial imaginary: Writing chicanas into history. Bloomington, IN: Indiana University Press.

Pesguera, B.M., \& Segura, D. A. (1996). With quill and torch: A chicana perspeictive on the American women's movement and feminist theories, In D.R. Maciel \& I.D. Ortiz (Eds.), Chicanas/Chicanos at the crossroads: Social, economic and political change, 231-247. Tucson, AZ: University of Arizona Press.

Pierce, C. (1974). Psychiatric problems of the black minority, In: S. Arieti (Ed.) American handbook of psychiatry. NY, NY: Basic Books, 512-523. 
Pike, G. R., \& Kuh, G. D. (2005). First- and second-generation college students: A comparison of their engagement and intellectual development. Journal of Higher Education, 76(3), 276-300.

Reindl, T. (2007). Hitting home: Quality, cost, and access challenges confronting higher education today. Lumina Foundation for Education: Making Opportunity Affordable.

Rendón, L. (1992). From the barrio to the academy: Revelations of a mexican american "scholarship girl". New Directions for Community Colleges(80), 55-64.

Richardson, R. C., Jr., \& Skinner, E. F. (1992). Helping first-generation minority students achieve degrees. New Directions for Community Colleges(80), 29-43.

Rodrigúez Martin, I. (2010). Insights into the complexities of identity in persisting latina college students. Unpublished dissertation, University of Massachusetts Amherst.

Roediger, D. (2002). Colored white: Transcending the racial past. University of California Press.

Saenz, V., Hurtado, S., Barrera, D., Wolf, D., \& Yeung, F. (2007). First in my family: A profile of first-generation college students at four-year institutions since 1971: Higher Education Research Institute (HERI), UCLA.

Sandoval, C. (1998). Mestizaje as method: Feminists-of-color challenge the canon. In C. Trujillo (Ed.), Living Chicana Theory, 352- 370. Berkeley, CA: Third Woman Press.

Saunders, M., \& Serna, I. (2004). Making college happen: The college experiences of first-generation Latino students. Journal of Hispanic Higher Education, 3(2), 146-163.

Schlesinger, A.M. (1993). The disuniting of America: Reflections on a multicultural society. New York: W.W. Norton \& Co.

Schlossberg, N. (1981). A model for analyzing human adaptation to transition. The Counseling Psychologist, 9(2), 2 - 18.

Seidman, A. (2005). College student retention: Formula for student success. Westport, CT: Praeger Publishers.

Silvestrini, B. (1997). The world we enter when claiming rights: Latinos and their quest for culture. In W. Flores \& R. Benmayor (Eds.), Latino Cultural Citizenship (pp. 39-53). Boston: Beacon Press.

Shulock, N., \& Moore, C. (2007). Rules of the game: How state policy creates barriers to degree completion and impedes student success in the California community colleges. Institute for Higher Education Leadership \& Policy.

Smith, W. (2004). Black faculty coping with racial battle fatigue: The campus racial climate in a post-civil rights era. In. D. Cleveland (Ed.), Broken silence: conversations about race by African-americans at predominantly white institutions. New York: Peter Lang. 
Solorzano, D. (1998). Critical race theory, racial microaggressions, and the experiences of chicana and chicano scholars. International Journal of Qualitative Studies in Education, 11 (1), 7-24.

Solorzano, D. G. (2005). Educational Inequities and Latina/o Undergraduate Students in the United States: A Critical Race Analysis of Their Educational Progress. Journal of Hispanic Higher Education, 4(3), 272-294.

Solórzano, D. G. \& Yosso, T., (2000). Critical race theory, racial microaggressions, and campus racial climate: The experiences of african-american college students. Journal of Negro Education, 69(1/2 Winter - Spring), pp. 60-73.

Solórzano, D. G., \& Bernal, D. D. (2001). Examining Transformational Resistance through a Critical Race and LatCrit Theory Framework: Chicana and Chicano Students in an Urban Context. Urban Education, 36(3), 308-342.

Solorzano, D. G., Villalpando, O., \& Oseguera, L. (2005). Educational inequities and Latina/o undergraduate students in the United States: A critical race analysis of their educational progress. Journal of Hispanic Higher Education, 4(3), 272294.

Solórzano, D. G. \& Villalpando, O. (1998). Critical race theory, marginality, and the experiences of students of color in higher education. In Sociology of Education: Emerging Perspectives. State University Press, Albany.

Spady, W. G. (1971). Dropouts from Higher Education: Toward an Empirical Model: Interchange.

Sue, D. W., Lin, A. I., Torino, G. C., Capodilupo, C. M., \& Rivera, D. P. (2009). Racial microaggressions and difficult dialogues on race in the classroom. Cultural Diversity and Ethnic Minority Psychology, 15(2), 183-190.

Swail, W. S., Cabrera, A. F., Lee, C., \& Pew Hispanic Center, W. D. C. (2004). Latino youth and the pathway to college: Pew Hispanic Center.

Swail, W.S., \& Holmes, D. (2000). Minority student persistence: A model for colleges and universities. In S.T. Gregory (Ed.), Academic achievement of minority students: Perspectives, practices, and prescriptions (pp. 391-433). Lanham, MD: University Press of America.

Swail, W.S., Redd, K.E., \& Perna, L.W. (2003). Retaining minority students in higher education: A framework for success (ASHE-ERIC Higher Education Report, 30(2); A. Kezar Series Ed. San Francisco: Wiley Subscription Services.

Terashini, R., Allen, W., \& Solórzano, D. (2000). Opportunity at the crossroads: Racial inequiatliy, school segregation, and higher education in california. Teachers College Record, 106(11), pp.2224-2245.

Terenzini, P. T. (1987). A Review of Selected Theoretical Models of Student Development and Collegiate Impact. ASHE Annual Meeting Paper. 
Terenzini, P. T., Rendón, L. I., Upcraft, M. L., Millar, S. B., Allison, K. W., Gregg, P. L., et al. (1994). The transition to college: Diverse students, diverse stories. Research in Higher Education, 35(1), 57.

Terenzini, P. T., Springer, L., Yaeger, P. M., Pascarella, E., \& Nora, A. (1996). Firstgeneration college students: Characteristics, experiences, and cognitive development. Research in Higher Education, 37(1), 1.

Tierney, W. G. (1999). Models of minority college-going and retention: Cultural integrity versus cultural suicide. Journal of Negro Education, 68(1), 80.

Tintiangco-Cubales, A. (2007). Final project runway: In the I's of asian american women. In Stahly, G. (Ed.) Gender identity, equity and violence: Multidisciplianry perspectives through service learning. Stylus Publishing.

Tinto, V. (1988). Stages of student departure: refelctions on the longitudinal characteristics of students leaving college. Journal of Higher Education, 59, 438-455.

Tinto, V. (1997). Classrooms as communities: Exploring the educational character of student persistence. Journal of Higher Education, vol. 68 (2), pp. 102-124.

Tinto, V. (2006-2007). Research and practice of student retention: What next? Journal of College Student Retentin: Research, Theory, and Practice, 8 (1), 1-19.

Tinto, V. (2009). How to Help Students Stay and Succeed. Chronicle of Higher Education, 55, A33-A33.

UCLA Institute for Democracy, E., and Access and University of California All Campus Consortium on Research for Diversity (2007). California Educational Opportunity Report 2007. Los Angeles, CA: UCLA Institute for Democracy, Education, and Access and University of California All Campus Consortium on Research for Diversity.

Valenzuela,A. (1999). Subtractive schooling: U.S.-Mexican youth and the politics of caring. SUNY Press: Albany, NY.

Vásquez, M.J. (1982). Confronting barriers to the participation of mexican-american women in higher education. Hispanic Journal of Behavioral Sciences, 4(2), 147165.

Vélez-Ibáñez, C. \& Greenberg, J. (1992). Formation and transformation of funds of knowledge among u.s. - mexican households. Anthropology and Eduation Quarterly, 23(4), 313-335.

Vera , H., \& de los Santos, E. (2005). Chicana identity construction: Pushing the boundaries. Journal of Hispanic Higher Education, 4(2), 102 - 113.

Villalpando, O. (2003). Self-segregation or self-preservation: A critical race theory and latina/o critical theory analysis of a sutdy of chicana/o college students. International Journal of Qualitative Studies in Education 16, 619-646. 
Villenas, S. (2001). Latina mothers and small town racisms: Creating narratives of dignity \& moral education in north carolina. Anthropology \& Education Quarterly, 32(1), 3-28.

Villenas, S. \& Moreno, M. (2001). To valerse por si misma between race, capitalism, and patriarchy: Latina mother-daughter pedagogies in north carolina. International Journal of Qualitative Studies in Education, 14(1), 671-687.

Wang, C.-C. D. C., \& Castañeda-Sound, C. (2008). The role of generational status, selfesteem, academic self-efficacy, and perceived social support in college students' psychological well-being. Journal of College Counseling, 11(2), 101-118.

White, J. (2005). Sociolinguistic challenges to minority collegiate success: Entering the discourse community of the college. Journal of College Student Retention, 6(4) $369-393$.

Wing, A.K. (1999). Race and gender issues: Critical race feminism. Journal of Intergroup relations, 26(3), 14-25.

Yosso, T. J. (2002). Toward a critical race curriculum. Equity and Excellence in Education, 35(2), 93-107.

Yosso, T. (2005). Whose culture has capital? A critical race theory discussion of commuinty cultural wealth. Race, Ethnicity, and Education, 8 (1), pp. 69-91).

Yosso, T. J., Smith, W. A., Ceja, M., \& Solorzano, D. G. (2009). Critical Race Theory, Racial Microaggressions, and Campus Racial Climate for Latina/o Undergraduates. Harvard Educational Review, 79(4), 659-690.

Yosso, T. J., \& Solórzano, D. G. (2006). Leaks in the Chicana and Chicano Educational Pipeline. Latino Policy \& Issues Brief. Number 13: UCLA Chicano Studies Research Center.

Yosso, T. J., \& Solorzano, D. G. (2006). Leaks in the Chicana and Chicano Educational Pipeline. Latino Policy \& Issues Brief. Number 13: UCLA Chicano Studies Research Center.

Yin, R. (2009). Case study research $\left(4^{\text {th }}\right.$ ed.). Thousand Oaks, CA: Sage Publications Inc. 
Appendices 
Appendix A

Recruitment Letter

\section{Hola Mujeres,}

I hope this message finds you doing well and off to a strong start this semester. My name is Maria Angelica Garcia and I am a staff member here. I am also a doctoral student at San Francisco State University and I am in the process of conducting research for my dissertation. I would like to invite you to consider being a participant in my study, as a first-generation AND Latina college student.

Participation in this research includes attending one focus group interview for 75-90 minutes, completing an anonymous demographics questionnaire containing questions related to your racial and ethnic identity, socioeconomic background, and a short survey. You may also be asked to participate in 4 individual interviews (75-90 minutes each) throughout the fall 2010 semester.

Your participation in this research study is purely voluntary; if you decide not to participate, there will not be any negative consequence whatsoever.

If you are interested in participating in this study, please email me at smcmag6@gmail.com or call me at 925-878-1519.

Thank you for your consideration, Angélica 


\section{Appendix B \\ Demographics Questionnaire \& Transformational Resistance Survey}

Introduction: Thank you in advance for your participation in the following confidential survey. This survey will take approximately $10-15$ minutes. All information from this survey is confidential and will be used solely for the purposes of my dissertation study.

Participation in this research includes completing this confidential survey and you may possibly be asked to attend at least one focus group interview in the fall 2010 semester. Your participation in this research study is purely voluntary; if you decide not to participate, there will be no negative consequences whatsoever.

1. What is your expected graduation year?

- Spring 2011

- Fall 2011

- Spring 2012

- Fall 2012

- Spring 2013

- Fall 2013

- Spring 2014

- Fall 2014

2. Do you live:

- On-campus

- Off-campus with roommates 
3. What is your major?

O Off-campus without roommates

- Off-campus at home

4. List any clubs or student organization of which you are a member.

5 . If you work, how many hours per week do you work?

6. What is your age?

$$
\begin{array}{ll}
\circ & 17-19 \\
\circ & 20-21 \\
\circ & 22-24 \\
\circ & 25 \text { or older }
\end{array}
$$

7. Do you identify as

○ Latina

- Chicana

- Hispanic

$\circ$ Other? [Please describe]

8. Where does your immediate family live?

9. Where you were growing up, who did you consider your primary caregiver(s)? (Check all that apply)

- Caregiver 1: (mother, father, grandparent, sibling, social worker, etc.)

- Caregiver 2: _ (mother, father, grandparent, sibling, social worker, etc.)

10. What was their highest level of education: (complete for each caregiver).

- Caregiver 1:

- Caregiver 2:

11. What is the highest level of education you aspire to complete? Open-Ended Questions

12. Why did you decide to stay at St. Mary's College?

13. If you have ever thought of leaving, what was the reason(s)?

14. Your Name

15. Your ID \#

16. Uncheck box if you are NOT interested in participating in a follow-up focus group. 


\begin{tabular}{|l|l|l|l|l|l|}
\hline & $\begin{array}{l}\text { Strongly } \\
\text { Agree }\end{array}$ & Agree & $\begin{array}{l}\text { Neither } \\
\text { Agree nor } \\
\text { Disagree }\end{array}$ & Disagree & $\begin{array}{l}\text { Strongly } \\
\text { Disagree }\end{array}$ \\
\hline $\begin{array}{l}\text { Oppression exists in } \\
\text { educational institutions. }\end{array}$ & & & & & \\
\hline $\begin{array}{l}\text { If I work hard enough, I } \\
\text { can overcome oppressive } \\
\text { structures. }\end{array}$ & & & & & \\
\hline $\begin{array}{l}\text { Being educated means I } \\
\text { have to act white. }\end{array}$ & & & & & \\
\hline $\begin{array}{l}\text { Being educated means I } \\
\text { have to be more } \\
\text { masculine than feminine. }\end{array}$ & & & & & \\
\hline $\begin{array}{l}\text { It is important to me to } \\
\text { remember where I come } \\
\text { from. }\end{array}$ & & & & & \\
\hline $\begin{array}{l}\text { My cultural values } \\
\text { influence my choices. }\end{array}$ & & & & & \\
\hline $\begin{array}{l}\text { Becoming educated is a } \\
\text { form of social justice for } \\
\text { me. }\end{array}$ & & & & & \\
\hline
\end{tabular}

\section{Closing Comments:}

Thank you for taking the time to complete this survey. Please do not hesitate to contact me with any questions or concerns at smcmag6@gmail.com. Again, all information provided is confidential and is used solely for the purposes of my dissertation study. 
Appendix C

\begin{tabular}{|c|c|c|c|c|c|c|}
\hline $\begin{array}{l}\text { Foc } \\
\text { Grp } \\
\#\end{array}$ & $\begin{array}{l}Y R \text { in } \\
\text { Schl }\end{array}$ & Identity & $\begin{array}{l}\text { Primary } \\
\text { caregiver(s) }\end{array}$ & $\begin{array}{l}\text { \# of } \\
\text { Clubs }\end{array}$ & $\begin{array}{l}\text { Educational } \\
\text { Aspiration }\end{array}$ & Major \\
\hline 1 & FR & Latina & Mother only & 0 & Master's & Undecided \\
\hline 1 & FR & Latina & $\begin{array}{l}\text { Mother, } \\
\text { Father }\end{array}$ & 1 & Law School & Pre-Law \\
\hline 1 & SO & Hispanic & Mother only & 2 & Psy.D. & Psych \\
\hline 1 & $\mathrm{JR}$ & $\begin{array}{l}\text { Mexican- } \\
\text { American }\end{array}$ & $\begin{array}{l}\text { Mother, } \\
\text { Father }\end{array}$ & 1 & Master's & Kines \\
\hline 1 & $J R$ & Bi-Racial & $\begin{array}{l}\text { Father, } \\
\text { Mother }\end{array}$ & 3 & Ph.D. & $\begin{array}{l}\text { English \& } \\
\text { Spanish }\end{array}$ \\
\hline 1 & SR & Xicana & Mother only & 2 & Ph.D & Comm \\
\hline 2 & SR & Chicana & $\begin{array}{l}\text { Mother, } \\
\text { Father }\end{array}$ & 3 & Ph.D & English \\
\hline 2 & $\mathrm{JR}$ & Latina & Mother, Tío & 2 & Bachelor's & Sociology \\
\hline 2 & SO & Latina & $\begin{array}{l}\text { Father, } \\
\text { Mother }\end{array}$ & 2 & MBA & $\begin{array}{l}\text { Int'l } \\
\text { Business }\end{array}$ \\
\hline 2 & SO & Hispanic & $\begin{array}{l}\text { Mother, } \\
\text { Siblings }\end{array}$ & 3 & Master's & Undecided \\
\hline 2 & FR & Hispanic & $\begin{array}{l}\text { Father, } \\
\text { Mother }\end{array}$ & 0 & M.D. & $\begin{array}{l}\text { Health } \\
\text { Science }\end{array}$ \\
\hline 2 & SO & Chicana & $\begin{array}{l}\text { Mother, } \\
\text { Father }\end{array}$ & 0 & Master's & Nursing \\
\hline 3 & $J R$ & Latina & Older Siblings & 1 & Master's & Sociology \\
\hline 3 & SR & Latina & Mother only & 2 & Ph.D. & History \\
\hline 3 & FR & Chicana & $\begin{array}{l}\text { Mother, } \\
\text { Father }\end{array}$ & 1 & Bachelor's & Marketing \\
\hline 3 & SR & Latina & $\begin{array}{l}\text { Mother, } \\
\text { Abuelo }\end{array}$ & 2 & Ph.D & Spanish \\
\hline 3 & JR & $\begin{array}{l}\text { Salvadoreñ } \\
\text { a }\end{array}$ & $\begin{array}{l}\text { Mother, } \\
\text { Father }\end{array}$ & 1 & $\mathrm{Ph} . \mathrm{D}$ & Psych \\
\hline 3 & $\mathrm{JR}$ & Hispanic & Mother only & 1 & Master's & $\begin{array}{l}\text { Liberal \& } \\
\text { Civic } \\
\text { Studies }\end{array}$ \\
\hline 4 & SO & Latina & $\begin{array}{l}\text { Father, } \\
\text { Mother }\end{array}$ & 2 & Law School & Integral \\
\hline 4 & SO & Chicana & Mother, Tía & $1 \mathrm{t}$ & Master's & Acctg \\
\hline 4 & $\mathrm{JR}$ & Latina & Mother only & 2 & Ph.D. & English \\
\hline 4 & FR & Hispanic & $\begin{array}{l}\text { Mother, } \\
\text { Father }\end{array}$ & 3 & M.D. & Biology \\
\hline 4 & SO & Hispanic & $\begin{array}{l}\text { Abuelo, } \\
\text { Abuela }\end{array}$ & 3 & MBA & Bus Ad \\
\hline 4 & SR & Chicana & $\begin{array}{l}\text { Mother, } \\
\text { Father }\end{array}$ & 4 & MSW \& Ph.D & Sociology \\
\hline
\end{tabular}


Appendix D

Interview Protocol for Focus Groups

1. As a warm-up: Look around and see who is in this room? Has this ever happened to you before at St. Mary's?

a. Name the group as a collective group of Latinas that are here to share their stories and their experiences.

b. Acknowledge that I am interested in this work because I want to hear their stories and give them space to be heard by others.

c. Name that we are a group of Latinas with similar AND different experiences.

2. Think back to your first weekend at the college.

a. What were your experiences?

b. What stands out to you the most about those experiences?

3. What does it mean to be a woman at this college?

a. How might those experiences be different for Latinas?

b. What are the differences for Latinas who are first-generation?

c. What does it feel like to be the only Latina in a classroom? What do you have to do to get through that class?

4. Tell me about some of your most important relationships?

a. With faculty? With Staff?

b. Friends? Family? Significant other?

5. How do you stay connected with your family/community back at home?

6. Talk about how your family understands you as a college student. 
a. What are your family's expectations for you as you get a college education?

b. How might they differ from your own expectations?

c. What do you share with them about your experiences (as they have shared above)? Why don't you share [highlight an aspect of their experiences stated above in \#3 that they did not share] those stories/testimonios with them?

7. What keeps you motivated to stay in school/do well in school?

8. Think back to the "Our Struggle is Tied with Yours" student protest that took place last spring. Why were you/ were you not involved with this student demonstration?

a. In what other ways have you engaged in addressing issues of social justice that might not be at the public forefront as "Our Struggle?"

9. How might you become involved/more involved in resisting the temptation to "blend in" and "assimilate" to the college culture?

a. What does that resistance look like for you?

10. What do you do to keep from conforming to what others "expect" of you?

a. How might you become involved/more involved in resisting the temptation to "blend in" and "assimilate" to the college culture?

b. What does that resistance look like for you?

11. Is there anything else you would like to share with me about your experiences in college so far?

\footnotetext{
***NOTE: Given the number of respondents and the type of data that is revealed from the transformational resistance survey, I can also begin the focus group with member checking - that is, sharing the data from the surveys with them and asking if that resonates with their experience. This might lead to the questions moving in a different, perhaps more intense, version than what I have originally outlined.
} 